\title{
Consenso chileno para la atención integral de niños y adultos con fibrosis quística*
}

\author{
MARÍA LINA BOZA C. ${ }^{1,2,3}$, JOEL MELO T. ${ }^{4}$, SALESA BARJA Y., ${ }^{5,6}$, ETHEL CODNER D..$^{7,3}$, \\ PATRICIO GOMOLAN G. ${ }^{8,9, a}$, RUBÉN HERNÁNDEZ M. ${ }^{2, b}$, LUIS ASTORGA F. ${ }^{3,8}$, \\ HORTENSIA BARRIENTOS I. ${ }^{2,3}$, RODRIGO BOZZO H. ${ }^{10}$, MAURICIO CALDERÓN R. ${ }^{2,11}$, \\ JEANETTE CÁCERES V., ${ }^{2, c}$, EDUARDO CHÁVEZ C. ${ }^{2,3}$, ILSE CONTRERAS E. ${ }^{12,13}$, \\ MARÍA TERESITA HENRÍQUEZ Y. ${ }^{14,15}$, OSCAR FIELBAUM C. ${ }^{16}$, LETICIA JAKUBSON S. ${ }^{3,17}$, \\ BEATRIZ JARA H..$^{17, d}$, PABLO JORQUERA P. ${ }^{18}$, RICARDO KOGAN A. ${ }^{3,11,19}$, VIVIANA LEZANA S. ${ }^{15,20}$, \\ RODOLFO MEYER P. ${ }^{12,21, a}$, FRANCISCO MORAGA M., ${ }^{2,3}$, GUSTAVO MOSCOSO G.,a, \\ ELIZABETH NAVARRO D. ${ }^{3,19}$, MARÍA DE LOS ÁNGELES ORELLANA F., ${ }^{4,}$, GENOVEVA PARRA O. ${ }^{10}$, \\ DANIELA PAVEZ A. ${ }^{3,17}$, MARÍA EUGENIA PÉREZ O. ${ }^{20}$, MARÍA JOSÉ PINOCHET N..$^{12, \mathrm{~d}}$, \\ HOMERO PUPPO G. ${ }^{3,19, a}$, ANA ISABELLA QUINTANILLA A. ${ }^{2, \mathrm{~d}}$, GABRIELA REPETTO L. ${ }^{13}$, \\ LISSET SLAIBE C. ${ }^{1, \mathrm{~d}}$, JULIO SOTO B. ${ }^{3,7}$, ADRIANA VEGA M. ${ }^{8, \mathrm{~d}}$ y CAROLINA WONG L., ${ }^{3,17}$
}

\section{Chilean consensus for the integral care of children and adults with cystic fibrosis}

Cystic Fibrosis (CF) is the most frequent hereditary disease in whites, with a reserved prognosis. Since 2003, Chile began a comprehensive National Cystic Fibrosis Program, directed by the Respiratory Health Unit of the Ministry of Health. To date, the main results of the Program record a significantly longer survival (average 27 years) and a significant reduction in the age of diagnosis of patients admitted from 2006 onwards. Access to Chilean Explicit Health Guarantees, the implementation of neonatal screening in some regions of the country, the organization and setting up of CF-trained teams of various specialties, has contributed to improving results. Although the main manifestations are of the respiratory and digestive system, the multisystemic nature of CF makes it necessary to know the different aspects involved in its management, in order to optimize the results of the treatment and the resources invested, both in the public and private sectors. This document is a review and an update on the main aspects of the diagnosis, monitoring and treatment of the respiratory and non-respiratory manifestations of $C F$.

Key words: Cystic Fibrosis, diagnosis, treatment, prognosis, health resourses. \footnotetext{
sustentan estas revistas.

Departamento Procesos Clínicos Integrados, DIGERA, Ministerio de Salud Chile.

Hospital San Borja Arriarán.

Universidad de Chile.

Instituto Nacional del Tórax (INT).

Hospital Josefina Martínez.

Pontificia Universidad Católica de Chile.

Instituto de Investigación Médica (IDIMI).

Hospital Calvo Mackena.

9 Facultad de Medicina Universidad de Santiago.

10 Hospital Roberto del Río.

11 Universidad Finis Terrae.

12 Hospital Padre Hurtado.

13 Facultad de Medicina, Clínica Alemana Universidad del Desarrollo.
}

*Este consenso será publicado contemporáneamente en la Revista Chilena de Enfermedades Respiratorias y en la Revista Neumología Pediátrica, con el consentimiento de sus respectivos editores y de las directivas de las sociedades que

14 Hospital Van Buren.

15 Universidad de Valparaíso.

16 Clínica Las Condes.

17 Hospital San Juan de Dios.

18 Hospital Sótero Del Río.

19 Hospital Exequiel González Cortés.

20 Hospital Gustavo Fricke.

21 Universidad Mayor.

a Kinesiólogo Respiratorio.

b Químico Farmaceútico Clínico.

c Nutricionista.

d Enfermera Universitaria. 


\section{Resumen}

La Fibrosis Quística (FQ) es la enfermedad hereditaria de pronóstico reservado más frecuente en raza blanca. Desde el año 2003, Chile inicia un Programa Nacional de Fibrosis Quística, de carácter integral, dirigido por la Unidad de Salud Respiratoria del Ministerio de Salud. Hasta la fecha, los principales resultados del Programa registran una significativa mayor sobrevida (promedio 27 años) y una significativa reducción en la edad de diagnóstico de los pacientes ingresados desde 2006 en adelante. El acceso a la canasta GES (Garantías Explícitas en Salud), la implementación del tamizaje neonatal en algunas regiones del país, la organización y la constitución de equipos entrenados en $F Q$ de diversas especialidades, ha contribuido a mejorar los resultados. Si bien las principales manifestaciones son del aparato respiratorio y digestivo, el carácter multisistémico de la $F Q$ obliga a conocer los distintos aspectos involucrados en su manejo, a fin de optimizar los resultados del tratamiento y los recursos invertidos, tanto en el sector público como privado. Este documento es una revisión y actualización sobre los principales aspectos del diagnóstico, seguimiento y tratamiento de las manifestaciones respiratorias y no respiratorias de la $F Q$.

Palabras clave: Fibrosis quística, diagnóstico, tratamiento, pronóstico, recursos de salud.

\section{Índice}

1. Introducción

2. Diagnóstico

3. Aspectos broncopulmonares

4. Hospitalización

5. Kinesiterapia

6. Aspectos nutricionales

294

7. Compromiso digestivo y hepatobiliar ........

8. Aspectos endocrinológicos

9. Compromiso otorrinlaringológico

10. Otras manifestaciones

11. Medicina personalizada (terapia moduladora)

12. Transición a centro de adultos

13. Trasplante pulmonar

14. Cuidados paliativos

15. Salud mental

16. Enfermería

17. Anexos

18. Glosario

19. Bibliografía

\section{Pilares generales}

- El médico general, frente a la sospecha del diagnóstico y de acuerdo a las recomendaciones de este documento, debe derivar al/la paciente a un centro de referencia de la red público o privada para realizar el diagnóstico. Si este se confirma, requiere el inicio precoz de un cuidado multidisciplinario.

- El diagnóstico molecular tiene utilidad en la caracterización clínica y pronóstico, como también permite la consejería genética. En los casos de duda diagnóstica, puede ser un examen confirmatorio si se demuestra la presencia de variante patogénica en los dos alelos.

- La kinesioterapia respiratoria es la principal herramienta del tratamiento respiratorio, debe realizarse en todos los pacientes, fundamentalmente por la familia, con la frecuencia indicada por el especialista y aumentar en los períodos de crisis o sobreinfección.

- La adecuada nutrición, junto al aporte enzimático y de vitaminas liposolubles, es otro de los pilares fundamentales para asegurar una mejor sobrevida. La meta es que los pacientes alcancen un peso para la talla o índice de masa corporal sobre el promedio, pero sin presentar sobrepeso.

\section{Introducción}

La FQ es una enfermedad hereditaria autosómica recesiva, que se produce por variantes patogénicas en el gen que codifica para la proteína reguladora de conductancia de transmembrana de la FQ (Cystic Fibrosis Transmembrane Conductance Regulator CFTR), ubicado en el brazo 
largo del cromosoma 7q 31. A la fecha, se han encontrado más de 2000 variantes, 360 catalogadas como patogénicas. De estas últimas, la más común es la actualmente denominada p.Phe508del, o c. 15211523 delCTT.

El defecto de la proteína CFTR provoca un trastorno del transporte del ion cloro $\left(\mathrm{Cl}^{-}\right)$y sodio $\left(\mathrm{Na}^{+}\right)$por las células de los epitelios. La alteración de la función del canal de cloruro lleva a la deshidratación de las secreciones de las glándulas exocrinas de las vías respiratorias, páncreas, intestino, vasos deferentes y a la eliminación de sudor con altas concentraciones de $\mathrm{Cl}^{-}$y $\mathrm{Na}^{+1,2}$.

El resultado final es el desarrollo de enfermedad pulmonar obstructiva crónica, compromiso sinusal, insuficiencia pancreática exocrina, desnutrición secundaria e infertilidad. Algunos pacientes, en el curso de la enfermedad, desarrollan diabetes, pancreatitis recurrente, osteoporosis, artropatía, compromiso renal y cáncer digestivo. Dado que el daño pulmonar se va produciendo con el correr del tiempo, el diagnóstico precoz y el enfoque del manejo respiratorio, nutricional y digestivo es crucial para mejorar el pronóstico de estos pacientes ${ }^{3}$.

La expresión fenotípica de la enfermedad varía ampliamente, dependiendo de las variantes presentes, además de otros factores modificadores tanto genéticos como ambientales. La correlación genotipo-fenotipo ha evidenciado una relación muy compleja, especialmente en el componente pulmonar de la enfermedad (más variable y menos predecible). En contraste, el genotipo es un buen predictor de la función exocrina pancreática.

En Chile, de acuerdo con el mestizaje existente y los estudios de las variantes y tamizaje neonatal, se estima una incidencia aproximada de $1 / 8.000$ a 1/10.000 recién nacidos vivos, lo que significa aproximadamente 25-30 casos nuevos anuales ${ }^{4}$. Estudios con un panel de 36 variantes comunes en más de 300 pacientes chilenos han resultado en una detección de $42 \%$ de los alelos estudiados. Entre estas variantes, predomina la p.Phe 508del, al igual que en el resto del mundo, con un $30,6 \%$ de los alelos estudiados. Otras variantes encontradas hasta la fecha son p. R334W $(3,1 \%)$, p. G542X $(2,4 \%)$ y c. $3849+10 \mathrm{KbC}->$ $\mathrm{T}$ con un $1,7 \%$. Las demás variantes no superan el $1 \%$ cada una ${ }^{5}$.

La baja sensibilidad del análisis molecular chileno implica que, si bien, el hallazgo de dos variantes patogénicas en un paciente confirma el diagnóstico, éste no puede ser descartado en aquellos pacientes con ninguna o sólo una variante identificada.

Actualmente el estudio del gen permite esta- blecer las alteraciones genéticas en ambos alelos con o sin carácter patológico productor de enfermedad. No está disponible en nuestro país, por lo que se envía a laboratorios en el extranjero y, a la fecha, debe ser financiado por los padres.

Es importante resaltar que los hallazgos clínicos y resultados del test de sudor ayudarán a establecer o descartar el diagnóstico.

Actualmente en el país, la proporción de pacientes adultos ha ido aumentando paulatinamente, corresponde al $45 \%$ del total, en comparación con el 7\% el año 2003 y de $38 \%$ el 2011 y el promedio actual de sobrevida (27 años) es muy superior a lo reportado inicios del año $2000^{6}$, reflejando un mejor diagnóstico y manejo de la enfermedad.

La formación de centros multidisciplinarios pediátricos y de adultos que se iniciaron el año 2014, apoyados por la Universidad de Alabama en Birmingham EE.UU. en convenio con el Ministerio de Salud, ha sido un pilar fundamental. En este proceso de formación de centros de atención, se han ido integrando progresivamente, junto al médico broncopulmonar pediátrico o de adulto, médicos interconsultores de subespecialidades, enfermera coordinadora, nutricionistas, kinesiólogos, psicólogos, asistente social y químico farmacéutico clínico. Se ha puesto especial énfasis en la mejoría del laboratorio microbiológico, en que la atención de los pacientes se realice en forma individual, en sala independiente para evitar la infección cruzada y se han establecido guías de atención que se actualizan cada 3 o 4 años. Esta mejor atención se ha visto reflejada en una mejoría importante de la nutrición y de la función pulmonar, lo que esperamos repercuta en un aumento de la sobrevida y de la calidad de vida como meta fundamental en los años venideros.

\section{Diagnóstico}

Es uno de los aspectos más relevantes en el manejo de la enfermedad y es fundamental realizarlo en forma precoz ${ }^{3,7}$. El diagnóstico tardío determina un inicio inoportuno del tratamiento, incrementando la gravedad del daño, especialmente pulmonar y nutricional. La evidencia demuestra que la intervención precoz mejora el pronóstico, que debe realizarse con tamizaje neonatal ${ }^{8} \mathrm{o}$ ante una sospecha diagnóstica con confirmación oportuna (Figura 1).

Al momento del diagnóstico el paciente y su familia deberán ser controlados en un centro multidisciplinario capacitado en el manejo de la enfermedad. 


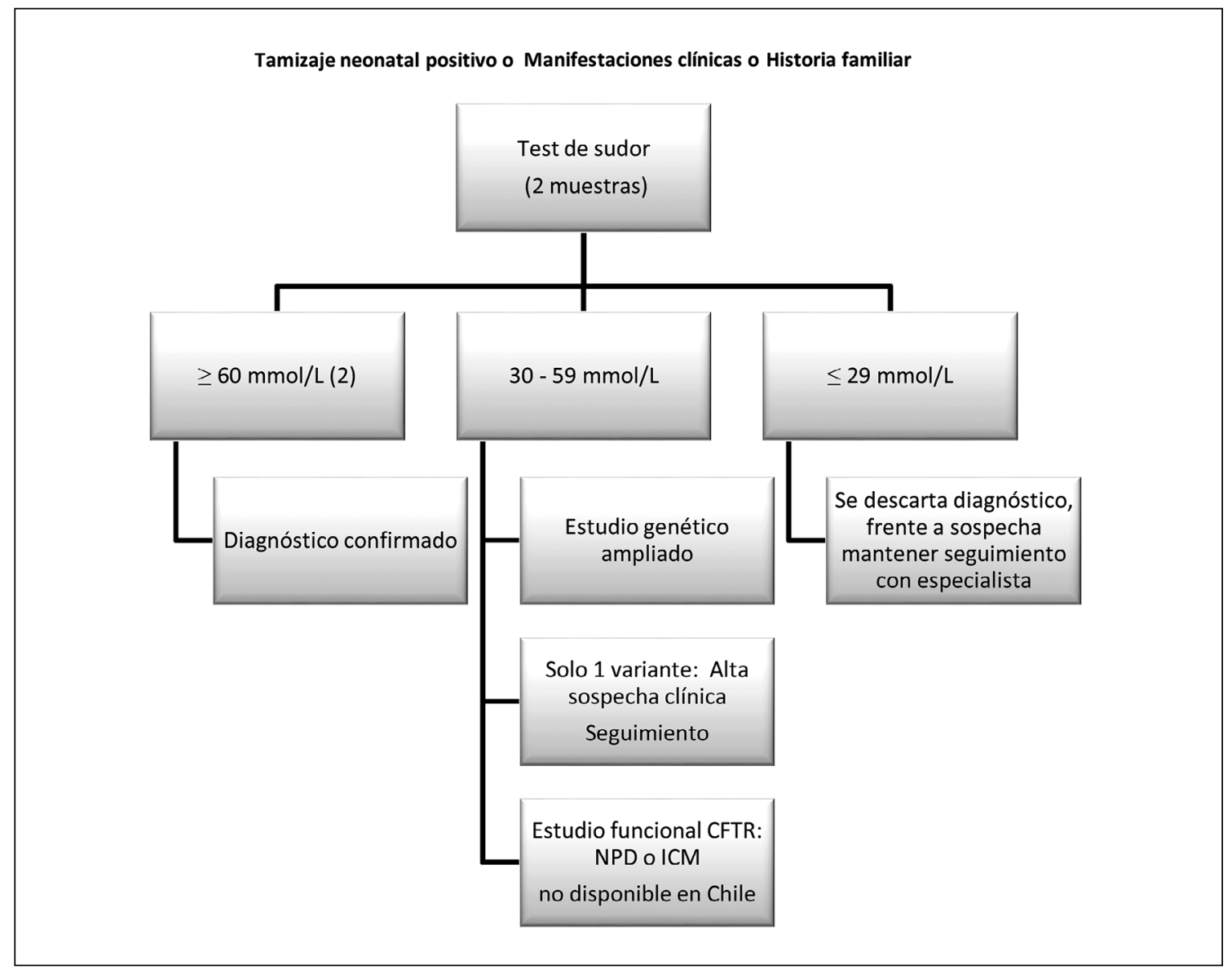

Figura 1. Flujograma diagnóstico. CFTR: Cystic Fibrosis Transmembrane Conductance Regulator (proteína reguladora de conductancia de transmembrana de la FQ), NPD: nasal potential difference (diferencia de potencial nasal), ICM: intestinal current measurement (medición de corriente intestinal).

\subsection{Test del sudor}

Es el examen fundamental para la comprobación diagnóstica. La solicitud debe ser hecha frente a la sospecha clínica ${ }^{9}$ se puede realizar desde de las $72 \mathrm{~h}$ de vida en recién nacido, a partir de las 36 semanas de gestación con peso corporal mayor a $2 \mathrm{~kg}^{10}$. En general una buena muestra se obtiene sobre los $3 \mathrm{~kg}$ de peso.

La familia debe recibir indicaciones por escrito, otorgado por el laboratorio, sobre cómo preparar al bebé para obtener una buena muestra.

La realización del test del sudor consta de 3 pasos: estimulación de la piel, recolección y procesamiento $^{11}$.

Estimulación de la piel: Con pilocarpina, en ambos brazos o muslos con la piel sana, durante 5 min.

Recolección del sudor: Existen 2 métodos para la recolección del sudor.
1. Gibson and Cooke: Recolección del sudor en un papel filtro de $2,5 \mathrm{~cm}$ de diámetro o en gasa de 9 x $9 \mathrm{~cm}$. Peso mínimo exigido de sudor: $100 \mathrm{mg}$.

2. Recolector desechable (Macroduct); Volumen mínimo exigido 15 microlitros. El tiempo de recolección no debe exceder 20 a $30 \mathrm{~min}$. Este método es el más recomendado por su fácil aplicación.

Las muestras escasas o insuficientes no deben exceder el $5 \%$ de la población enviada a estudio y en menores de 3 meses, el $10 \%$ es aceptable ${ }^{12}$. Los laboratorios que tengan cifras superiores a estos porcentajes deben revisar la técnica, la toma de la muestra y el entrenamiento de los profesionales que procesan la muestra de sudor.

$\mathrm{Si}$ se necesitara conservar el sudor para trasporte (no es lo ideal), debe mantenerse a $-4{ }^{\circ} \mathrm{C}$ por un máximo de 3 días en un tubo fuertemente sellado que no permita evaporación. 
Procesamiento: Dentro de las primeras horas de recolección debe ser enviada al laboratorio para ser procesada en el clorhidrómetro digital (lectura del $\mathrm{Cl}^{-}$) en las 2 muestras separadas. El laboratorio entrenado que procesa el test de sudor debe estar disponible para realizarlo al menos 2 veces por semana y el tiempo de espera entre la solicitud y la realización del examen no debe ser mayor a 2 semanas.

Nota: El laboratorio a cargo del examen debe tener control de calidad anual y se considera con experiencia si procesa sobre 150 test anuales.

El Informe final del laboratorio debe incluir:

- La técnica de recolección del sudor: gasa, papel filtro o Macroduct.

- La cantidad de sudor en miligramos o microlitros dependiendo de la técnica.

- La técnica de medición de $\mathrm{Cl}^{-}$(clorhidrometría).

- El valor de la concentración de $\mathrm{Cl}^{-}$en $\mathrm{mmol} / 1$ (en 2 muestras separadas).

- El profesional responsable del informe.

Los valores de referencia se describen en la Tabla 1. Hay que tener presente que puede haber valores falsos negativos por: falla en la técnica ${ }^{13}$, durante el primer mes de vida, o por la presencia de edema e hipoproteinemia.

Todo examen positivo debe ser repetido en días siguientes para seguridad del diagnóstico.

\section{¿A quiénes practicar el test del sudor?}

Dado que la presentación clínica de esta enfermedad es muy variada, es necesario tener presente este diagnóstico. En 1995, la OMS publicó criterios de sospecha en las distintas edades ${ }^{14}$. Se debe derivar para practicar test de sudor a pacientes que tengan al menos uno de los siguientes antecedentes:

- Neumonía repetida (2 o más anuales).

- Síndrome bronquial obtructivo refractario a tratamiento o persistente.

- Tos crónica de causa no precisada.
- Diarrea crónica, esteatorrea.

- Desnutrición crónica.

- Tríada: anemia, edema e hipoproteinemia, compromiso nutricional en el lactante.

- Deshidratación hiponatrémica con alcalosis metabólica hipoclorémica.

- Ileo meconial.

- Prolapso rectal.

- Ictericia neonatal prolongada.

- Obstrucción intestinal distal.

- Hepatomegalia y/o enfermedad hepática inexplicada.

- Pancreatitis.

- Esterilidad masculina.

- Hermano con diagnóstico de FQ.

- Hermano fallecido por causa respiratoria.

Otros hallazgos que sugieren FQ:

- Imágenes radiológicas pulmonares intersticiales o retículo-nodulares persistentes o crónicas.

- Bronquiectasias.

- Hipocratismo digital.

- Presencia de Pseudomonas aeruginosa a cualquier edad.

- Poliposis nasal.

\subsection{Elastasa fecal}

La elastasa es una enzima que forma parte de la secreción pancreática exocrina que cataliza la hidrólisis de la elastina nativa. Sus características bioquímicas le confieren resistencia en su paso a través del tracto digestivo. Se concentra en deposición 5 a 6 veces más que en líquido pancreático.

El nivel de elastasa fecal 1 (EF1) se determina con un test de ELISA específico y refleja el estado de la capacidad pancreática exocrina. $\mathrm{Su}$ determinación se realiza mediante una técnica simple, no invasiva y altamente sensible (96\%) y específica $(88 \%)^{15}$ para la determinación de la función pancreática normal o insuficiente (Tabla 2). Se preconiza incluir este examen en forma precoz en pacientes con tamizaje positivo en que fracasa la medición de sudor (no suda o

Tabla 1. Valores de referencia e interpretación del test del sudor

\begin{tabular}{|ccl|}
\hline Concentración de $\mathbf{C l}^{-}(\mathbf{m E q} / \mathbf{L})$ & Resultado & Conducta \\
{$\left[\mathrm{Cl}^{-}\right] \geq 60$} & Positivo & El test debe repetirse para certificar el diagnóstico \\
{$\left[\mathrm{Cl}^{-}\right] 30-59$} & Limítrofe & $\begin{array}{l}\text { Repetir el test. En caso de duda, frente a una alta sospecha clínica, } \\
\text { debe derivarse al especialista } \\
\text { Se recomienda estudio genético }\end{array}$ \\
{$\left[\mathrm{Cl}^{-}\right]<30$} & Negativo & $\begin{array}{l}\text { Descarta el diagnóstico, sin embargo, ante fuerte sospecha clínica, } \\
\text { reevaluar por especialista }\end{array}$ \\
\hline
\end{tabular}


la muestra es insuficiente repetidamente) ${ }^{15}$. La elastasa alcanza valores normales al $3^{\circ}$ día en recién nacidos de término y a las 2 semanas, en prematuros menores de 28 semanas de gestación. Los valores de corte de la elastasa fecal para el diagnóstico de insuficiencia pancrática se describen en la Tabla 2 .

Se debe tomar en consideración que los valores de corte de la elastasa fecal en FQ son referenciales y que prima la evaluación clínica para la indicación de enzimas pancreáticas, aunque su valor sea normal ${ }^{16,17}$.

Los resultados son altamente reproducibles intra paciente y no se alteran en aquellos que toman enzimas pancreáticas y no determina la cantidad de enzimas a aportar en un paciente insuficiente. Los resultados normales deben reevaluarse anualmente y en los lactantes menores, cada 3 meses.

La muestra debe procesarse siguiendo las indicaciones del laboratorio encargado (deposiciones formadas, sin diarrea).

Tabla 2. Interpretación de los valores de elastasa fecal $^{16}$

\begin{tabular}{|cc|}
\hline Normal & Insuficiencia \\
\hline$>200 \mu \mathrm{g} / \mathrm{g}$ & $\leq 199 \mu \mathrm{g} / \mathrm{g}$ \\
\hline
\end{tabular}

\subsection{Tamizaje o pesquiza neonatal (screening)}

El tamizaje es la única manera de diagnosticar el inicio de la enfermedad en un paciente aparentemente sano, sin embargo, existe un compromiso inflamatorio respiratorio que puede ocurrir muy temprano en la vida, desde recién nacido, aunque el paciente no tenga síntomas. El tamizaje ha demostrado beneficio nutricional al poder realizarse una intervención precoz (antes de los 2 meses de vida) ${ }^{18}$. También permite la investigación y reconocimiento precoz de infección por $P$. aeurginosa dado que presencia de esta bacteria es un marcador de sobrevida, por lo que el tratamiento y erradicación temprana son fundamentales.

Los protocolos de tamizaje en distintos países son diversos, utilizando IRT (tripsinógeno inmunoreactivo) en 2 muestras de sangre del recién nacido o en una muestra IRT/PAP (proteína asociada a pancreatitis) o IRT/DNA y otras combinaciones $^{19,20}$.

En Chile en un proyecto piloto que abarca la Región Metropolitana y la Quinta Región, se eligió la técnica de tamizaje IRT/PAP que es más costo efectiva y aunque produce más falsos positivos requiriendo aumentar los test del sudor para confirmar la enfermedad. La elección para nuestro país es la más adecuada dado que aún no tenemos estudio genético incorporado en la canasta GES. Esta técnica de tamizaje adoptada consiste en una primera determinación de IRT en sangre del recién nacido, si este es positivo se hace determinación de PAP en la misma muestra (tarjeta Guthrie). Presenta la ventaja que evita que el paciente tenga que concurrir a tomarse una segunda muestra, con el riesgo de no asistir. Si este segundo test es positivo debe confirmarse la enfermedad con test del sudor.

Un resultado de tamizaje positivo no diagnostica fibrosis quística, solo permite sospechar la enfermedad, que debe ser confirmada con test del sudor ${ }^{21,22}$.

Una vez confirmado el diagnóstico el paciente deberá ser referido y controlado por especialista lo antes posible, no más allá de 60 días.

\section{Seguimiento de lactantes confirmados con $F^{23,24}$}

\section{Conceptos generales}

- Control mensual por equipo multidisciplinario (pedíatra especialista, enfermera, nutricionista, kinesiólogo, asistente social e idealmente químico farmacéutico clínico y psicólogo).

- Realizar test sudor a los hermanos y medio hermanos.

- Educación sobre la enfermedad al cuidador por enfermera o médico.

- Tener comunicación expedita con el equipo que está a cargo (teléfono, Whatsapp).

- Asesoramiento genético a los padres.

\section{Manejo nutricional (ver capítulo de nutrición)}

- Demografía: peso, talla y circunferencia craneana en cada visita en percentiles.

- Lactancia materna de preferencia.

- Inicio de enzimas pancreáticas apenas se tenga la sospecha del diagnostico.

- La administración de enzimas en lactantes menores alimentados con leche materna debe ser monitorizada por nutricionista con experiencia del equipo FQ.

- Medición de elastasa fecal.

\section{Intervención kinésica}

- Iniciar educación en técnicas kinésicas para los padres con evaluación frecuente del aprendizaje, indicaciones sobre la administración de terapia inhalatoria, cuidado del compresor y del nebulizador (ver capítulo de kinesioterapia).

- Cultivos de secreción respiratoria en cada con- 
trol (hisopado o esputo inducido).

- Si el niño presenta síntomas respiratorios o tiene cultivos positivos seguir normas de este consenso.

En los pacientes en los que no se ha realizado tamizaje o los que tengan tamizaje con resultado negativo y presenten alta sospecha clínica, se debe realizar test del sudor y/o estudio genético.

\subsection{Estudio genético}

La identificación de las variantes patogénicas en el gen CFTR tiene varios propósitos. En la persona con FQ confirmada, tiene utilidad en la caracterización clínica y el pronóstico, en especial del compromiso pancreático. En los casos de duda diagnóstica, puede ser un examen confirmatorio si se demuestra la presencia de variantes patogénicas en los dos alelos del gen. También es útil para las personas con manifestaciones oligosintomáticas, como la agenesia del vas deferens. Es además un método capaz de identificar portadores sanos entre los parientes sanos de un caso con variantes conocidas. Hoy día es crucial para identificar pacientes con indicaciones de terapias específicas para ciertas variantes ${ }^{25}$ y también mejora la especificidad de los programas de pesquisa neonatal. Esto hace esencial incorporar el diagnóstico molecular y el asesoramiento genético para los padres y familia de las personas con FQ.

El asesoramiento genético es el proceso de ayudar a las personas a entender y adaptarse a las consecuencias médicas, psicológicas y familiares de las enfermedades de causa genética. Integra historia médica familiar y personal para evaluar la posibilidad de ocurrencia o recurrencia de una enfermedad. La toma de decisiones informadas se basa en: educación sobre la herencia, diagnóstico, manejo, prevención, recursos y eventual acceso a protocolos investigación. El asesoramiento es particularmente relevante en FQ, dado su patrón de herencia autosómico recesivo implica que una pareja que ha tenido un hijo con $\mathrm{FQ}$, tiene un $25 \%$ de probabilidades de tener otro hijo con la misma enfermedad en cada futuro embarazo. Los padres son portadores obligados y los hermanos sanos tienen $2 / 3$ de probabilidades de serlo también.

La FQ se debe a variantes que causan pérdida de la función de la proteína CFTR, codificada por el gen del mismo nombre. El gen está localizado en la región cromosómica $7 \mathrm{q} 31$ y es un gen grande, de alrededor de $200 \mathrm{~Kb}$ organizado en 27 exones.

Se han descrito varios miles de variantes o cambios en el gen, pero la mayoría son variantes benignas (Tabla 3 ), es decir, que no causan enfermedad. En base a estudios funcionales y otros criterios, la base de datos CFTR2 a la fecha contiene catalogadas como patogénicas, 48 de efecto clínico variable y 11 de significado incierto, es decir, que no hay suficiente información para catalogarlas como patogénicas o benignas ${ }^{26}$. Varios cambios tecnológicos y de nomenclatura, ocurridos en los últimos años, han impactado la relevancia e interpretación del estudio genético. El desarrollo de nuevas tecnologías de secuenciación, como la secuenciación masiva en paralelo o secuenciación de nueva generación, ha reducido los costos del análisis genético y ha acelerado el descubrimiento de nuevas variantes.

La secuenciación del gen completo ha ido reemplazando gradualmente el uso de paneles de variantes comunes, pues tiene mayor rendimiento diagnóstico y menor costo.

Se ha actualizado la nomenclatura de las variantes en las secuencias genéticas para reducir ambigüedades e inconsistencias. Se ha eliminado los términos "variante y "polimorfismos", y reemplazarlo por "variante", "cambio" o "alteración". Se ha clarificado la descripción de dichos cambios a nivel de secuencia de genes (precedidos por c. o g. por codificante o genómico, respectivamente) y proteínas (precedidos por p.). También se ha cambiado el uso de los símbolos de aminoácidos de 1 a 3 letras, entre otras modificaciones ${ }^{27}$. Algunos ejemplos de cambios en la nomenclatura de variantes causantes de FQ frecuentes en chilenos se muestran en la Tabla 4.

Tabla 3. Recomendaciones para la clasificación de variantes genéticas en el ámbito clínico

1. Patogénicas

2. Probablemente patogénicas

3. De significado incierto

4. Probablemente benignas

5. Benignas

Los laboratorios clínicos informan hallazgos en las 3 primeras categorías ${ }^{28}$.

\subsection{Otras consideraciones díagnósticas}

\section{a. Manifestaciones relacionados a disfunción de CFTR}

No se recomienda hablar de FQ no clásica $o$ atípica, pero se debe incluir a estos pacientes dentro del programa de seguimiento y manejo de fibrosis quística en un centro especializado. Es una entidad clínica que no cumple con todos los 
Tabla 4. Ejemplos de cambios de nomenclatura de variantes patogénicas en el gen CFTR más comunes en pacientes chilenos ${ }^{5,26}$

\begin{tabular}{|c|c|c|}
\hline Nomenclatura antigua & $\begin{array}{l}\text { Nomenclatura nueva } \\
\text { (según secuencia del gen) }\end{array}$ & $\begin{array}{l}\text { Nomenclatura nueva } \\
\text { (según secuencia de la proteína) }\end{array}$ \\
\hline $\mathrm{R} 117 \mathrm{H}$ & c. $350 \mathrm{G}>\mathrm{A}$ & p. Arg117His \\
\hline R334W & c. $1000 \mathrm{C}>\mathrm{T}$ & p.Arg334Trp \\
\hline $5 \mathrm{~T}$ & c. $1210-12[5]$ & $\begin{array}{l}\text { Es variante intrónica, no tiene nombre } \\
\text { en la proteína }\end{array}$ \\
\hline F508 del o delta F508 & c.1521_1523delCTT & p.Phe508 del \\
\hline G542X & c. $1624 \mathrm{G}>\mathrm{T}$ & p.Gly542X o p.Gly542* \\
\hline R553X & c. $1657 \mathrm{C}>\mathrm{T}$ & p.Arg553X o p.Arg553* \\
\hline $\mathrm{R} 1162 \mathrm{X}$ & c. $3484 \mathrm{C}>\mathrm{T}$ & p.Arg1162X o p.Arg1162* \\
\hline $3849+10 \mathrm{kbC}->\mathrm{T}$ & c. $3718-2477 \mathrm{C}>\mathrm{T}$ & $\begin{array}{l}\text { Es variante intrónica, no tiene nombre } \\
\text { en la proteína }\end{array}$ \\
\hline W1282X & c. $3846 \mathrm{G}>\mathrm{A}$ & p.Trp1282X \\
\hline
\end{tabular}

*Codón de término ${ }^{27}$.

criterios diagnósticos de FQ y es de presentación más frecuente en el adulto ${ }^{29}$.

Se caracteriza por:

- Manifestaciones multisistémicas con test sudor de valor intermedio o una variante CFTR, sin relevancia clínica.

- Mono sintomática: obstrucción de vasos deferentes, bronquiectasias y/o pancreatitis recurrente.

\section{b. Diagnóstico de fibrosis quística no resuelto ${ }^{30}$} Manifestaciones clínicas de FQ o tamizaje positivo o familiar con FQ con:

- Test sudor de valor intermedio.

- Estudio genético no concluyente e imposibilidad de realizar estudio de funcionalidad CFTR; se recomienda manejar como FQ y evaluar la respuesta al tratamiento.

c. Tamizaje para $F Q$ con diagnóstico inconcluso (Cystic Fibrosis Screen Positive, Inconclusive Díagnosis: CFSPID) ${ }^{31}$ o Síndrome metabólico relacionado al CFTR (Cystic Fibrosis Transmembrane Conductance Regulator-

Tabla 5. Caracterización de la enfermedad para financiamiento de canasta GES (garantías explicitas en salud)

\begin{tabular}{|c|c|c|}
\hline Leve & Moderado & Severo \\
\hline $\begin{array}{l}\text { Test de sudor y/o estudio genético } \\
\text { positivo sin manifestaciones } \\
\text { clínicas de la enfermedad. }\end{array}$ & $\begin{array}{l}\text { FQ con compromiso respiratorio, } \\
\text { de manejo ambulatorio. }\end{array}$ & $\begin{array}{l}\text { Antecedente de infección por } P \text {. } \\
\text { aeurginosa, Burkholderia sp o } \\
\text { microorganismos multirresistentes. }\end{array}$ \\
\hline $\begin{array}{l}\text { Enfermedad sin compromiso } \\
\text { pancreático ni pulmonar. }\end{array}$ & Insuficiencia pancreática. & $\begin{array}{l}\text { Presencia de bronquiectasias en } \\
\text { TAC de tórax. }\end{array}$ \\
\hline $\begin{array}{l}\text { Desórdenes relacionados a } \\
\text { disfunción de CFTR }\end{array}$ & Compromiso hepático moderado. & - Diabetes asociada a FQ \\
\hline $\begin{array}{l}\text { Diagnóstico de FQ } \\
\text { NO resuelto }\end{array}$ & & $\begin{array}{l}\text { Antecedente de descompensación } \\
\text { de la FQ que haya requerido } \\
\text { hospitalización. }\end{array}$ \\
\hline \multirow{5}{*}{$\begin{array}{l}\text { Tamizaje positivo para FQ con } \\
\text { diagnóstico inconcluso o Síndrome } \\
\text { metabólico relacionado al CFTR }\end{array}$} & & $\begin{array}{l}\text { Desnutrición crónica refractaria a } \\
\text { manejo nutricional inicial }\end{array}$ \\
\hline & & - Infección crónica confirmada \\
\hline & & - Antecedente de ABPA \\
\hline & & - Compromiso hepático severo \\
\hline & & $\begin{array}{l}\text { Compromiso respiratorio y } \\
\text { pancreático }\end{array}$ \\
\hline
\end{tabular}


Related Metabolic Syndrome: CRMS) ${ }^{31}$

Paciente con tamizaje positivo con alguna de las 2 situaciones siguientes:

- Test Sudor: $\mathrm{Cl}^{-}<30 \mathrm{mmol} / 1+2$ variantes CFTR (1 de ellas de consecuencias fenotípicas no claras).

- Test sudor $\mathrm{Cl}^{-}: 30-59 \mathrm{mmol} / 1+1$ o ninguna variante conocida de FQ.

Se recomienda:

- Repetir el test sudor en un centro acreditado y con experiencia ( $\geq 150$ test anuales).

- Seguimiento en centro de FQ.

- Estudio genético ampliado.

- Estudio de la funcionalidad CFTR (no disponible en Chile).

\section{Aspectos broncopulmonares}

La enfermedad respiratoria es la causa de morbilidad y mortalidad más frecuente, que ocurre en más del $90 \%$ de los pacientes con FQ y varía en la edad de presentación. Se debe estar muy alerta frente a síntomas sospechosos (ver a quien practicar test del sudor) y en que el tamizaje neonatal presta una ayuda muy valiosa. Sospechado o confirmado el diagnóstico, el paciente debe ser evaluado con exámenes de laboratorio, de imágenes, estudios funcionales y bacteriológicos ${ }^{32}$.

\subsection{Clasificación para el financiamiento}

Con la finalidad que los pacientes puedan acceder a financiamiento a las Garantías Explícitas en Salud (GES) en Chile se consensuó una clasificación que otorga diferente presupuesto, dependiendo de la caracterización (Tabla 5), la cual no es clínica, sino que determina los recursos asignados por el Ministerio de Salud. Esta evaluación es dinámica pudiendo ser cambiada en cualquier momento por el médico tratante.

\subsection{Exacerbación respiratoria}

Una exacerbación respiratoria debe considerarse un evento serio y la necesidad de tratamiento con antibióticos endovenosos en general la define como severo $^{33}$. Las exacerbaciones múltiples tienen el riesgo en general de una declinación de la función pulmonar ${ }^{34,35}$. A pesar que no hay consenso internacional, el criterio de Fuchs es el más usado ${ }^{36}$.

Se debe sospechar exacerbación respiratoria y tomar cultivo de expectoración ante la presencia de dos o más de los siguientes síntomas y sig- $\operatorname{nos}^{37}$ :

- Aumento de la tos y/o secreciones bronquiales.

- Cambio en el volumen, apariencia y color de la expectoración.

- Aumento de la frecuencia respiratoria o de la disnea.

- Deterioro de las pruebas de función pulmonar (caída del $\mathrm{VEF}_{1} \geq 10 \%$ y/o reducción de $2 \mathrm{o}$ más puntos en la saturación de $\mathrm{O}_{2}$ ) o nuevos infiltrados en la radiografía de tórax.

- Pérdida del apetito, decaimiento, baja de peso.

- Fatiga o disminución de la tolerancia al ejercicio.

La exacerbación leve se define como la modificación de la cantidad y calidad de la expectoración con aumento de la tos sin otros hallazgos y respuesta favorable dentro de las primeras $48 \mathrm{~h}$ de tratamiento oral. El diagnóstico de una exacerbación leve debe basarse en cambios clínicos sutiles, que permitirá abordar su tratamiento en forma ambulatoria.

Las exacerbaciones severas requieren de tratamiento antibiótico endovenoso hospitalizado o domiciliario.

- No descartan el diagnóstico de exacerbación: la ausencia de fiebre y de hallazgos al examen pulmonar, la falta de cambios en la radiografía de tórax y la presencia de un hemograma o reactantes de fase aguda dentro de la normalidad.

\subsection{Evaluación respiratoria}

Una vez diagnosticado el paciente deberá realizarse, dependiendo de la edad, exámenes generales, que se repetirán anualmente o con la frecuencia que amerite la condición clínica.

\section{Exámenes generales dependiendo de la edad}

- Hemograma, PCR.

- Perfil bioquímico.

- Electrolitos plasmáticos.

- Electrolitos urinarios + creatinina plasmática y urinaria.

- Cálculo de FENa (fracción excretada de sodio).

- Ferritina.

- IgE total.

- Cuantificación de inmnoglobulinas (IgA, IgM, IgG).

- Niveles de vitamina D.

- Ecografía abdominal con Doppler portal.

- Densitometría ósea sobre los 10 años.

- Test de tolerancia a la glucosa sobre 8 años o 
antes según sospecha clínica.

- Glicemia capilar en ayunas y a las $2 \mathrm{~h}$ sobre los 8 años en pacientes hospitalizados.

\section{Evaluación respiratoria con imágenes}

- Radiografía de tórax: Se debe realizar en proyección anteroposterior y lateral, al diagnóstico y luego según la situación clínica.

- Tomografía computada de tórax de alta resolución (TAC) con contraste: Puede mostrar alteraciones precoces que incluso aparecen antes de los cambios espirométricos, por lo que son de importancia pronóstica y para la evaluación del grado de avance del daño pulmonar. Se debe solicitar dependiendo del criterio clínico cada 2 a 4 años. Ningún estudio ha demostrado que el TAC frecuente mejore el pronóstico. El hallazgo de bronquios dilatados puede reflejar atrapamiento aéreo y taponamiento mucoso y no daño estructural; puede ser transitorio y no necesariamente catalogado como bronquiectasia (daño irreversible) $)^{38}$.

- Tomografía computada cavidades perinasales: Para el diagnóstico de sinusitis crónica y pretrasplante.

\section{Evaluación funcional respiratoria}

Idealmente el paciente debe hacer pruebas de función pulmonar antes de la visita al médico, como primer paciente del laboratorio o último si está infectado con MNTB (micobacteria no tuberculosis) o Burkholderia. Si no se dispone de filtro HEPA (High Efficiency Particulate Air) esperar mínimo 30 min entre cada paciente con FQ. Pacientes con Complejo Burkholderia deben dejarse para el final para luego hacer aseo terminal del laboratorio.

- Espirometría y curva flujo-volumen: Deben efectuarse desde que el niño sea capaz de colaborar para realizar la espirometría, lo que puede ocurrir entre los 3 y 5 años. Las pruebas de función pulmonar se correlacionan con el grado de avance de la enfermedad (Tabla 6).

El volumen espiratorio forzado en el primer segundo $\left(\mathrm{VEF}_{1}\right)$ permite anticipar y evaluar exacerbaciones agudas y la respuesta al tratamiento, siendo además el principal parámetro de seguimiento, orientando el pronóstico. La espirometría basal y con respuesta a broncodilatador debe realizarse en cada visita y en cada una de las exacerbaciones respiratorias.

- Test de marcha de 6 min: El test de marcha de 6 min (TM6), es considerado la prueba sub máxima ideal para evaluar capacidad funcional. Es fácil de realizar, de bajo costo y alta correlación con la vida cotidiana. Es un test reproducible y bien tolerado. Se recomienda para el seguimiento, la evaluación pre y post trasplante pulmonar y en rehabilitación pulmonar (Ver kinesioterapia).

- Índice de aclaramiento pulmonar (Lung clearance index LCI): Aun no está disponible en Chile. Es una herramienta más sensible que la espirometría para la detección de enfermedad precoz, compromiso de vía aérea periférica y bronquiectasias. Mide la falta de homogeneidad de ventilación a través del lavado pulmonar de múltiples respiraciones (MBW: multiple breath washout). La prueba necesita poca coordinación y cooperación, se realiza a volumen corriente, puede ser utilizada en todos los grupos de edad y es capaz de predecir exacerbación pulmonar ${ }^{39,40}$.

- Saturación arterial de oxígeno: Se debe realizar en cada control ambulatorio. La disminución de los valores puede indicar una exacerbación aguda o, en los casos más graves, la instalación de una insuficiencia respiratoria crónica oxígeno-dependiente en cuyo caso se debe realizar saturación nocturna continua (al menos $8 \mathrm{~h}$ ) y evaluar la necesidad de oxígeno ambulatorio.

Tabla 6. Grados de compromiso respiratorio según registro espirométrico: $\mathrm{VEF}_{1}$

\begin{tabular}{|lc|}
\hline $\begin{array}{l}\text { Grado del compromiso } \\
\text { respiratorio }\end{array}$ & $\begin{array}{c}\text { VEF }_{1} \text { (\% valor } \\
\text { predeterminado) }\end{array}$ \\
\hline Normal & $>90$ \\
\hline Compromiso Leve & $89-70$ \\
\hline Compromiso Moderado & $69-40$ \\
Compromiso Grave & $<40$ \\
\hline
\end{tabular}

\subsection{Infección pulmonar}

\section{a. Procesamiento de las muestras microbiológicas}

\section{- Estudio bacteriológico de esputo}

El cultivo de esputo debe realizarse en cada control del paciente con FQ y al inicio de una exacerbación bronquial ${ }^{41}$.

- Características mínimas del laboratorio microbiológico en $F Q$

El laboratorio que procesa las muestras debe conocer el listado de pacientes FQ.

- La orden y la muestra deben consignar el diagnóstico de FQ.

- El laboratorio debe contar con un protocolo para el procesamiento de las muestras de pa- 
cientes con FQ.

- Debe utilizar los medios de cultivo recomendados en FQ (Tabla 7).

- Debe realizar estudio de susceptibilidad.

- Debe tener capacidad de reportar fenotipo mucoide para los aislados de Pseudomonas.

- Debe tener capacidad de realizar diagnóstico para complejo Burkholderia.

- Consideraciones para el análisis de las muestras

Toma de muestra: En los pacientes FQ, la muestra puede ser tomada de las siguientes formas:

- Hisopado oro-faríngeo: Utilizar una tórula gruesa (dacrón) hacia la pared posterior de la faringe evitando tocar las amígdalas. Se induce la tórula y toma la muestra. Colocar en frasco estéril con o sin medio de trasporte. Principal utilidad en pacientes menores de 10 años que no pueden producir expectoración.

- Secreción bronquial (esputo): Hacer una inspiración profunda y un esfuerzo de tos evitando contaminación con saliva. Colocar en frasco estéril de boca ancha sin medio de transporte. Si el paciente no es capaz de ejecutar la maniobra, debe ser tomado con kinesiólogo post técnica kinésica o con esputo inducido (solución hipertónica 5-7\%).

\section{Otras consideraciones importantes}

No utilice el criterio de rechazo de muestras ( $>10$ células epiteliales en promedio con objetivo $10 \mathrm{x}$ ) para expectoración, aspirado traqueal $\mathrm{y}$ secreción bronquial. Las muestras de los pacientes con FQ desarrollan patógenos $>90 \%$ de las veces, independiente de la calidad de la muestra.

Para el estudio de micobacterias no tuberculosas (anualmente) solo enviar esputo.

Para el estudio de hongos, sirve muestra de esputo, aspirado o lavado bronco-alveolar (LBA).

\section{Transporte y procesamiento de la muestra}

- Identificar la muestra como FQ (para procesamiento especial).

- Transporte rápido (idealmente menor a $3 \mathrm{~h}$ ).

- Procesar inmediatamente o guardar a $4^{\circ} \mathrm{C}$.

\section{Proceso de las muestras}

- Realizar lectura de placas diariamente hasta completar el período de observación de 5 a 7 días.

- El hallazgo de $S$. aureus, P. aeruginosa y B. cepacia debe considerarse siempre clínicamente significativo y debe informarse independien-
Tabla 7. Medios de cultivo específicos en fibrosis quística

\begin{tabular}{|ll|}
\hline Agente & Medios de cultivo \\
S. aureus & $\begin{array}{l}\text { Agar sangre } \\
\text { Agar manitol salado } \\
\text { Test cromogénicos }\end{array}$ \\
\hline H. influenzae & Agar chocolate con o sin Bacitracina \\
\hline P. Aeruginosa & Agar Mac Conkey \\
B. cepacia & $\begin{array}{l}\text { BCSA (Burkholderia complex } \\
\text { selective agar) }\end{array}$ \\
\hline S. maltophilia & Agar Mac Conkey \\
A. xylosidans & Agar Mac Conkey \\
\hline Hongos & Agar Sabouraud \\
\hline
\end{tabular}

te de la cantidad aislada, tipo o calidad de la muestra.

- Si existe crecimiento significativo de una cepa pura, se debe estudiar (identificación y susceptibilidad).

- Si hay crecimiento significativo de hasta 3 cepas, estudiarlas por separado (identificación y susceptibilidad).

- Frente al hallazgo de crecimiento de hongos filamentosos como por ejemplo Aspergillus spp, se debe descartar contaminación del laboratorio y deben solicitarse nuevas muestras.

\section{Estudio de susceptibilidad ${ }^{42,43}$}

- P. aeruginosa: Los pacientes FQ pueden infectarse por distintos morfotipos de este agente. Cada cepa, mucoide y no mucoide, deben identificarse por separado y someter la sensibilidad a difusión por disco, e-test o microdilución. No se recomienda la utilización de métodos automatizados para probar la susceptibilidad en cepas mucoides.

- Haemophilus influenzae: Screening o tamizaje de $\beta$-lactamasas.

- Staphylococcus aureus: Resistencia a la oxacilina. Susceptibilidad puede realizarse por métodos automatizados (Vitek, MicroScan, Phoenix) o e-test o métodos de difusión por disco (Kirby-Baur).

- S. maltophilia y B. cepacia: No se sugiere el estudio de susceptibilidad por métodos automatizados.

\section{b. Definiciones ${ }^{44}$}

El primer aislamiento de un micoorganismo debe ser tratado. Estas definiciones son en gene- 
ral aplicadas para $P$. aeuginosa.

Primo infección: Cultivo (+) que aparece por primera vez.

Erradicación: Se debe entender que no es sinónimo de "cura "sino lo que se quiere lograr es demorar el comienzo de una infección crónica. No hay consenso de definición, varios estudios indican que sería suficiente tener 3 cultivos negativos en 6 meses para considerar erradicación, otros estudios luego de 12 meses $^{45,46}$.

Reinfección: Aparición P. auerginosa luego de un período de cultivos negativos (arbitrario) de 12 a 24 meses.

Infección intermitente: Esta es una definición basada solo en cultivos lo que lo hace difícil de interpretar, depende del número de cultivos en 12 meses que es muy variable en distintos centros de atención y depende también de la técnica (hisopado, esputo, LBA), puede enmascarar una infección crónica. Esta definición es más correcta cuando se cuenta con medición de anticuerpos anti Pseudomonas.

Infección crónica: No hay consenso en diversos estudios basado solo en cultivos, en general se considera cultivos $(+)$ para PA en la mitad o más de las muestras tomadas en un año (Criterio de Leeds $)^{47}$. El tratamiento tiene como fin disminuir la carga bacteriana y no necesariamente negativizar los cultivos.

\section{c. Microbiología y conducta a seguir}

Las dosis de los antibióticos se especifican para los siguientes micoorganismos en el Anexo 3.

\section{- Staphilococcus aureus meticilino sensible}

Es una cocácea gran positiva que infecta en forma precoz, siendo habitualmente el primer microorganismo aislado en las secreciones respiratorias con capacidad de producir infección intermitente y/o crónica. La portación nasofaríngea es un importante factor de riesgo para el desarrollo de infección.

El uso de antibióticos profilácticos para $S$. aureus no se recomienda, ya que favorece la adquisición precoz de $P$. aeuriginosa por falta de inhibición competitiva.

\section{Recomendación de conducta a seguir}

En la primera infección, estando el paciente con exacerbación respiratoria: Hospitalizar para tratamiento endovenoso (EV).

En la primera infección estando el paciente asintomático: flucloxacilina o cotrimoxazol por 14 días. Se puede utilizar alternativamente amoxicilina/ácido clavulánico.
En pacientes con infección crónica asintomáticos: no se indica tratamiento.

En pacientes con infección crónica cursando una exacerbación: si es leve o moderada se debe tratar en forma ambulatoria, si es severo se debe hospitalizar.

\section{- Staphilococcus aereus meticilino resistente (MRSA)}

La presencia de esta bacteria es un factor pronóstico y se discute si asocia a mayor mortalidad $^{48-50}$. Mundialmente la multirrestencia ha ido aumentando ${ }^{51}$, por lo que el tratamiento debe ser más agresivo, con vancomicina o linezolid $\mathrm{EV}$ en el primer episodio sintomático. Como alternativa se debe usar cotrimoxazol asociado a rifampicina.

\section{- Pseudomonas aeruginosa (PA)}

Es un bacilo Gram negativo común en pacientes con FQ cuya prevalencia ha disminuido los últimos 20 años $^{52}$. Es el principal microorganismo al cual están enfocados todos los esfuerzos terapéuticos. Una vez que se establece la infección crónica el deterioro de la función pulmonar es progresivo y la sobrevida disminuye.

\section{Recomendación de conducta a seguir}

Primera infección con paciente sintomático: Hospitalizar para tratamiento EV, siempre con 2 antibióticos asociados por al menos 10 a 14 días y luego continuar con tobramicina inhalada por 1 mes.

Primera infección con paciente asintomático: Alternativas utilizadas en diferentes centros. No hay consenso internacional.

1. Tobramicina inhalada por 28 días y controlar cultivo, si continúa positivo administrar tobramicina inhalada un segundo mes. Actualmente es la más utilizada.

2. Tobramicina inhalada más ciprofloxacino oral por 28 días.

3. Colistín polvo seco $1.600 .000 \mathrm{UI}$ cada $12 \mathrm{~h}$ por 3 meses más ciprofloxacino oral.

4. Colistín nebulizado $3.000 .000 \mathrm{UI} \mathrm{c} / 12 \mathrm{~h}$ por 3 meses más ciprofloxacino oral.

Si el cultivo continúa positivo, hospitalizar para tratamiento endovenoso.

En pacientes que tengan cultivo con bacterias multirresistentes o ante la duda del manejo se sugiere hospitalización para manejo EV.

Luego de completado el tratamiento, el seguimiento es con cultivos según norma.

\section{Infección crónica}

Infección crónica en paciente asintomático. 
Tobramicina inhalada (tobramicina en polvo es igualmente efectiva) o colistín inhalado mes por medio. En caso de respuesta insuficiente se deben alternar ambos antibióticos mensualmente. Como coadyudante el uso de azitromicina 3 veces por semana ${ }^{53}$.

Alternativa de tercera línea (sólo pacientes con falla a tratamiento y resistencia demostrada a otros antibióticos: aztreonam nebulizado $75 \mathrm{mg}$ cada 8 h por 30 días, alternado con tobramicina o colistin.

Infección crónica en paciente sintomático: Hospitalizar para efectuar terapia ev.

\section{- Stenotrophomonas maltophilia}

Bacilo Gram negativo con resistencia a varios antibióticos, es un hallazgo cada vez más frecuente. Puede aislarse en forma intermitente o producir infección bronquial crónica, aún no está claro si la infección crónica es solo un marcador de gravedad de la enfermedad o si la presencia tiene una relación causal con la progresión clínica ${ }^{54}$.

La decisión de tratamiento antibiótico debe ser individualizada según síntomas del paciente, compromiso de la función pulmonar y el aislamiento del patógeno en los cultivos.

Tratamiento de elección: Cotrimoxazol oral por 3-4 semanas. Si no hay respuesta asociar cotrimoxazol con doxiciclina, levofloxacino, o tigeciclina (Tabla 8$)^{55}$.

\section{- Achromobacter ${ }^{57}$}

El Achromobacter xylosoxidans es un bacilo Gram negativo, cuya tasa de infección es de un
2-18\% $\%^{58}$. El impacto clínico está en discusión, afectando a pacientes de mayor edad y con mayor compromiso pulmonar. Se puede asociar a un deterioro clínico y exacerbaciones pudiendo ser causante de neumonías y bacteremias ${ }^{59}$.

Tienen resistencia innata a múltiples antibióticos como aminoglucósidos, aztreonam y sensibilidad disminuida algunas penicilinas, cefalosporinas, y fluoquinolonas, sumado a su capacidad de producir biofilm complica su manejo. Los antibióticos más activos son carbapenémicos, cotrimoxazol y piperacilina/tazobactam y dentro de los betalactámicos, ceftazidima es la que presenta mejor susceptibilidad.

En caso de exacerbación debido a este germen se sugiere asociar meropenem o imipenem con ciprofloxacino o trimetropin/sulfametoxazol por 14 a 21 días (Tabla 9) ${ }^{57,60}$.

\section{Burkholderia cepacia complex (BCC)}

Es un grupo de bacilos Gram negativos cuyas especies más frecuentemente implicadas en infecciones respiratorias son $B$. cenocepacia (genomovar III) y B. multivorans (genomovar II).

El curso clínico de pacientes infectados por $\mathrm{BCC}$ es variable, desde una infección asintomática a un deterioro progresivo e incluso fulminante, aunque lo habitual es que el paciente presente un compromiso funcional progresivo.

El manejo es complejo dado que son microorganismos resistentes a múltiples antibióticos siendo la erradicación muy difícil, por lo que el objetivo del tratamiento es disminuir la carga

Tabla 8. Indicación y dosis de antibióticos para el tratamiento de la Stenotrophomonas maltophilia

\begin{tabular}{|c|c|c|}
\hline Antibióticos & Dosis pediátrica & Dosis adulto \\
\hline Cotrimoxazol & $\begin{array}{l}5 \mathrm{mg} / \mathrm{kg} / \text { dosis de trimetoprim EV u oral } \\
\text { cada c/6 h } \\
\text { Los bacilos Gram negativos no fermen- } \\
\text { tadores necesitan dosis altas de cotri- } \\
\text { moxazol. No existe en la literatura una } \\
\text { dosis máxima }\end{array}$ & $\begin{array}{l}5 \mathrm{mg} / \mathrm{kg} / \text { dosis de trimetoprim } \mathrm{EV} \mathrm{u} \text { oral } \\
\text { cada c/6 h } \\
\text { Los bacilos Gram negativos no fermen- } \\
\text { tadores necesitan dosis altas de cotri- } \\
\text { moxazol. No existe en la literatura una } \\
\text { dosis máxima }\end{array}$ \\
\hline $\begin{array}{l}\text { Asociar en falta de respuesta: } \\
\text { Doxiciclina* }\end{array}$ & $2 \mathrm{mg} / \mathrm{kg} /$ dosis cada $12 \mathrm{~h}$ oral & $100 \mathrm{mg}$ cada $12 \mathrm{~h}$ oral \\
\hline Levofloxacino & $\begin{array}{l}<5 \text { años: } 10 \mathrm{mg} / \mathrm{kg} / \text { dosis } \mathrm{EV} \text { u oral } \\
\text { cada } 12 \mathrm{~h} \\
>5 \text { años } 10 \mathrm{mg} / \mathrm{kg} / \text { dosis } \mathrm{EV} \mathrm{u} \text { oral una } \\
\text { vez al día }\end{array}$ & 500-750 mg EV u oral una vez al día \\
\hline Tigeciclina & $1,2 \mathrm{mg} / \mathrm{kg} /$ dosis EV cada $12 \mathrm{~h}$ & $\begin{array}{l}50 \mathrm{mg} \text { EV cada } 12 \mathrm{~h} \\
\text { En pacientes con infección severa consi- } \\
\text { dere dosis de } 100 \mathrm{mg} \text { cada } 12 \mathrm{~h}^{56}\end{array}$ \\
\hline
\end{tabular}

*No utilizar en menores de 8 años. EV: endovenoso. Max: máximo. 
Tabla 9. Terapia antibiótica por 14 a 21 días para Achromobacter

\begin{tabular}{|c|c|c|}
\hline Antibióticos & Dosis pediátrica & Dosis adulto \\
\hline $\begin{array}{l}\text { Meropenem } \\
\text { o } \\
\text { Imipenem } \\
\text { Más uno de los siguientes }\end{array}$ & $\begin{array}{l}40 \mathrm{mg} / \mathrm{kg} / \mathrm{dosis} \text { ev cada } 8 \mathrm{~h} \\
25 \mathrm{mg} \mathrm{kg} / \text { dosis ev cada } 6 \mathrm{~h}\end{array}$ & $\begin{array}{l}2 \mathrm{~g} / \mathrm{dosis} \text { ev cada } 8 \mathrm{~h} \\
500 \mathrm{mg}-1 \mathrm{~g} \text { dosis ev cada } 6 \mathrm{~h} \\
\text { Dosis máxima } 4 \mathrm{~g} / \text { día }\end{array}$ \\
\hline Ciprofloxacino* & $\begin{array}{l}10 \mathrm{mg} / \mathrm{kg} / \mathrm{dosis} \text { ev cada } 8 \mathrm{~h} \text { o } 10-15 \mathrm{mg} / \\
\mathrm{kg} \text { vo cada } 8 \mathrm{~h}^{*}\end{array}$ & $\begin{array}{l}400 \mathrm{mg} \text { cada } 8 \mathrm{~h} \text { ev o } 750 \mathrm{mg} \text { vo cada } \\
12 \mathrm{~h}\end{array}$ \\
\hline Trimetropin/sulfametoxazol & $\begin{array}{l}5 \mathrm{mg} / \mathrm{kg} / \mathrm{dosis} \text { de trimetropin ev } \mathrm{u} \text { oral } \\
\text { cada } 6 \text { a } 8 \mathrm{~h}\end{array}$ & $\begin{array}{l}5 \mathrm{mg} / \mathrm{kg} / \text { dosis de trimetropin ev u oral } \\
\text { cada } 6 \text { a } 8 \mathrm{~h}\end{array}$ \\
\hline
\end{tabular}

*El efecto bactericida se potencia administrándolo 3 veces al día. *Considerar que la biodisponibilidad de ciprofloxacino se ve disminuida un $40 \%$ al administrarlo con lácteos. ev: endovenoso, vo: vía oral.

bacteriana y la respuesta inflamatoria.

La antibioterapia combinada usando 2 o 3 antibióticos por 21 días es la estrategia más utilizada, con meropenem o ceftazidima más amikacina o tobramicina, trimetropin/sulfametoxazol o aztreonam (Tabla 10). Sugiriéndose un período de consolidación de 2 meses con trimetropin/ sulfametoxazol, tobramicina inhalada o en polvo o azitromicina trisemanal (Tabla 11).

Se recomienda ciclos con tobramicina inhalada en infección crónica por BCC en pacientes con deterioro funcional progresivo, reevaluando su continuidad en caso de no observar beneficio clínico $^{61}$.

\section{- Micobacterias no TBC (Non tuberculous Mycobacterium: NTMB $^{62,63}$}

Incluye todas las mycobacterias no comprendidas dentro del complejo tuberculoso. Son microorganismos ácido-alcohol resistentes, ubicuos en el ambiente con amplia distribución en aguas y suelos, identificándose más de 60 especies

Tabla 10. Terapia antibiótica inicial para Burkholderia cepacia complex: inducción de 21 días

\begin{tabular}{|lll|}
\hline Antibióticos & Dosis pediátrica & Dosis adulto \\
$\begin{array}{l}\text { Meropenem } \\
\text { o }\end{array}$ & $40 \mathrm{mg} / \mathrm{kg} /$ dosis ev cada $8 \mathrm{~h}$ & $2 \mathrm{~g}$ ev cada $8 \mathrm{~h}$ \\
$\begin{array}{l}\text { Más uno de los siguientes } \\
\text { Amikacina }\end{array}$ & $70 \mathrm{mg} / \mathrm{kg} /$ dosis ev cada $8 \mathrm{~h}$ & $2 \mathrm{~g}$ cada $8 \mathrm{~h} \mathrm{ev}$ \\
$\begin{array}{l}\text { o } \\
\text { Tobramicina }\end{array}$ & $30 \mathrm{mg} / \mathrm{kg} /$ dosis ev cada $24 \mathrm{~h}$ & $30 \mathrm{mg} / \mathrm{kg} / \mathrm{dosis}$ ev cada $24 \mathrm{~h}$ \\
$\begin{array}{l}\text { Trimetropin/sulfametoxazol } \\
\text { Dosis máxima } 1,5 \mathrm{~g} / \mathrm{día}\end{array}$ \\
$\begin{array}{l}10 \mathrm{mg} / \mathrm{kg} / \text { dosis ev cada } 24 \mathrm{~h} / \mathrm{kg} / \mathrm{dosis} \text { de trimetropin ev u oral } \\
\text { cada } 8 \mathrm{a} 12 \mathrm{~h}\end{array}$ & $\begin{array}{l}5 \mathrm{mg} / \mathrm{kg} / \mathrm{dosis} \text { de trimetropin ev u oral } \\
\text { cada } 8 \mathrm{a} 12 \mathrm{~h}\end{array}$ \\
\hline
\end{tabular}

Max: máximo, ev.: endovenoso

Tabla 11. Terapia antibiótica de consolidación para Burkholderia cepacia complex de 2 meses

\begin{tabular}{lll|}
\hline Antibióticos & Dosis pediátrica & Dosis adulto \\
$\begin{array}{l}\text { Trimetropin/sulfametoxazol } \\
\text { Tobramicina inhalada }\end{array}$ & $\begin{array}{l}\mathrm{mg} / \mathrm{kg} / \text { dosis de trimetropin ev u oral } \\
\text { cada } 8-12 \mathrm{~h}\end{array}$ & $\begin{array}{l}5 \mathrm{mg} / \mathrm{kg} / \mathrm{dosis} \text { de trimetropin ev u oral } \\
\text { cada } 8-12 \mathrm{~h}\end{array}$ \\
$\begin{array}{l}\text { Ton } 300 \mathrm{mg} \text { cada } 12 \mathrm{~h} \\
\begin{array}{l}\text { Tobramicina en polvo } \\
\text { (Podhaler) } 28 \mathrm{mg} / \text { cápsula) }\end{array}\end{array}$ & 4 cápsulas cada $12 \mathrm{~h}$ & 4 cápsulas cada $12 \mathrm{~h}$ \\
\hline Azitromicina & $250 \mathrm{mg} /$ dosis oral trisemanal & $500 \mathrm{mg} /$ dosis oral trisemanal \\
\hline
\end{tabular}

Max: máximo, ev: endovenoso, NBZ: nebulización. 
causantes de patología humana. Tienen una prevalencia más alta en pacientes con FQ que ha ido en aumento, estimándose entre 6-13\% de tasa de cultivos positivos. En pacientes de Estados Unidos la especie más comúnmente aislada es Mycobacterium avium complex (MAC) y Mycobacterium abscessus en Europa e Israel.

Los criterios diagnósticos de la enfermedad pulmonar por NTMB (ATS/IDSA) son los mismos para pacientes con y sin FQ:

1. Imágenes compatibles: Bronquiectasias multifocales con nódulos pequeños múltiples en TAC pulmonar de alta resolución.

2. Presencia de al menos dos cultivos de expectoración positivos para NTMB o al menos un cultivo positivo obtenido por lavado bronco alveolar y la exclusión de otras alternativas díagnósticas.

\section{Tratamiento Mycobacterium abcessus s $^{64,65}$}

Fase intensiva de 3-4 semanas: Incluye un macrólido oral diario (preferiblemente azitromicina) más amikacina endovenosa y alguno de los siguientes: Tigeciclina, imipenem o cefoxitina ev.

Fase de continuación debe incluir un macrólido oral diario (preferiblemente azitromicina), amikacina inhalada (de uso ev), junto con 2 o más de los siguientes antibióticos orales adicionales: minociclina, clofazimina, moxifloxacina y linezolid.

La enfermedad pulmonar por Mycobacterium Avium sensible a claritromicina debe tratarse con un régimen diario de antibióticos orales que contiene un macrólido (preferiblemente azitromicina), rifampicina y etambutol. Si hay evidencia radiológica de cavitación o síntomas sistémicos se puede considerar el uso de 1 a 3 semanas de amikacina endovenosa.

\section{Recomendación}

1. Tomar cultivo de expectoración cada 4 a 8 semanas y mantener tratamiento hasta 12 meses posterior a la negativización de los cultivos.

2. Monitorizar activamente la función visual, auditiva, renal y hepática, debido a la alta incidencia de toxicidad por fármacos.

3. Búsqueda en forma dirigida en cultivos de expectoración por lo menos una vez por año.

Se considera éxito del tratamiento a cultivos negativos por más de 1 año.

\section{- Hongos}

Aspergillus: Es el hongo más común encontrado en el esputo de pacientes con FQ (10 a $25 \%$ en adolescentes y adultos). La colonización puede ser inicial, esporádica o persistente, es un hallazgo en el 32,5\%. La implicancia clínica es controversial: $\mathrm{Si}$ se presenta deterioro de la función pulmonar y/o exacerbaciones frecuentes no atribuibles a otros agentes, se debe descartar bronquitis por Aspergillus.

La enfermedad invasiva y el aspergiloma son muy infrecuentes.

\section{Bronquitis por Aspergillus ${ }^{66}$}

Se define como cultivo de secreción bronquial positivo para Aspergillus más:

- Exacerbaciones respiratorias con caída de función pulmonar que no responden con antibióticos.

- IgE específica para Aspergillus +.

- IgG específica para Aspergillus +.

- IgE total más de 500 UI sin imágenes tomográficas nuevas.

El galactomanano en LBA, ha mostrado una sensibilidad y especificidad de 77,2\% y 77,0\% respectivamente, con mejores resultados que la medición en sangre. Tiene un punto de corte $>0,5$ del índice de densidad óptica (optical density index $[\mathrm{ODI}])^{67}$.

También se puede medir PCR en tiempo real en sangre y LBA, con diferentes resultados con respecto a sensibilidad y especificidad en distintos estudios.

El tratamiento (Tabla 12) es con itraconazol o voriconazol, de 2 a 6 semanas o hasta observar mejoría de tos, calidad de esputo y función pulmonar. Se recomienda realizar antifungigrama (test de sensibilidad).

Aspergillosis broncopulmonar alérgica (ABPA): Es el resultado de una respuesta de hipersensibilidad TH2, mediada por IgE, en pacientes con FQ. Inicialmente ocurre sensibilización para Aspergillus y luego en el $40 \%$ de los casos se manifiesta como ABPA ${ }^{68-71}$. Se debe sospechar ante deterioro clínico agudo o subagudo que no responde a tratamiento antibiótico y no es atribuible a otra etiología. El cuadro clínico se caracteriza por: sibilancias, dolor u opresión torácica, falta de respuesta a antibióticos, fiebre y malestar general, desgarro espeso de color café o moldes bronquiales oscuros, aunque estos síntomas pueden no estar presentes.

\section{Criterios para el diagnóstico de ABPA ${ }^{72,73}$}

\section{Obligatorios (ambos presentes)}

Test cutáneo + para Aspergillus (mayor a $3 \mathrm{~mm}$ ) o IgE específica (+) a Aspergillus fumigatus (alto valor diagnóstico). 


\section{Tabla 12. Dosis de antifúngicos}

\begin{tabular}{|c|c|}
\hline Antifúngico & Dosis \\
\hline Itraconazol & $\begin{array}{l}\text { 5-10 mg/kg/día cada } 12 \text { h (Por PK no se justifica una vez día) } \\
\text { Dosis máxima: } 400 \mathrm{mg} / \text { día }(200 \mathrm{mg} \mathrm{c} / 12 \mathrm{~h})\end{array}$ \\
\hline $\begin{array}{l}\text { Voriconazol } \\
\text { (Tomar } 1 \text { hora antes o después } \\
\text { de alguna comida) } \\
\text { Tras } 3 \text { días, monitorizar niveles valle } \\
\text { cuyo valor debe ser entre } 1-5 \mathrm{mg} / \mathrm{ml}\end{array}$ & $\begin{array}{l}\text { Endovenoso: } \\
\text { Paciente }<\text { de } 12 \text { años o peso }<50 \mathrm{~kg} \text { : } \\
\text { Dosis de carga: } 9 \mathrm{mg} / \mathrm{kg} / \mathrm{dosis} \text { cada } 12 \mathrm{~h} \text { por } 2 \text { dosis } \\
\text { Dosis de mantención: } 8 \mathrm{mg} / \mathrm{kg} / \text { dosis cada } 12 \mathrm{~h} \\
\text { Pacientes }>12 \text { años con peso }>\text { a } 50 \mathrm{~kg} \text { o pacientes }>15 \text { años: } \\
\text { Dosis de carga: } 6 \mathrm{mg} / \mathrm{kg} / \mathrm{dosis} \text { cada } 12 \mathrm{~h} \text { por } 2 \text { dosis } \\
\text { Dosis de mantención: } 4 \mathrm{mg} / \mathrm{kg} / \text { dosis cada } 12 \mathrm{~h} \\
\text { Oral: } \\
\text { Paciente }<12 \text { años o peso }<50 \mathrm{~kg} \text { : } \\
\text { Dosis de carga de } 9 \mathrm{mg} / \mathrm{kg} / \mathrm{dosis} \text { cada } 12 \mathrm{~h} \\
\text { Pacientes }>12 \text { años con peso }>\text { a } 50 \mathrm{~kg} \text { Pacientes }>15 \text { años: } \\
400 \text { mg cada } 12 \mathrm{~h} \text { por } 2 \text { dosis y luego mantener con } 200 \text { mg cada } 12 \mathrm{~h}\end{array}$ \\
\hline Anfotericina liposomal inhalada ${ }^{78}$ & $25-50 \mathrm{mg}$ día 3 veces por semana \\
\hline
\end{tabular}

PK: farmacocinética.

IgE total $>1.000$ UI (Alto valor diagnóstico). Alza brusca 4 veces el valor basal que alcance $\geq 500$ UI.

\section{Otros criterios (debe cumplir 2 de 3 )}

IgG especifica positiva.

Nuevas imágenes radiológicas o del TAC.

Eosinofilia $>500 \times \mathrm{mm}^{3}$.

\section{Tratamiento $^{74,75}$}

Corticoides orales y terapia antifúngica más manejo ambiental (evitar lugares con humedad, tierra, desechos orgánicos y demoliciones).

Corticoides: Constituye el tratamiento principal.

1. Prednisona oral: $2 \mathrm{mg} / \mathrm{kg}$ /día (máximo $40 \mathrm{mg}$ diarios) por 2 semanas, luego $1 \mathrm{mg} / \mathrm{kg} / \mathrm{día}$ (máximo $20 \mathrm{mg}$ ) por 2 semanas y luego $1 \mathrm{mg} /$ kg (máximo $10 \mathrm{mg}$ ) en días alternos por 10 semanas.

La evaluación de la respuesta al tratamiento se evidencia por la mejoría de los síntomas y retorno a la función pulmonar previa al tratamiento. Hay que tener en cuenta que los niveles de IgE demoran varios meses en descender. Puede haber recaída al 2 do o 3 er año, necesitando dosis altas por períodos más largos de tiempo.

2. Pulsos de metilprednisolona: Es una alternativa cuando el corticoide oral no es bien tole- rado bajo circunstancias especiales. Se indica en bolos (15 a $20 \mathrm{mg} / \mathrm{kg} /$ día) administrados en $6 \mathrm{~h}$, por 3 días seguidos (dosis máxima $1 \mathrm{~g}$ ) cada mes, hasta la mejoría clínica y disminución de IGE, lo que habitualmente ocurre en 3 meses $^{74,75}$.

Los efectos adversos con este tratamiento incluyen hipertensión arterial, debilidad, mialgias, hiperglicemia transitoria, cefalea y a veces arritmias.

Tratamiento antifúngico ${ }^{76}$ de rutina en pacientes con $\mathrm{ABPA}^{71}$ (ver las dosis Tabla 12).

Hay que recordar que la resistencia a los azólidos ha ido aumentando (5-8\%).

1. Itraconazol: Se debe administrar por 6 semanas, dependiendo de la evolución se puede prolongar hasta 6 meses. Es importante vigilar la función renal y hepática regularmente. Suspender ranitidina y omeprazol y dar con cítricos (jugo de naranja), con el estómago vacío ${ }^{76}$.

2. Voriconazol: Tiene mejor absorción y no se afecta con el $\mathrm{pH}$, pero presenta mucha variación de los niveles plasmáticos entre pacientes.

Se debe medir niveles plasmáticos valle (predosis) después de la quinta dosis de tratamiento. Los niveles plasmáticos óptimos son 1,5-5 ug/ $\mathrm{ml}^{77}$.

Los efectos colaterales son la alteración de pruebas hepáticas, hipoacusia y fotosensibilidad, 
en cuyo caso y en mayores de 8 años se puede indicar posaconazol.

3. Otras alternativas en casos excepcionales:

Anfotericina nebulizada (no liposomal): Se ha usado para casos refractarios a tratamiento. Puede producir broncoespasmo y tos por lo que se debe administrar un broncodilatador previamente. Si no hay respuesta considerar anfotericina liposo$\mathrm{mal}^{78}$.

Anticuerpo monoclonal anti IgE ${ }^{79}$ Omalizumab: Se ha usado para disminuir la dosis de corticoides en pacientes difíciles de manejar, sin embargo un metaanálisis Cochrane no muestra mejoría significativa para recomendar su uso de rutina.

Corticoides inhalados no han demostrado eficacia terapéutica.

Otros hongos: El hallazgo de otros hongos como el complejo de especies Scedosporium apiospermum, Lomentospora prolificans y Candi$d a$ spp son hallazgos cada vez más frecuentes en secreciones de pacientes con FQ. La prevalencia ha ido en aumento siendo Scedosporium el segundo más frecuente de los hongos filamentosos encontrados (14\%). Este hongo se encuentra en la tierra, agua contaminada y estiércol de animales. Al colonizar la vía aérea genera respuesta inmune. Puede asociarse con Aspergillus y su rol patogénico no está bien establecido.

Virus respiratorios ${ }^{80}$ : Los pacientes con $\mathrm{FQ}$ no tienen mayor riesgo de infectarse con virus comparado con la población general, sin embargo cuando contraen una enfermedad viral tienen mayor riesgo de hacer compromiso de la vía aérea inferior y tener caída del $\mathrm{VEF}_{1}$ con mayor posibilidad de no recuperar la función pulmonar basal. Las infecciones virales están asociadas con un aumento de la inflamación de la vía aérea y mayor aislamiento de bacterias habituales en $\mathrm{FQ}^{81}$. En épocas epidémicas de virus respiratorios se debe iniciar tratamiento antibiótico. Amoxicilina/ ácido clavulánico o macrólidos por 1-2 semanas y prolongar por 1 semana desde que el paciente este asintomático. Evitar las cefalosporinas por aparición de resistencia de la $P$. aerurginosa. Si el paciente no está libre de síntomas a las 2 semanas debe ser reevaluado.

\subsection{Otros tratamientos para el compromiso pulmonar en fibrosis quística}

\section{- Hidratantes de la secreción bronquial: Solución hipertónica}

El trastorno del CFTR que se produce en FQ determina que el epitelio respiratorio no se pueda hidratar en forma normal. Rehidratar como parte del tratamiento puede reducir o prevenir la injuria pulmonar $^{82,83}$.

Esta es una alternativa barata y segura que se debe utilizar desde el diagnóstico tanto en fase aguda como crónica ${ }^{84}$.

La solución de uso habitual es al 7\%, la que se prepara con $2 / 3$ de solución de $\mathrm{NaCl}$ al $10 \%$ diluida con 1/3 de agua bidestilada. De la solución resultante, nebulizar $4 \mathrm{ml} 2$ veces al día. En lactantes nebulizar al 5\% (mitad de $\mathrm{NaCl}$ al $10 \%$ y mitad de agua destilada) por 2 veces al día y si es bien tolerada se debe subir la concentración al $7 \%{ }^{85,86}$. Se puede usar sola o alternada con DNasa (desoxiribonucleasa). Tiene un efecto complementario de fluidificar secreciones.

\section{- Mucolíticos: Alfa-Dornasa}

Alfa Dornasa es una desoxiribonucleasa recombinante humana que hidroliza el DNA extracelular en pacientes con FQ y reduce la viscoelasticidad del esputo ${ }^{87,88}$. Los ensayos clínicos han mostrado mejoría del $\mathrm{VEF}_{1}$ y disminución del número de exacerbaciones con respecto a placebo.

\section{Indicaciones $^{89}$}

Uso crónico en paciente con compromiso pulmonar moderado a severo a cualquier edad ${ }^{84}$. Aunque no hay consenso, en exacerbación grave, los pacientes pueden beneficiarse con su indicación 2 veces al día.

La dosis es de 2,5 $\mathrm{mg}(2,5 \mathrm{ml})$ sin diluir, en nebulizador PARI LC Jet Plus ${ }^{\circledR}$, Parí Baby durable side stream ${ }^{\circledR}$ o nebulizador de malla $\left(\mathrm{e} \mathrm{flow}^{\circledR}\right.$ ) con compresor, hasta que se consuma todo, una vez al día.

Los efectos adversos más frecuentes son las alteraciones de la voz, faringitis, edema facial y malestar gástrico, son transitorios y no constituyen indicación de suspensión de la droga. Otros mucolíticos (orales o inhalatorios) no tienen indicación en FQ.

\section{- Broncodilatadores}

Agonistas Beta 2 adrenérgicos de acción corta. Deben usarse en aerosol presurizado con aerocámara antes de kinesioterapia, tratamientos nebulizados y ejercicio, como también a libre demanda en aquellos pacientes que presentan clínicamente sibilancias y que demuestran respuesta broncodilatadora significativa.

Agonistas Beta 2 adrenérgicos de acción prolongada: En mayores de 2 años con hiperreacti- 
vidad en la que se demuestre beneficio clínico $\mathrm{y} / \mathrm{o}$ funcional, utilizar en aerosol presurizado con aerocámara, asociado siempre a corticoide inhalado.

\section{- Corticoides}

\section{Corticoides sistémicos: Prednisona}

$\mathrm{Su}$ uso principal es en el tratamiento de ABPA

Tiene indicación en obstrucción aguda severa de la vía aérea su indicación es cura corta de 5 a 7 días, en dosis de 1 a $2 \mathrm{mg} / \mathrm{kg} /$ día con tope de $40 \mathrm{mg} /$ día, en dosis única matinal ${ }^{90}$.

En caso de bronco espasmo severo intratable: $2 \mathrm{mg} / \mathrm{kg} /$ día con tope de $40 \mathrm{mg} /$ día. Reducir lo más pronto posible dependiendo de la respuesta y continuar con dosis cada $48 \mathrm{~h}$. Como alternativa se pueden usar bolos de metilprednisolona

Se debe estar atento a los efectos colaterales, en especial a la diabetes, retraso del crecimiento, hipertensión arterial, cataratas y osteoporosis.

Corticoides inhalatorios: Su uso es un factor de riesgo para la adquisición de aspergillus y de resistencia antibiótica en bacterias habituales. No hay beneficio con el uso prolongado en niños asintomáticos ${ }^{91}$. En teoría podría ser beneficioso para la inflamación bronquial; sin embargo esto no está demostrado. Está indicado en pacientes con hiperreactividad bronquial moderada y severa.

\section{- Antiinflamatorios}

Azitromicina: Es un antibiótico del grupo de los macrólidos con efecto antiinflamatorio demostrado. Reduce el daño pulmonar progresivo en pacientes que tengan o hayan tenido infección por $P$. aeruginos $a^{92}$. También se ha visto efecto en preescolares sin infección por $P$. aeruginosa. El inicio de acción es lento (1-2 meses) y debe usarse por lo menos durante 6 meses. Usar una vez al día, tres veces por semana, en las siguientes dosis según el peso corporal ${ }^{33}$.

$$
\begin{array}{ll}
<25 \mathrm{~kg}: & 10 \mathrm{mg} / \mathrm{kg} / \text { día} . \\
25-40 \mathrm{~kg}: & 250 \mathrm{mg} / \text { día. } \\
40 \mathrm{~kg}: \quad 500 \mathrm{mg} / \text { día} .
\end{array}
$$

Ibuprofeno: Dosis altas de ibuprofeno han demostrado ser útiles, sin embargo el nivel terapéutico está muy cercano al nivel tóxico, por lo que se debe monitorizar con niveles plasmáticos ${ }^{94}$.

\section{- Oxigenoterapia ambulatoria}

Indicaciones según protocolo del Programa Nacional de Oxígeno Ambulatorio. Ver norma técnica disponible en http://www.oxigenoambulatorio.cl

\subsection{Secuencia de administración de terapia inhalatoria}

En los pacientes que usan más de un fármaco por vía inhalatoria la administración debe ser cada $12 \mathrm{~h}$ y en el siguiente orden:

- $1^{\circ}$ Agonista Beta 2 adrenérgico de acción corta.

- $2^{\circ} \mathrm{DNasa}$ o solución hipertónica,7\%.

- $3^{\circ}$ Kinesioterapia respiratoria.

- $4^{\mathrm{o}}$ Antibiótico nebulizado o polvo.

\section{Uso del nebulizador y compresor ${ }^{95}$}

La aerosol terapia es la administración de medicamentos por vía inhalatoria hacia la vía aérea a través de pequeñas partículas sólida o líquidas en suspensión en un gas (aerosol), produciendo un rápido efecto. La ventaja de administrar medicamentos en aerosol, es la baja dosis necesaria para producir un efecto con una rápida respuesta y escaso efecto secundario.

Nebulizador: Es de uso personal y se debe cambiar cada 6 meses. La duración de la nebulización no debe ser superior a $15 \mathrm{~min}$. Si la nebulización se prolonga llevar al centro de control para su revisión.

$>$ El nebulizador se debe acoplar (ajustar) bien a la cara del niño o boca, para evitar fuga.

> Se debe utilizar un nebulizador por cada fármaco, uno para tobramicina y otro para la Dnasa, debido a que la mezcla entre estos fármacos produce una inactivación de ellos.

$>$ Lavar el nebulizador a diario con agua y jabón neutro, enjuagar bien con agua hervida o esterilizada y dejar secar sobre toalla de papel absorbente. Realizar una desinfección cada 3 días, de bajo nivel (Ver manual del equipo).

- Limpiar la pieza del nebulizador con alcohol. Se puede utilizar nebulizador de malla (e flow).

Se deben consultar las indicaciones de su utilización en el prospecto del nebulizador.

\section{Manejo del compresor}

- Revisar color del filtro, el que debe estar de color blanco, de lo contrario se debe cambiar. La duración es en general de 6 meses, aunque se debe cambiar antes si se moja o se obstruye.

$>$ El tiempo de duración del compresor dependerá del cuidado, uso y manejo que se le de al equipo. Se estima una duración promedio de 3 años. Usar la batería solo en caso de no disponer de red eléctrica, lo que aumenta la vida útil del equipo.

$\mathrm{Si}$ se presenta un desperfecto en el equipo 
deberá acudir al centro hospitalario que hizo entrega del compresor para su revisión.

\subsection{Prevención de infección y control de microorganismos $^{96}$}

El personal de salud debe asumir que TODOS los pacientes con FQ pueden tener microorganismos patógenos en su vía respiratoria potencialmente transmisibles a otros pacientes con FQ.

\section{Precauciones estándar para TODOS los pacientes $^{97}$}

- Precauciones de transmisión por contacto para TODOS los pacientes independiente de su historial microbiológico ya sea en la atención ambulatoria u hospitalizada.

- En pacientes ambulatorios: Realizar aseo terminal una vez finalizada la atención. Las secreciones quedan en las superficies, en los equipos, y fonendoscopios.

- Precauciones de transmisión por gotitas: usar mascarilla quirúrgica para atender pacientes con sospecha o confirmación de microorganismos transmisibles por gotitas (Adenovirus, Rhinovirus, Influenza, M. pneumoniae).

- Uso de mascarilla quirúrgica para los pacientes que circulan dentro de las instalaciones hospitalarias excepto durante la ejecución de prueba de función pulmonar, del examen clínico y/o la habitación hospitalaria.

- Pacientes con sospecha o confirmación de infección por M. tuberculosis (bacilo de Koch) deben circular con de mascarilla N95.

- Todos los pacientes con FQ independiente de sus cultivos, debe estar separados por al menos 2 metros de los otros pacientes con FQ en todos los ambientes, excepto aquellos que residen en la misma casa.

- Pacientes con infección crónica por P. aeruginosa, $S$. aureus meticilino resistente o multirresistente y B. cepacia deben estar separados no permitiéndose su interacción dentro o fuera del hospital y debe indicarse que no se mezclen socialmente fuera del hospital, para evitar la infección cruzada.

- Evitar actividades con tierra, desechos orgánicos, lugares húmedos, construcción de viviendas.

- Evitar actividad en sauna. Se puede utilizar piscina con adecuada desinfección y no temperada.

\section{Precauciones para las familias}

- Educar en el lavado de manos, especialmente en maniobras de kinesioterapia y nebulizaciones.
- Uso de agua hervida o estéril para aseo nasal del paciente y para el enjuague final de los equipos y para los humidificadores.

Precauciones para el personal

- Lavado de manos, en los 5 momentos definidos para realizarlo.

- Usar delantal y guantes.

- Deben usar mascarilla solo a quienes ejecutan procedimientos (toma de muestras).

- Personal con lesiones de la piel no deben tener contacto con paciente infectados con estafilococo multirresistentes.

- Realizar aseo del box entre la atención de cada paciente.

\subsection{Complicaciones respiratorias ${ }^{98}$}

\section{- Insuficiencia respiratoria}

Tratamiento convencional.

\section{- Neumotórax}

Se manifiesta como dolor torácico unilateral, de inicio brusco. El diagnóstico es clínico y radiológico.

\section{Recomendaciones de manejo del neumotórax ${ }^{99,100}$}

Neumotórax pequeño: Acumulación aérea con distancia menor a $2 \mathrm{~cm}$ de la pleura visceral o menor del $20 \%$ del volumen del hemitórax con el paciente hemodinámicamente estable. Esta definición no está validada en niños dado que el tamaño del tórax está relacionado con la edad y la estatura, por lo tanto la condición clínica comanda el tratamiento.

Manejo ambulatorio con control médico a las $48 \mathrm{~h}$ y radiológico según evolución clínica.

Neumotórax con acumulación aérea mayor: Hospitalizar para tratamiento con tubo pleural. Solo si el neumotórax es recurrente, debe considerarse pleurodesis.

No suspender tratamiento inhalatorio, suspender uso de BiPAP y técnicas kinésicas.

Una vez dado de alta, el paciente no debe levantar elementos pesados $(>2 \mathrm{~kg})$, ni hacer espirometría, ni volar en avión o hacer ejercicio entre 4 a 6 semanas.

\section{- Hemoptisis $^{98,101}$}

Ocurre en el 9\% de los pacientes, en general adolescentes y adultos, con deterioro de la función pulmonar, aunque se puede presentar a cualquier edad. Se asocia en general a infección por estafilococo.

La aparición de desgarro con estrías de sangre al igual que volúmenes menores a $5 \mathrm{ml}$ refleja 
activación de la infección, debe hacerse cultivo e indicar antibióticos y continuar con kinesioterapia habitual para eliminar secreciones.

En hemoptisis moderada, menos de $250 \mathrm{ml}$ día: Contacto estricto con equipo FQ para observar su evolución (sobre $100 \mathrm{ml}$ posiblemente hospitalización), indicar cultivo y antibióticos. Se debe disminuir la kinesioterapia y evitar aquello que aumenten la presión intratorácica, suprimir la tos irritativa, continuar con DNasa. Suspender drogas potencialmente hemorragíparas o irritantes de vía aérea (aspirina, solución hipertónica y antibióticos nebulizados) $)^{32,101}$.

Hemoptisis severa mayor a $250 \mathrm{ml}$ día: Es una emergencia y puede amenazar la vida. Es la manifestación de rotura de un vaso sanguíneo y se produce en general en pacientes con enfermedad pulmonar severa.

Pedir hemograma, screening de coagulación y radiografía de tórax.

\section{Tratamiento}

- Hospitalización.

- Reposo en decúbito supino con cabecera levantada a $30^{\circ}$. Si el paciente es capaz de determinar el lado del sangramiento, (sensación de gorgoteo) colocar en decúbito lateral con el sitio sangrante hacia abajo.

- Antibióticos que incluya anti estafilocócico.

- Administración de vitamina $\mathrm{K}$ por vía intramuscular (IM): $0,5 \mathrm{mg} / \mathrm{kg}$ (dosis máxima 10 $\mathrm{mg}$ ) en espera de exámenes y ácido tranexámico $30-50 \mathrm{mg} / \mathrm{kg} / \mathrm{día}$, fraccionado cada $6-8 \mathrm{~h}$, por vía ev.

- No suspender terapia inhalada con DNasa.

- Suspender kinesioterapia respiratoria habitual, pero se pueden hacer maniobras suaves de modo de eliminar secreciones espesas y coágulos, $2 \mathrm{~h}$ después que el paciente haya dejado de sangrar.

- Suspender drogas potencialmente hemorragíparas o irritantes de vía aérea (aspirina, solución hipertónica y antibióticos nebulizados).

- Suministrar oxigeno según necesidad.

- Suspender la ventilación no invasiva y en caso de inestabilidad hemodinámica indicar tranfusión sanguínea.

- Si la hemorragia persiste, programar angiografía selectiva con embolización o eventualmente cirugía como última alternativa cuando haya recidiva del sangramiento. En estos casos puede ser necesario lobectomía del sitio de sangramiento en un centro capacitado de alta complejidad.

\subsection{Procedimientos}

\section{Broncoscopia flexible}

No hay evidencia que el lavado broncoalveolar (LBA) realizado en forma rutinaria sea superior a una muestra adecuada de expectoración, de esputo por aspiración traqueal o hisopado ${ }^{102}$.

\section{Indicaciones}

- En todo paciente (incluido lactantes) con síntomas persistentes, con exacerbaciones muy frecuentes o con respuesta subóptima a antibióticos convencionales y cultivos negativos.

- Por la sospecha de $P$. aeurginosa en pacientes en que no se ha aislado nunca y presentan deterioro clínico u otros microorganismos más difíciles de aislar.

- Ante la presencia de signología focalizada clínica y radiológica.

- Para la evaluación anatómica y funcional.

- En pacientes trasplantados para evaluar: Infecciones, revisión de los sitios de anastomosis por posibles complicaciones quirúrgicas (estenosis bronquial), realizar biopsia transbronquial, vigilancia de recuentos celulares y marcadores de rechazo ${ }^{103,104}$.

- En hemoptisis (no masiva) para intentar localizar sitio de sangramiento.

Al realizar un LBA se debe solicitar: Análisis de celularidad, estudio microbiológico con recuento cuantitativo de rutina, incluido micobacterias, hongos y estudio de marcadores de inflamación en caso de contar con ello. Según el cuadro clínico, solicitar: reacción en cadena polimerasa para otros gérmenes, galactomanano, lipófagos y hemosiderófagos ${ }^{105}$.

\section{Hospitalización}

Siempre en aislamiento respiratorio con medidas de control de infección intrahospitalarias.

\subsection{Indicaciones de hospitalización $\mathbf{n}^{32,106}$}

- Exacerbación respiratoria severa.

- Hallazgo de cultivos positivos a: estafilococo multirresistentes, primera infección, enterococo resistente, bacterias resistentes a carbapenémicos y Clostridium difficile.

- Mala respuesta a tratamiento ambulatorio.

- Complicaciones graves (neumotórax- hemoptisis).

- Trastorno hidroelectrolítico. 
- Complicaciones nutricionales (poco progreso en peso).

- Complicaciones digestivas (obstrucción intestinal, pancreatitis).

- Trastorno familiar y/o falta de red de apoyo.

- Cirugía electiva (catéter, gastrostomía, cirugía dental, sinusitis).

La historia clínica debe consignar:

- Motivo de hospitalización.

- Anamnesis y examen físico completo con peso (en $\mathrm{kg}$ y percentiles), talla (percentiles o $\mathrm{Z}$ score dependiendo de la edad), circunferencia craneana (en menor de 1 año), signos vitales y saturometría evaluada por oxímetro de pulso.

- Ultimo cultivo positivo de secreción bronquial y su sensibilidad (con la fecha).

- Pruebas de función pulmonar $\left(\mathrm{VEF}_{1}, \mathrm{CVF}\right.$, $\mathrm{FEF}_{25-75 \%}$ ) realizadas el último año, si aplica por la edad.

- Antecedentes de hospitalizaciones anteriores.

- Tratamientos actuales con dosis y frecuencia.

- Evaluar conocimiento del nebulizador y equipo.

- Técnicas kinésicas usadas.

- Alergia o reacciones adversas a medicamentos.

- Antecedentes psicosociales: Registrar ausentismo escolar, condiciones de la vivienda, presencia de mascotas, tabaquismo activo o pasivo, situación socio-económica, embarazo $\mathrm{y}$ adherencia al tratamiento.

\subsection{Procedimientos y examenes durante la hospitalización}

- Pesar dos veces por semana y medir la circunferencia de cráneo en el menor de 1 año.

- Al ingreso: Hemograma, proteína $\mathrm{C}$ reactiva, electrolitos plasmáticos, perfil bioquímico y renal, perfil hepático con tiempo de protrombina y niveles de vitaminas liposolubles y otros según decisión del médico tratante. Los que luego se repetirán según el cuadro clínico, resultados y uso de medicamentos.

- Cultivo de esputo corriente o inducido con solución hipertónica o hisopado faríngeo al ingreso, salvo que tenga un cultivo anterior dentro de los 7 días previos.

- Aspirado nasofaríngeo para diagnóstico viral según sospecha clínica.

- Radiografía de tórax.

- Función pulmonar (espirometría) al ingreso, luego semanal si aplica por la edad.

- Oximetría continua nocturna al egreso en pacientes con $\mathrm{VEF}_{1}<50 \%$ o sospecha de desaturación nocturna.
- Monitorizar niveles plasmáticos de antibióticos.

- Evaluación auditiva (ver toxicidad por amikacina).

\subsection{Indicaciones de tratamiento durante la hospitalización}

Recordar que la farmacocinética de los antibióticos en FQ es diferente a pacientes que no padecen la enfermedad: en general se necesitan dosis mayores.

Acceso venoso: Catéteres de inserción periférica mediante inserción percutánea o catéter venoso central con reservorio en pacientes con difícil acceso o que requieren tratamiento parenteral frecuente (ver capítulo de enfermería).

Tratamiento antibiótico en paciente hospitalizado

En pacientes con cultivos previos (-), cultivos con flora comensal y/o falta de cultivos previos: Iniciar tratamiento antibiótico triasociado con cobertura para $S$. aureus y $P$. aeruginosa hasta el rescate del cultivo (5 a 7 días).

Si el resultado del cultivo es (+) ajustar el tratamiento según el microorganismo identificado y antibiograma, completando 10-14 días, excepcionalmente podrá ser más prolongado según respuesta clínica y el microorganismo aislado.

Si el resultado es (-), con buena evolución clínica completar 10 días de tratamiento triasociado.

Pacientes con cultivos $(+)$ a microorganismos habituales (Streptococo pneumoniae, Moraxella catharralis, Hemofilus influenzae) completar 10 días de tratamiento convencional de primera línea según antibiograma.

Pacientes con cultivos previos $(+)$ : iniciar tratamiento antibiótico según ultimo microorganismo documentado y considerando cubrir microorganismos que estén provocando una infección crónica. Luego ajustar el tratamiento según resultados de cultivo y antibiograma.

\section{Suministro de antibióticos}

Idealmente en el manejo de las drogas se debería contar con un químico farmacéutico clínico $(\mathrm{QF})^{107}$ cuyo rol es:

- Optimizar los tratamientos antimicrobianos según los parámetros de farmacocinética y farmacodinamia.

- Interpretar los niveles plasmáticos de antibióticos y antifúngicos.

- Generar planes de farmacovigilancia activa y reportar reacciones adversas.

- Orientar al equipo clínico en el uso de nuevos 
medicamentos.

- Evaluar interacciones farmacológicas de los pacientes que reciben múltiples drogas.

- Apoyar al equipo de enfermería con respecto a diluciones, administración y estabilidad de los medicamentos.

Para su correcto uso, el suministro de algunos antibióticos debe acompañarse con medición de niveles plasmáticos.

\section{Medición de niveles de aminoglucósidos ${ }^{108}$}

Nivel peak: Se relaciona con la eficacia y se mide entre 30 min a 1 hora después de finalizada la infusión. El valor debe ser 10 veces al de la concentración inhibitoria mínima (CIM). En caso de estar en un tratamiento empírico se sugiere un nivel peak de $40 \mu \mathrm{g} / \mathrm{ml}$.

Nivel Valle: se toma previo (hasta $30 \mathrm{~min}$ ) a la administración del aminoglucósido, su valor debe ser menor a $1 \mu \mathrm{g} / \mathrm{ml}$ para así evitar la aparición de nefrotoxicidad.

El peak se debe medir luego de la segunda dosis del antibiótico mientras que el valle puede ser previo la tercera dosis. Los pacientes con dosis altas de amikacina $(30 \mathrm{mg} / \mathrm{kg} / \mathrm{día})$, tratamiento mayor a 7 días y uso concomitante de fármacos nefrotóxicos, son los que más se benefician con la monitorización ${ }^{108}$.

Los aminoglucósidos pueden producir ototoxicidad, por lo que se debe realizar una evaluación auditiva (ver manifestaciones otorrinolaringológicas).

\section{Medición de niveles de Vancomicina ${ }^{109}$}

Fármaco que depende tanto del tiempo como de la concentración para ejercer su efecto bactericida. Se recomienda medir niveles peak y valle con el fin de aproximarse a un valor de área bajo la curva sobre la CIM, el cual, debe ser mayor a $400 \mu \mathrm{g} / \mathrm{ml}$. En caso de no contar con QF clínico, monitorizar niveles valle (pre dosis), el que debe estar en un rango de 10-20 $\mu \mathrm{g} / \mathrm{ml}$. El tiempo ideal de monitorización es previo a la $4^{\mathrm{a}}$ dosis, así también, en el caso de niveles fuera de rango terapéutico se recomienda volver a tomar niveles luego de 4 dosis posterior al ajuste.

En tratamientos prolongados se recomienda la medición de niveles plasmáticos de forma seriada semanal y si el tratamiento está asociado con aminoglucósidos, control semanal de la función renal con creatinina sérica y nitrógeno ureico.

Beta lactámicos: Utilizar infusiones prolongadas de $3 \mathrm{~h}$ para cefepime, ceftazidima y meropenem, con el fin de aumentar su eficacia, especialmente en pacientes con infección crónica por $P$. aeruginosa.

Colistínmetato sódico inhalado: No está disponible en Chile para nebulizar, se puede usar la solución intravenosa. Utilizar mínimo $4 \mathrm{ml} \mathrm{de}$ suero fisiológico por ampolla de colistínmetato y administrar inmediatamente, ya que el paso del tiempo favorece el paso de colistínmetato a colistín el que se asocia con broncoespasmo. Durante el procedimiento de nebulización y debido al espesor que tiene el medicamento, se pueden adicionar al nebulizador $4 \mathrm{ml}$ de suero fisiológico a fin de lograr una mezcla que permita alcanzar el tamaño ideal de la partícula, para mejorar la penetración al parénquima pulmonar y el funcionamiento del nebulizador mismo evitando que este se obstruya.

\subsection{Otras indicaciones durante la hospitalización}

- Kinesioterapia respiratoria al menos 3 veces día.

- DNasa díaria.

- Solución hipertónica $\mathrm{NaCl}$ al 7 \% 2 veces al día.

- Según estado clínico: Alimentación oral, por sonda naso gástrica o por gastrostomía.

- Mantener o ajusrar tratamiento enzimático y vitaminas.

- Evaluación psicológica del paciente y su familia.

- Realizar intervenciones durante y después de la hospitalización (ver cuidado paliativo).

- Idealmente y en forma semanal se debe discutir la situación de los pacientes hospitalizados, en una reunión interdisciplinaria con todos los miembros del equipo de salud a cargo.

\section{Kinesioterapia}

En FQ la participación de los kinesiólogos/as es de gran importancia, siendo esta una enfermedad con predominio de compromiso pulmonar, el buen manejo integral determinara el aumento de sobrevida.

Los kinesiólogos son los principales responsables de la labor educativa y de aplicar las técnicas kinésicas respiratorias y los regímenes de ejercicio en los pacientes con $\mathrm{FQ}^{110,111}$.

El tratamiento kinésico es realizado en diversos escenarios clínicos como el hospitalario, atención primaria y terciaria, consulta privada ambulatoria y atención domiciliaria. 
Los padres y/o cuidadores tienen un rol importante que cumplir en el aprendizaje de las técnicas kinésicas respiratorias descritas más adelante, que ejecutarán ( 2 a 3 veces al día) previa capacitación y supervisión del profesional kinesiólogo/a, especialmente si se deben realizar a nivel domiciliario.

El enfoque del tratamiento debe ser flexible y cada paciente debe tener un régimen de tratamiento individual que tiene que ser aceptado por ambas partes, principalmente en relación al tiempo dedicado y la elección de la terapia más efectiva. Muchos de los factores que afectan la adherencia están asociados a sentimientos negativos a la terapia (ej. no sienten beneficio, están aburridos, se sienten muy cansados posterior a la sesión de tratamiento) ${ }^{112}$.

Las técnicas de drenaje de secreciones retenidas en la vía aérea y el ejercicio físico son la piedra angular de la terapia respiratoria del paciente con $\mathrm{FQ}^{110,111}$. El objetivo de la eliminación de secreciones es reducir el daño de la vía aérea a largo plazo disminuyendo la obstrucción, resistencia y corrigiendo zonas con atelectasia lo que facilitará la ventilación y el intercambio gaseoso. Con ello se pretende disminuir el riesgo de infección e inflamación, aspectos inherentes de la enfermedad y contribuir a controlar la caída progresiva de la función pulmonar ${ }^{111,113}$.

\section{Modalidades de técnicas de permeabilización de la vía aérea disponibles}

- Uso de la gravedad con el objetivo de transportar secreciones.

- Aplicación de técnicas manuales sobre la pared torácica.

- Dispositivos mecánicos diseñados para inducir presión positiva y oscilación en la vía aérea.

- Utilización de técnicas respiratorias combinadas (manuales y mecánicas).

- Estimulación de la actividad física.

\section{Kinesioterapia respiratoria (KNT)}

Hay poca evidencia actual que apoye el uso de una técnica de KTR sobre otra ${ }^{114}$. Los procedimientos que se señalan a continuación esta indicados principalmente para lactantes, antes de la alimentación.

- Drenaje postural modificado (DPM): Necesita la participación de un kinesiólogo o alguna persona responsable de la familia entrenada para su realización, siendo utilizado principalmente en pacientes no cooperadores. Incluye el uso de la gravedad en posiciones de drenaje postural en conjunto con percusión y vibración $^{115}$. El DPM excluye las posiciones con cabeza bajo la línea medía (Trendelenburg), evitando así muchos de los efectos secundarios desfavorables (vómitos, reflujo gastro-esofágico $)^{111}$. Es un tratamiento que dura máximo 15 min con 3 o 4 posiciones de pocos minutos cada vez.

- Percusiones: Consisten en aplicar un golpeteo rítmico, de 4-5 Hertz, sobre el tórax del paciente con una mano ahuecada, mientras se le pide que respire profundamente ${ }^{115}$. También está técnica se conoce con el nombre en inglés clapping.

- Vibraciones: Son oscilaciones finas de las manos colocadas sobre la pared torácica intentando obtener una coordinación con la exhalación ${ }^{115}$.

Estas técnicas son ejecutables en cualquier lugar y no dependen de dispositivos mecánicos.

\section{Desde lactante menor hasta los 8 años}

- Tos provocada: Se realiza en pacientes no colaboradores y consiste en la estimulación de los receptores mecánicos del reflejo de la tos ubicados en la tráquea extratorácica a nivel de la escotadura esternal para así lograr aumentar el volumen de aire espirado cuando la tos es ineficiente o no se desencadena de forma espontánea ${ }^{116}$.

- Espiración lenta prolongada (ELPr): Técnica pasiva de ayuda espiratoria aplicada al paciente no-colaborador (por medio de una presión manual tóraco-abdominal lenta, que se inicia al final de una espiración espontánea y continúa hacia volumen residual. Su objetivo es obtener un volumen espiratorio mayor que el de una espiración habitual, promover el flujo bifásico y el reflejo de Hering-Breuer y con ello contribuir al desplazamiento de las secreciones ubicadas más periféricamente en el árbol respiratorio hacia la vía aérea central $^{116}$.

\section{Pacientes mayores de 6 años}

- Tos asistida: Se realiza en pacientes colaboradores y consiste en disponer las manos en el tórax del paciente, pedir una inspiración profunda seguida de una espiración forzada para luego solicitar toser de forma voluntaria. De forma paralela se ejerce una presión abdominal y/o vibro-presión torácica que acompañe la aceleración del flujo espiratorio generada durante la tos ${ }^{116}$.

- Técnica de espiración forzada (TEF): Consiste en realizar espiraciones forzadas con la glotis abierta desde volúmenes pulmonares di- 
ferentes: bajos, medios y altos intercalados con respiraciones tranquilas a volumen corriente. El objetivo a lograr es desplazar secreciones bronquiales para que puedan ser deglutidas o expectoradas. No es aconsejable su uso en pacientes con hiperreactividad bronquial ya que puede resultar en un aumento de la obstrucción bronquial $^{115}$.

- Ciclo activo de la respiración: Es una técnica que utiliza una secuencia de maniobras respiratorias para movilizar secreciones desde vía aérea distal hacia proximal. Estas incluyen el control de la respiración, ejercicios de expansión torácica y TEF ${ }^{116}$.

\section{Pacientes desde los 8 años}

- Drenaje autógeno (DA): Es una técnica que consta de 3 etapas: despegamiento, acumulación y expulsión de secreciones. El objetivo es movilizar las secreciones desde las vías aéreas distales hasta proximales mediante inspiraciones y espiraciones lentas, previniendo el colapso prematuro de la vía aérea para luego facilitar su expectoración mediante el aumento del flujo espiratorio, así evitando la generaciónn excesiva de tos ${ }^{111,116}$

- Espiración lenta total con glotis abierta en lateral (ELTGOL): Técnica activa-asistida. El paciente se ubica en decúbito lateral con el pulmón a tratar en el plano de apoyo. En esta posición, el kinesiólogo presiona con una mano la pared abdominal cercana al reborde costal inferior del pulmón apoyado, facilitando el ascenso diafragmático y con la otra mano, apoyada sobre la pared torácica supra lateral, se realiza una presión dirigida contra el hombro contra lateral, favoreciendo una desinsuflación más completa del pulmón apoyado. La espiración debe ser con la boca abierta, lenta y prolongada. Esta técnica tiene como objetivo desprender y movilizar secreciones bronquiales desde la zona media y distal del árbol respiratorio para desplazarlas hacia las vías aéreas proximales ${ }^{116,117}$ (Figura 2).

\section{Dispositivos mecánicos}

Son de ayuda en la kinesioterapia que se pueden usar desde los 4 a 5 años de edad.

Dispositivos de presión positiva (PEP): Estos dispositivos son de ayuda para el paciente, pero no reemplazan a la kinesioterapia respiratoria.

Generan presión de forma continua o discontinua de forma oscilante $\left(5-20 \mathrm{~cm} \mathrm{H}_{2} 0\right)$. El objetivo es evitar el colapso precoz de la vía aérea y mejorar la ventilación colateral desarrollando un gradiente de presión distal a la obstrucción, buscando desplazar las secreciones hacia las vías aéreas más centrales desde donde pueden ser eliminadas ${ }^{111,115,116}$. Algunos dispositivos, pueden ser utilizados en conjunto con los sistemas de nebulización. Todos ellos poseen una válvula unidireccional conectada a una pieza ajustable con varios orificios de distinto tamaño donde se genera una resistencia o freno a la espiración ${ }^{115,116}$.

Dispositivos de presión positiva: $\mathrm{PEP}$ másk $^{\circledR}$; Thera PEPR ${ }^{\circledR}$; PiPEP $^{\circledR}$; PariPEP ${ }^{\circledR}$; AeroPEP $^{\circledR}$.

Dispositivos presión discontinua: Aerobika ${ }^{\circledR}$; Acapella $^{\circledR}$ y Flutter ${ }^{\circledR}$.

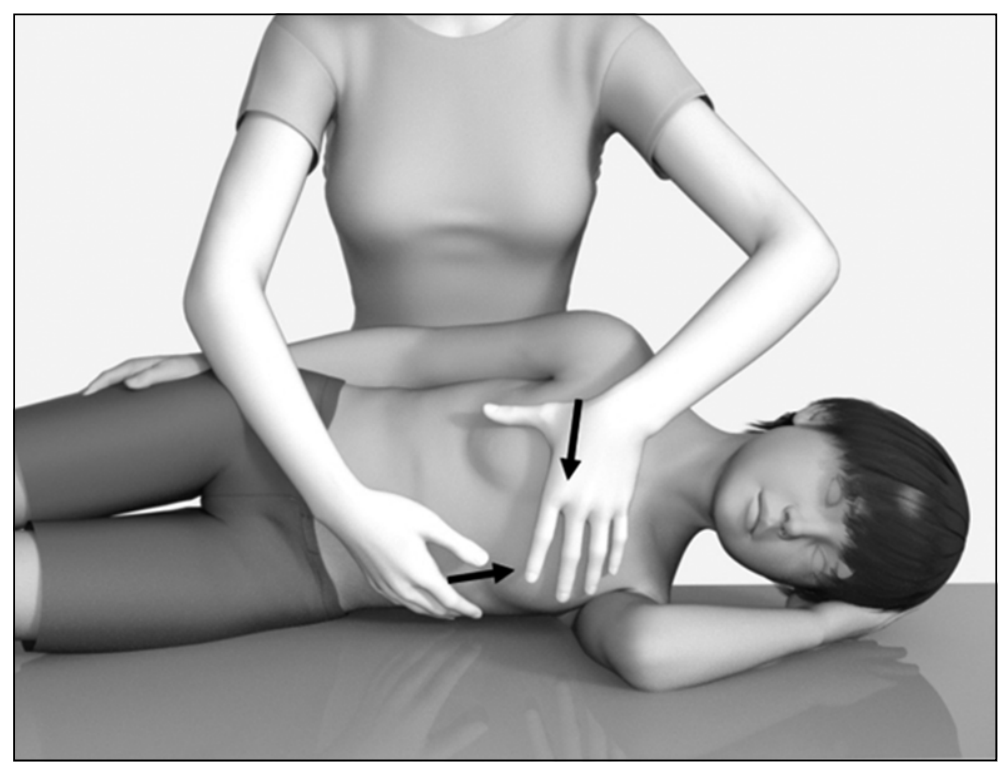

Figura 2. Espiración lenta total con glotis abierta en decúbito lateral (ELTGOL) (imagen original preparada por los autores). 
Dispositivos electromecánicos desde preescolar

Chaleco inflable: Son aparatos que producen una compresión oscilatoria de alta frecuencia de la pared torácica. Es un chaleco que se ajusta firmemente sobre el tórax proporcionando compresiones oscilatorias externas a la pared torácica con una frecuencia entre $5-25 \mathrm{~Hz}$. Se recomiendan 1 a 2 sesiones diarias de 20 a 30 min cada una. Existen diversos modelos en el mercado adaptados según la edad ${ }^{115,116}$.

Nota: No reemplaza la kinesioterapia respiratoria y puede ser de ayuda para pacientes mayores.

\section{Ejercicio físico para la eliminación de secreciones}

El ejercicio disminuye la impedancia mecánica del esputo, lo que indica un posible papel del ejercicio en el mantenimiento de la higiene bronquial, un aspecto crucial del cuidado de la FQ, pudiendo una sesión de ejercicios alternados con técnicas kinésicas respiratorias ser un sustituto aceptable para una sesión de kinesioterapia respiratoria (KTR) aislada, en niños con fibrosis quística leve $\mathrm{e}^{111,118}$.

\section{Recomendaciones generales ${ }^{110,111,116,117}$}

Los kinesiólogos deben tener el conocimiento y la habilidad para enseñar, adaptar, entrenar y cambiar los tratamientos según las necesidades individuales del paciente.

- El número de KTR diaria varía entre cada paciente, sin embargo se recomienda que esta debe ser realizada al menos dos veces al día durante toda la vida, y deben aumentar su frecuencia en caso de exacerbación aguda.

- A partir de la edad preescolar se puede instruir en la técnica de espiración forzada (TEF) asociada a maniobras de presión tóraco-abdominal espiratoria eventualmente con tos provocada.

- Es esencial que los kinesiólogos manejen de manera experta las distintas formas de provocar/asistir la tos.

- Las terapias basadas en la presión espiratoria positiva (PEP), la oscilación PEP y el drenaje autógeno son técnicas efectivas que pueden usarse en forma independiente.

- El drenaje postural con la cabeza bajo la línea medía no debe utilizarse en forma rutinaria en niños con $\mathrm{FQ}$ o en persona que no se sepa si tienen diagnóstico médico de reflujo gastroesofágico. Se recomienda DPM en niños menores que no participan activamente de su terapia respiratoria.

- Cada paciente debe ser evaluado de forma individual por el kinesiólogo(a) para establecer el régimen de técnicas kinésicas más adecuado, que se modificará de forma regular en relación al estado clínico, respuesta al tratamiento, edad y preferencias del sujeto.

- En el contexto domiciliario y previa capacitación, los padres y/o cuidadores, aplicarán técnicas kinésicas respiratorias tales como, drenaje postural modificado, vibraciones y percusiones torácicas. En niños mayores y adultos, además, podrá apoyar las técnicas de espiración forzada, drenaje autógeno y ciclo activo de la respiración que autoejecutan los pacientes. Los padres y/o cuidadores deberán recibir capacitación para el uso de los distintos dispositivos mecánicos y electromecánicos. El profesional kinesiólogo(a) tiene la responsabilidad de supervisar el correcto uso de estos dispositivos como de la correcta ejecución de la distintas técnicas kinésicas respiratorias.

\subsection{Rehabilitación respiratoria}

La rehabilitación respiratoria (RR), en ausencia de exacerbación, es un componente esencial en el manejo de las enfermedades respiratorias crónicas en la infancia. La RR ha demostrado mejorar los síntomas, el rendimiento físico, la calidad de vida y su participación social en aquellos niños que tienen limitaciones en el desarrollo de sus actividades de la vida diaria ${ }^{119}$.

\section{Evaluación y entrenamiento de la musculatura respiratoria}

En niños con FQ se debe evaluar tanto la fuerza muscular inspiratoria como la resistencia de estos músculos al menos cada 6 meses $^{119}$ es aconsejable de forma más frecuente si las mediciones están bajos los valores de referencia recomendados de Szeinberg Szeinberg 1987 $7^{120}$. El sistema de entrenamiento muscular inspiratorio (EMI) más validado actualmente, es el entrenamiento con válvula umbral ${ }^{119}$.

Desde la década de los años 80 la literatura reporta que el entrenamiento muscular inspiratorio (EMI) en personas con FQ puede ser beneficioso y que el EMI que combine cargas bajas (al menos $30 \%$ de la presión inspiratoria máxima) con cargas altas (hasta $80 \%$ de la Pimax) puede tener efecto sobre la fuerza y resistencia de la musculatura respiratoria.

\section{Recomendaciones generales ${ }^{119}$}

El EMI debe realizarse en ausencia de exacerbación, 1 vez al día, 5 veces a la semana, a una 
intensidad de al menos el 30\% de la Pimax y que agregue, en cada sesión, 3 series de repeticiones, de 10 esfuerzo cada una, a carga alta $(70 \%)$.

El período de entrenamiento será de al menos 10 semanas. Se sugiere iniciar con 3 series de $3 \mathrm{~min}$, con dos minutos de descanso entre cada serie.

Cuando el paciente logre tolerar adecuadamente el esquema anterior, aumentar el tiempo de sobrecarga y el número de series hasta finalmente lograr las 4 series de 5 min de entrenamiento por cada sesión, manteniendo el descanso de 2 min entre cada serie. Controlar Pimax a la segunda semana y luego mensualmente.

Para un correcto EMI, el paciente debe ser instruido por personal especializado $\mathrm{y}$, si es posible, aprendiendo a controlar el patrón respiratorio, de tal modo que la frecuencia respiratoria que el paciente utilice en cada sesión sea similar a la utilizada en condiciones de reposo.

Es importante consignar que el entrenamiento es parcialmente supervisado ya que gran parte de las sesiones se realizarán en el domicilio del paciente.

\section{Entrenamiento físico general}

La actividad física es esencial para el normal crecimiento y desarrollo del niño, además de disminuir el riesgo de desarrollar enfermedades crónicas en la edad adulta. Una alta capacidad aeróbica en sujetos con fibrosis quística está asociada de forma positiva a mejor pronóstico, menor riesgo de hospitalización y mejor calidad de vida ${ }^{111,118}$. El uso de programas de entrenamiento ha mostrado que mejora el estado físico y la movilidad torácica, mantienen la densidad mineral ósea, mejora la sarcopenia y altos niveles de actividad física se asocian a menor caída del $\mathrm{VEF}_{1}{ }^{113}$. Un programa de entrenamiento debe estar asociado a un test de ejercicio para evaluar la capacidad de realizar ejercicio, la capacidad funcional, la respuesta al tratamiento y la progresión de la enfermedad, siendo estos la base para la prescripción del ejercicio. Entre los más utilizados están el test de marcha de 6 min (Anexo 8), shuttle walking test modificado y el test escalón de tres minutos ${ }^{118,119}$.

\section{Recomendaciones generales ${ }^{111,118,119,121}$}

- Los test de ejercicio son recomendados para evaluar la respuesta a la terapia en pacientes hospitalizados y ambulatorios y son una herramienta para prescripción de ejercicio en programas de entrenamiento.

- El test de 6 min debe ser realizado como una parte de la evaluación inicial del paciente previo al inicio del entrenamiento. Existen valores de referencia para niños chilenos ${ }^{121}$. El ejercicio se recomienda para los pacientes con FQ a lo largo de su vida.

- El ejercicio físico está indicado para reducir la impedancia mecánica del esputo mejorar la función pulmonar a corto plazo y facilitar la eliminación de secreciones.

- El entrenamiento debería ser por al menos 3 días a la semana (en lo posible 5 o más), con una duración de 30 min por sesión.

- Una combinación de ejercicio aeróbico y de resistencia sería ideal para conseguir un máximo beneficio.

- El ejercicio realizado antes de las técnicas de eliminación de secreciones habituales puede mejorar su eficacia.

- La prescripción de ejercicio debe ser adaptada a cada individuo y debe cumplir con las guías de ejercicio recomendadas. Al momento de estar la persona cursando una exacerbación se deberá evaluar la pertinencia de realizar algún tipo de entrenamiento físico teniendo en cuenta la necesidad de prevenir las infecciones cruzadas.

- El uso de oxígeno suplementario debe ser considerado en aquellos pacientes que puedan desaturar con el ejercicio.

\subsection{Complicaciones músculo esqueléticas en FQ}

Las complicaciones pueden surgir en distintas etapas de la enfermedad debido a anormalidades multifactoriales como las alteraciones de la mecánica respiratoria, desbalance muscular y alteraciones de la mineralización ósea ${ }^{111,118}$.

El dolor músculo esquelético está asociado con disminución de la calidad de vida, incremento de los síntomas respiratorios, alteraciones del sueño, ansiedad, depresión, y disminución de la capacidad de realizar ejercicios respiratorios y actividad física. Programas de entrenamiento vigoroso de extremidades junto al uso de la terapia manual y técnicas músculo esquelético por 3,6 y 12 semanas, son útiles para el manejo del dolor y la disminución de la movilidad torácica en pacientes adultos ${ }^{11,118,119}$

Recomendaciones generales ${ }^{111,118,119}$

La evaluación músculo esquelética debe realizarse en forma anual desde edades tempranas (prepúberes), evaluado la aparición de dolor y restricción de movimiento o riesgo de alteración de mineralización ósea.

- La actividad física regular de moderada y alta intensidad, incluyendo el ejercicio con cargas, 
debe ser realizado durante el transcurso de la vida, en orden de optimizar la densidad ósea y disminuir la declinación de la función pulmonar medida por $\mathrm{VEF}_{1}$.

- Programas de entrenamiento y elongaciones deben prescribirse en función de optimizar la masa muscular.

- Para los diabéticos se recomienda realizar ejercicio físico aeróbico moderado por al menos 150 min por semana, monitorizando los niveles de glucosa con tira reactiva, pre y post ejercicio aumentar el consumo de carbohidratos o modificar la dosis de insulina ${ }^{111,118}$.

\subsection{Adherencia al tratamiento ${ }^{112,118}$}

La pobre adherencia al tratamiento es reportada por hasta el $50 \%$ de las personas que padecen condiciones crónicas, que incluye FQ. Diversos estudios han indicado que existe variabilidad con respecto a cada tipo de tratamiento, donde la KTR diaria y el ejercicio físico han mostrado bajos niveles de adherencia $(29,5 \%$ y $24,2 \%)$, refiriendo además que las principales razones para no realizar la terapia son la falta de tiempo y el aburrimiento.

\section{Aspectos nutricionales}

Los pacientes con FQ presentan una alta prevalencia de desnutrición calórico-proteica aguda y crónica, así como déficit de micronutrientes. Las principales causas son la baja ingesta alimentaria, el alto requerimiento calórico (basal y secundario a exacerbaciones), al igual que las pérdidas de nutrientes en las deposiciones debidas a la mala absorción. Además, debe considerarse el potencial genético de crecimiento y el ritmo de progresión en forma individualizada.

\section{Hay una clara asociación entre el estado} nutricional y la sobrevida.

La monitorización nutricional debe ser regular, con énfasis en los siguientes períodos críticos ${ }^{122}$.

- Los primeros 12 meses después de hecho el diagnóstico de FQ.

- El primer año de vida en los lactantes diagnosticados precozmente, hasta que alcancen un ritmo de crecimiento normal en peso, talla y circunferencia craneana.

- Período peri-pubertad: 9 a 16 años en niñas y 12 a 18 años en niños.

- Durante exacerbaciones y/o sobre infecciones.
Actualmente ha aumentado la prevalencia de exceso de peso en pacientes con FQ; la obesidad favorece complicaciones que incrementan la morbimortalidad futura. El ejercicio físico mejora la sarcopenia, optimizando el estado nutricional y la función respiratoria.

El ejercicio físico mejora la sarcopenia, optimizando el estado nutricional y la función respiratoria.

\subsection{Evaluación nutricional}

\section{Frecuencia de evaluaciones nutricionales (Tabla 13)}

Al diagnóstico la evaluación será realizada por médico o nutricionista. En los períodos críticos antes mencionados, de mayor riesgo o de crecimiento insatisfactorio, los controles deben ser mensuales por médico especialista y nutricionista.

\section{Anamnesis nutricional}

a) Aspectos generales:

- Historia alimentaria.

- Hábitos y horarios de alimentación, apetito y sus fluctuaciones, grado de rechazo, intolerancia y preferencias de alimentos.

- Actividad física.

- Patologías respiratorias, digestivas u otras.

- Factores psicosociales (actitud, entorno, cuidadores).

b) Aspectos específicos:

- Encuesta de alimentación para estimar la ingesta diaria: Composición, preparación y aceptación de las fórmulas lácteas y comidas.

- Enzimas pancreáticas: Formulación, horarios y método, dosis con cada alimentación. Calcular unidades de lipasa $/ \mathrm{kg} /$ día.

- Vitaminas hidro/liposolubles, minerales: formulación y dosis.

- Sal ( $\mathrm{NaCl})$ : Suplementación, ingesta en comidas.

- Otros medicamentos y su adherencia: antibióticos, corticoesteroides, bloqueadores $\mathrm{H} 2$ del ácido gástrico, probióticos.

- Suplementos nutricionales, medicinas alternativas u otros complementos.

\subsection{Antropometría}

Pesar y medir correctamente al paciente, construir curvas de crecimiento y actualizarlas en forma periódica, usando como referencia los patrones OMS (Organización Mundial de la 
Tabla 13. Frecuencia de controles nutricionales en niños y adolescentes con fibrosis quística

\begin{tabular}{|lccc|}
\hline Mediciones & Al diagnóstico & Trimestral & Semestral \\
Peso corporal & $\mathrm{X}$ & $\mathrm{X}$ & \\
Longitud/Estatura & $\mathrm{X}$ & $\mathrm{X}$ & \\
Perímetro Craneano (hasta los 2 años) & $\mathrm{X}$ & $\mathrm{X}$ & \\
Perímetro braquial & $\mathrm{X}$ & $\mathrm{X}$ & \\
Pliegues cutáneos & $\mathrm{X}$ & $\mathrm{X}$ & \\
Maduración puberal & & & $\mathrm{X}$ \\
Evaluación de ingesta (24 h) & $\mathrm{X}$ & $\mathrm{X}$ & \\
Orientación anticipatoria, dietaria y de hábitos alimentarios & $\mathrm{X}$ & $\mathrm{X}$ & \\
\hline
\end{tabular}

Tabla 14. Índices antropométricos para población pediátrica general

\begin{tabular}{|c|c|c|}
\hline Índice & Aplicación: Interpretación & $\begin{array}{l}\text { Rango normal } \\
\text { (Referencia) }\end{array}$ \\
\hline Peso/Edad (P/E) & En menores de 1 año: marcador más sensible de déficit nutricional & $\begin{array}{c}-0,9 \mathrm{a}+0,9 \mathrm{DE} \\
(\mathrm{OMS} 2006)\end{array}$ \\
\hline Talla/Edad (T/E) & $\begin{array}{l}\text { En todos: Detectar precozmente cambios en la velocidad de creci- } \\
\text { miento considerar la estatura parental }\end{array}$ & $\begin{array}{c}-1,9 \mathrm{a}+1,9 \mathrm{DE} \\
(\mathrm{OMS} 2006 \text { y OMS 2007) }\end{array}$ \\
\hline Peso/Talla $(\mathrm{P} / \mathrm{T})$ & En los menores de 5 años: Indica adecuación del peso para la talla & $\begin{array}{c}-0,9 \mathrm{a}+0,9 \mathrm{DE} \\
(\mathrm{OMS} 2006)\end{array}$ \\
\hline IMC & En los mayores de 5 años: Indica adecuación del peso para talla & $\begin{array}{l}-0,9 \mathrm{a}+0,9 \mathrm{DE} \\
(\mathrm{OMS} 2007)\end{array}$ \\
\hline $\begin{array}{l}\text { Mediciones } \\
\text { complementarias }\end{array}$ & $\begin{array}{l}\text { Permiten estimar la composición corporal, para detectar déficit } \\
\text { de masa magra (perímetro braquial) y de masa grasa (pliegues } \\
\text { cutáneos) }\end{array}$ & $\begin{array}{l}\text { VN: Pc 10-90 } \\
\text { (Frisancho) }\end{array}$ \\
\hline
\end{tabular}

OMS: Organización mundial de la salud. IMC/Edad: índice de masa corporal según la edad. DE: desviación estándar.

Salud) 2006 y 2007 según normativa ministerial. Calcular los índices y evaluarlos en forma integrada (Tabla 14).

\subsection{Diagnóstico nutricional}

Las definiciones de riesgo nutricional y de falla nutricional para FQ (Tabla 15) difieren de las utilizadas para la población general, con el fin de aumentar la sensibilidad para detectar el déficit, adelantarse y tomar conductas precozmente. En los menores de un año considerar también peso/ edad, que debe encontrarse entre la mediana y + 09 DE (desviación estándar).

\section{Examen físico general}

Valorar el aspecto global del niño, evaluar masas musculares, masa grasa, signos carenciales específicos (piel, mucosas, fanéreos) y desarrollo puberal con estadios de Tanner.

\subsection{Laboratorio}

Entre 85 y $90 \%$ de los pacientes presentan insuficiencia pancreática, que se corrobora con el test de elastasa en materia fecal y que no se altera por la suplementación enzimática. Debe realizarse de modo anual, en los pacientes con valores normales previos.

Niveles plasmáticos vitaminas $A, E$ y $D$ : 250HVitamina D plasmática al comienzo y después anualmente (al final del invierno), monitorizando según necesidad. La medición de vitaminas A y E está menos disponible, de modo que el nivel de $25 \mathrm{OHvitD}$ puede ser un indicador general del status de las vitaminas liposolubles.

\section{Otros Exámenes laboratorio}

Anualmente o de modo más frecuente, según necesidad: hemograma, proteínas totales, albúmina, calcio/fósforo, ferritina, pruebas de función hepática, protrombina, electrolitos plasmáticos, 
Tabla 15. Puntos de corte para definir el estado nutricional en niños y adolescentes con fibrosis quística

\begin{tabular}{|c|c|c|c|c|}
\hline Estado nutricional & T/E (todos) & $\begin{array}{l}\text { P/T } \\
(<5 \text { años })^{1}\end{array}$ & $\begin{array}{l}\text { IMC } \\
(5-19 \text { años })^{1}\end{array}$ & Conducta \\
\hline Obesidad & - & $\geq+2 \mathrm{DE}$ & & $\begin{array}{l}\text { Promover un peso } \\
\text { saludable }\end{array}$ \\
\hline Sobrepeso & - & $+1 \mathrm{a}+1,9 \mathrm{DE}$ & & \\
\hline Aceptable & $\begin{array}{c}-1,9 \mathrm{a}+1,9 \mathrm{DE} \\
\text { Ritmo normal de crecimiento } \\
\text { y concordante con la carga } \\
\text { genética }\end{array}$ & $\frac{\text { Meta en FQ: }}{\mathrm{M} \mathrm{a}+0,9 \mathrm{DE}}$ & & Monitorizar, prevenir \\
\hline $\begin{array}{l}\text { Riesgo nutricional } \\
\text { en } \mathrm{FQ}^{* 2}\end{array}$ & $\begin{array}{c}-1,9 \mathrm{a}+1,9 \mathrm{DE} \\
\text { Desaceleración o menor a la } \\
\text { carga genética }\end{array}$ & $\begin{array}{l}\text { M a }-0,9 \\
\text { Peso estaciona }\end{array}$ & o baja ponderal ${ }^{3}$ & $\begin{array}{l}\text { Estudiar y dar apoyo } \\
\text { nutricional precoz }\end{array}$ \\
\hline $\begin{array}{l}\text { Falla nutricional } \\
\text { en FQ* }\end{array}$ & $<-2 \mathrm{DE}$ (Talla baja) & $\leq-1 \mathrm{DE}$ & & Tratar activamente \\
\hline
\end{tabular}

${ }^{1}$ Curvas de crecimiento OMS 2006 en menores de 5 años y curvas OMS 2007 en 5 a 19 años. ${ }^{2}$ Incluye retraso puberal: Tanner I mamás en niñas de $\geq 13$ años, ausencia de menarquia en niñas $\geq 16$ años y Tanner I en hombres $\geq 14$ años. ${ }^{3}$ Baja ponderal durante 2 meses o peso estacionario por 3 meses (en $<5$ años) o por 6 meses (en $>5$ años). M: mediana.

sodio urinario. En condiciones especiales, considerar medición de prealbúmina, nitrógeno ureico, creatinina y evaluación de sodio en orina en muestra aislada o de fracción o de fracción excretada de sodio (FE Na).

Anualmente: Perfil lipídico, curva de tolerancia a la glucosa (TTGO) en mayores de 8 años o antes, si existe sospecha clínica, y hemoglobina glicosilada (HbAlc). Densitometría ósea DEXA (L1-L4) en niños mayores de 10 años o con factores de riesgo (cada 3 años).

Test de elastasa fecal anual en aquellos pacientes con valores normales previos.

\subsection{Reemplazo enzimático}

Si bien existe una dosis establecida para el inicio de su prescripción, existen aspectos individuales que deben ser considerados, como la progresión pondo-estatural, los síntomas abdominales, las características de las deposiciones y el tipo de alimentación.

Idealmente debiera dosificarse según el contenido de grasa de cada alimentación (1.000 a 2.000 UI lipasa/g de grasa), pero habitualmente se indica según edad y peso promedio.

Dosis de suplementación de enzimas pancreáticas en niños con $\mathbf{F} \mathbf{Q}^{123}$.

Lactantes: Comenzar con 2.000 UI de Lipasa por cada $120 \mathrm{ml}$ de fórmula láctea o alimentación al pecho. Dosis habituales son 2.000 a 5.000 UI con cada alimentación.
Frente al diagnóstico clínico en lactantes, se recomienda comenzar de inmediato la suplementación enzimática, aún antes de confirmada la insuficiencia pancreática ${ }^{124}$.

Niños de 1-4 años: 1.000 UI de Lipasa / kg de peso para cada comida y $500 \mathrm{UI} / \mathrm{kg}$ antes de cada colación.

Niños > 4 años: Comenzar con 500 UI de Lipasa / $\mathrm{kg}$ antes de cada comida y $250 \mathrm{UI} / \mathrm{kg}$ antes de cada colación.

En todos: Ajustar la dosis de enzimas según respuesta clínica.

No se debe sobrepasar la dosis de $2.500 \mathrm{UI} /$ $\mathrm{kg} /$ comida, ni las $10.000 \mathrm{UI} / \mathrm{kg} /$ día, por riesgo de desarrollar colonopatía fibrosante. En casos especiales en que se necesite superar esas dosis, debe controlarse frecuentemente y revisar falta de respuesta.

Ante la falta de respuesta clínica a las dosis máximas, se requiere revisar exhaustivamente otros factores como:

- Mala adherencia al tratamiento.

- Caducidad o almacenamiento inadecuado de preparado enzimático.

- Ingesta excesiva de jugos, bebidas gaseosas y/o de comidas ricas en grasas.

- Tiempo de alimentación prolongado.

- Presencia de reflujo gastroesofágico (RGE) con control insuficiente o sin tratamiento.

- Otra enfermedad gastrointestinal concomitan- 
te: enfermedad celíaca, enfermedad inflamatoria intestinal (EII).

\section{Administración de las enzimas pancreáticas}

Las enzimas pancreáticas deben ser administradas al comienzo de cada alimentación, cada vez que el paciente ingiera leche materna, alguna fórmula láctea, colación o comida. Si el tiempo de alimentación es prolongado, es necesario fraccionar la dosis de las enzimas $(50 \%$ al comienzo y $50 \%$ a la mitad de la comida), mientras se corrige el hábito o se plantean vías complementarias o alternativas de alimentación.

Las cápsulas que contienen las enzimas deben ser deglutidas intactas. En los lactantes, la cápsula se abre justo antes de alimentarse, y se administran los gránulos, sin molerlos, con un poco de líquido o papilla de manzanas directamente en la boca. No se debe administrar los gránulos de enzimas en el volumen total de comida o leche, sino que inmediatamente antes de la alimentación. Los gránulos no deben ser masticados y en lactantes debe asegurarse que sean deglutidos, ya que su activación precoz puede causar irritación y ulceración de la mucosa oral.

Alimentos que ingeridos en forma individual no requieren de suplementación enzimática son: frutas (excepto palta), jugo de frutas naturales, verduras (excepto papas y leguminosas), azúcar, caramelos, miel, jarabes dulces, gaseosas, jugos artificiales, sorbetes, algunos suplementos caló- ricos como maltodextrina aportados en agua o jugo.

\subsection{Recomendaciones nutricionales}

\section{Energía}

El manejo nutricional debe ser individualizado porque hay gran variabilidad en las necesidades nutricionales de los pacientes; en aquellos con formas leves de la enfermedad, con suficiencia pancreática y estado nutricional aceptable (Tabla 15) puede ser suficiente aportar $100 \%$ de la recomendación para población general (Tabla 16).

\section{Vitaminas}

Es frecuente la deficiencia de vitaminas liposolubles: A, D, E y K, en general de modo subclínico, y aún con suplementación adecuada, por lo que se recomienda al menos la medición anual de 25-OH-vitamina D. (Tabla 17).

Los requerimientos de vitaminas con propiedades antioxidantes (Vitamina E, $\beta$ caroteno) son mayores, por el stress oxidativo que acompaña a las infecciones respiratorias crónicas y están contenidas en los preparados habitualmente usados en FQ.

La vitamina $\mathrm{K}$ no sólo está involucrada en la síntesis de protrombina. Además, es un cofactor en la carboxilación de osteocalcina, necesaria para la osificación del hueso, por lo que su déficit,

Tabla 16. Recomendaciones de aporte de energía y nutrientes para pacientes con fibrosis quística

\begin{tabular}{|ll|}
\hline Energía y nutrientes & Recomendaciones \\
\hline Energía & $120-200 \%$ RDI* \\
\hline Proteínas & $100-150 \%$ RDI** \\
\hline Lípidos & $35-45 \%$ de las calorías totales de la alimentación \\
Ácidos grasos esenciales & $3-5 \%$ de las calorías totales de la alimentación \\
\hline Hidratos de carbono $(\mathrm{CHO})$ & $55-60 \%$ de las calorías totales de la alimentación*** \\
\hline
\end{tabular}

RDI: Recomendaciones internacionales. *Recomendación internacional ESPGHAN-ESPEN-ECFS 2016 ${ }^{122}$. **Ajustar, según requerimiento energético, para $\mathrm{P} \%>15 . * * *$ Adecuar a 40-50\% en pacientes con diabetes o intolerancia a la glucosa.

Tabla 17. Recomendaciones de vitaminas liposolubles en pacientes con fibrosis quística ${ }^{107,122}$

\begin{tabular}{|ccccc|}
\hline Edad & $\begin{array}{c}\text { Vitamina A (UI/día) } \\
\text { (Retinol y } \boldsymbol{\beta} \text {-caroteno) }\end{array}$ & $\begin{array}{c}\text { Vitamina E } \\
\text { (UI/día) }\end{array}$ & $\begin{array}{c}\text { Vitamina D } \\
\text { (UI/día) }\end{array}$ & $\begin{array}{c}\text { Vitamina K } \\
\text { (mg/día) }\end{array}$ \\
\hline $0-12 \mathrm{~m}$ & 1.500 & 50 & 400 (max. 1000) & $0,3-1$ \\
\hline $1-3$ años & 5.000 & $100-400$ & 800 & $1-10$ \\
$4-10$ años & $5.000-10.000$ & & $<10$ años max. 2.000 & \\
$>10$ años & 10.000 & & $>10$ años max. 4.000 \\
\hline
\end{tabular}

max: máximo. 
junto al de vitamina $\mathrm{D}$, favorece la osteopenia. La disbiosis intestinal secundaria al uso intensivo de antibióticos contribuye también al déficit de vitamina $\mathrm{K}$.

Las vitaminas hidrosolubles deben aportarse según recomendaciones internacionales (RDI), a dosis habituales, excepto la vitamina $\mathrm{B}_{12}$ en pacientes con resección ileal en quienes idealmente debiera medirse niveles plasmáticos, para el ajuste de la dosis a suplementar.

Estos preparados vitamínicos liposolubles deben ser aportados después de una dosis de enzimas para optimizar su absorción.

\section{Minerales y electrolitos}

- Calcio: Los pacientes con FQ tienen una alta prevalencia de déficit en la osificación de causa multifactorial. Debe asegurarse el aporte según la recomendación de ingesta diaria propuesta para pacientes con $\mathrm{FQ}$, que se expone en la Tabla 18.

- Hierro: Su déficit es de prevalencia variable y multifactorial. La administración debe ser alejada de las enzimas pancreáticas $y$ de la alimentación. La dosis debe ser acorde al peso, habiéndose estudiado también otras causas de anemia, distintas a la ferropénica.

- Zinc: Los pacientes con FQ tienen mayor utilización, mayores pérdidas fecales (en caso de esteatorrea significativa y persistente) y menor absorción intestinal de zinc. Las recomendaciones en pacientes con FQ se exponen en la Tabla 19.

- Sodio: Los pacientes con FQ tienen mayores pérdidas de sodio, que en lactantes puede manifestarse como progreso pondoestatural deficiente. Deben suplementarse siempre con $\mathrm{NaCl}$ en forma preventiva, ya que tanto la leche materna como las fórmulas lácteas tienen bajo contenido de sodio. Cuando hay aumento de pérdidas hídricas existe alto riesgo de deshidratación, sea por mayor sudoración (fiebre, clima cálido, abrigo excesivo), diarrea, vómitos, taquipnea o en niños mayores, frente al ejercicio intenso. En estas situaciones se recomienda el uso de soluciones de hidratación oral de osmolaridad reducida $(60 \mathrm{mmol} / \mathrm{L}$, SRO 60). Ver recomendaciones en la Tabla 20.

\section{Ácidos grasos (AG) esenciales}

$\mathrm{Su}$ uso debe ser considerado en pacientes con deficiente evolución nutricional; no existe

Tabla 18. Recomendación de ingesta de calcio en FQ, en mg/día*

\begin{tabular}{|cccccccc|}
\hline Edad & $\mathbf{0 - 6}$ meses & $\mathbf{7 - 1 1}$ meses & $\mathbf{1 - 3}$ años & $\mathbf{4 - 1 0}$ años & $\mathbf{1 1 - 1 7}$ años & $\mathbf{1 8 - 2 5}$ años & $>\mathbf{2 5}$ años \\
Calcio (mg/día) & 200 & 280 & 450 & 800 & 1.150 & 1.000 & 950 \\
\hline
\end{tabular}

*European Food Safety Authority EFSA 2015.

Tabla 19. Suplementación de zinc en paciente con fibrosis quística

\begin{tabular}{|ccc|}
\hline Edad (años) & Dosis recomendada & Período de tratamiento (meses) \\
\hline Lactantes $<2$ & $1 \mathrm{mg} / \mathrm{kg} /$ día (máximo: $15 \mathrm{mg} /$ día) & 6 \\
\hline Niños de 2 a 18 & $15 \mathrm{mg} /$ día & 6 \\
\hline Adultos $>18$ & $25 \mathrm{mg} /$ día & 6 \\
\hline
\end{tabular}

Tabla 20. Recomendaciones de aporte de sodio* en pacientes con fibrosis quística

\begin{tabular}{|c|c|c|c|c|c|c|}
\hline \multirow[t]{2}{*}{$\begin{array}{l}\text { Edad } \\
\text { (años) }\end{array}$} & \multicolumn{2}{|c|}{$\begin{array}{l}\text { Recomendación para } \\
\text { población general }\end{array}$} & \multicolumn{3}{|c|}{$\begin{array}{l}\text { Recomendación para pacientes con } \\
\text { fibrosis quística }\end{array}$} & \multirow[t]{2}{*}{ Consideraciones } \\
\hline & $\begin{array}{c}\text { Sodio } \\
\text { (mg/día) }\end{array}$ & $\begin{array}{c}\text { Sal } \\
\text { (g/día) }\end{array}$ & $\begin{array}{c}\text { Sodio } \\
\text { (mg/día) }\end{array}$ & $\begin{array}{c}\text { Sodio } \\
(\mathrm{mEq} / \mathrm{kg} / \mathrm{día})\end{array}$ & $\begin{array}{c}\text { Sal } \\
\text { (g/día) }\end{array}$ & \\
\hline$<1$ & 120 & 0,3 & $200-420$ & $1-2$ & $0,5-1$ & Suplementar siempre \\
\hline 1 a 3 & 1.000 & 2,5 & $1.500 * *$ & $\operatorname{Max} 4$ & $\operatorname{Max} 3,5$ & \multirow{3}{*}{$\begin{array}{c}\text { La dieta occidental puede cubrir } \\
\text { las recomendaciones basales. } \\
\text { Debe ajustarse según ingesta y } \\
\text { suplementar extra si hay pérdidas } \\
\text { hídricas }\end{array}$} \\
\hline 4 a 8 & 1.200 & 3,0 & $2.300 * *$ & - & $3,5-6$ & \\
\hline 9 a 19 & 1.500 & 3,75 & $3.500-6000^{* *}$ & - & $9-15$ & \\
\hline
\end{tabular}

*1 $\mathrm{mEq} \mathrm{Na}=1 \mathrm{mmol} \mathrm{Na}=23 \mathrm{mg}$ (molar) $\mathrm{Na}=57,5 \mathrm{mg}$ de sal. 1/4 cucharada de té $=1,5 \mathrm{~g}$ de sal. 1 tapa de lápiz $\mathrm{BIC}=1 \mathrm{~g}$ de sal. ${ }^{* *}$ Calculado con peso ideal por rango etario. Se debe incluir el contenido en los alimentos. 
suficiente evidencia a favor ni en contra de la suplementación rutinaria con AG Omega 3. Se recomienda la ingesta de 3 porciones de pescado por semana o más. La suplementación con ácido docosahexaenoico (DHA) se recomienda actualmente solo en aquellos con enfermedad hepática o hipertrigliceridemia.

\subsection{Suplementos e intervención nutricional}

El paciente con FQ debe ser incorporado normalmente a la alimentación de la familia con educación a los padres y pacientes (según edad).

\section{Alimentación durante el primer año de vida}

La lactancia materna (LM) es la alimentación óptima durante este período, que puede ser suficiente, requerir fortificación o uso complementario de fórmulas lácteas. Cuando se emplean estas últimas, se puede aumentar la concentración, suplementar con módulos calóricos y/o proteicos o utilizar fórmulas poliméricas, hipercalóricas e hiperproteicas.

Tanto la alimentación al pecho como las fórmulas lácteas y la alimentación sólida (a comenzar el sexto mes de vida) requieren de la administración previa de enzimas pancreáticas.

\section{Alimentación durante el período escolar y de la adolescencia}

El primer paso es la fortificación de la alimentación habitual, destacando la importancia de estructurar una alimentación ordenada, con 4 comidas fijas. Se adiciona una o dos colaciones extra en caso de no lograr buena ingesta, recordando que toda alimentación debe ser precedida por la dosis indicada de enzimas.

Es recomendable fortificar la dieta mediante adición a las comidas de porciones controladas de alimentos ricos en lípidos de origen vegetal (canola, maravilla, soya) y especialmente marinos (AG Omega 3).

\section{Suplementos nutricionales}

Para su indicación, es necesario considerar el estado nutricional, la edad, los requerimientos y la función gastrointestinal.

Los suplementos más utilizados en la práctica clínica en niños con FQ son:

- Fórmulas poliméricas: Preparados líquidos o en polvo, de baja viscosidad, alta densidad calórica $(1 \mathrm{Cal} / \mathrm{mL})$ e isotónicas. Su composición es balanceada en macronutrientes y contienen vitaminas y minerales. La fórmula pediátrica se indica en concentración de 16 a $18 \%$ en los menores de 1 año y de $20 \%$ a $22 \%$ entre 1 y 10 años. En los mayores a los 10 años es recomendable la formulación para adultos al $20 \%$ y en caso necesario, al $25 \%$.

- Fórmulas semi elementales y elementales: Preparados líquidos o en polvo, de fácil absorción. Son de uso excepcional, en caso de insuficiencia pancreática severa, síndrome de malabsorción, síndrome de intestino corto y/o alergia a proteína leche de vaca. Tienen menor densidad calórica, mayor osmolaridad y menor palatabilidad. Su composición está dada por nutrientes en forma hidrolizada, junto a minerales y vitaminas.

- Módulos: Son preparados simples, con un nutriente específico.

a) Calóricos: Triglicéridos de cadena mediana $\left(\mathrm{MCT}^{\circledR}\right)(8,5 \mathrm{Cal} / \mathrm{g})$, aceite, uso: $1-2 \%$. $\mathrm{Y}$ maltosa-dextrina (4 Cal/g), polvo, uso: $3-7 \%$.

b) Proteicos: caseinato de calcio (4 Cal/g), suero de proteína de leche de vaca $(4 \mathrm{Cal} / \mathrm{g})$, polvo, uso $1-3 \%$.

\section{Indicaciones}

- Fórmulas poliméricas: en pacientes con riesgo, se usan como complemento (aporte parcial), monitorizando que no se reemplacen las comidas.

- Módulos calóricos: se adiciona maltodextrina a la leche entera, postres o guisos, en concentración de 2-7\%. El aceite de triglicéridos de cadena mediana (MCT ) se adiciona a alimentos o fórmulas en casos especiales, como pacientes con daño hepático o síndrome de intestino corto.

- Módulo proteico: se utiliza si existe insuficiente ingesta proteica y en condiciones de hipercatabolismo.

\subsection{Nutrición enteral (ne) y parenteral ${ }^{125}$}

Indicada en las siguientes situaciones:

a. Fracaso en las metas nutricionales con la alimentación por vía oral, de acuerdo al estado nutricional, con énfasis en lactantes y habiéndose descartado previamente otras causas (algoritmo en Figura 1).

b. Compromiso del estado nutricional: "Riesgo nutricional" que no mejora o presencia de "falla nutricional" según criterios para FQ detallados en Tabla 15.

c. Durante exacerbaciones, en que el paciente no se alimenta bien puede ser necesaria temporalmente, como apoyo en pacientes hospitalizados. 
Condiciones para el inicio de la alimentación por vía enteral:

- Fracaso del tratamiento nutricional por vía oral: intentos repetidos de mejorar la ingesta mediante modificaciones dietarias y uso de suplementos.

- Familia y paciente motivados.

- Control óptimo de la enfermedad respiratoria.

- Apoyo por psicólogo.

Otras causas de mal progreso ponderal son:

- Esteatorrea sin control exitoso.

- Sobreinfección pulmonar o sinusal no controlada, o subclínica.

- Hipoxia nocturna.

- RGE con control deficiente.

- Sobrepoblación bacteriana intestinal.

- Diabetes asociada a FQ.

- Enfermedades gastrointestinales: (intolerancia a la lactosa, enfermedad celíaca, alergia proteína de leche de vaca, enfermedad inflamatoria intestinal).

- Pérdida exagerada de sodio en lactantes.

- Deficiencia de micronutrientes (hierro, zinc).

\section{Vías de aporte enteral}

Se utilizan sondas nasoentéricas o un acceso artificial al tubo digestivo (ostomías).

- Sonda nasogástrica: apropiada para períodos de uso menores a 3 meses. Su instalación fácil hace que su acceso sea universal. Sin embargo, puede haber dificultades en tolerancia y mantención de su posición, con el consecuente riesgo de aspiración, así como complicaciones locales en el uso prolongado.

- Sonda nasoyeyunal: de uso mucho menos frecuente, requiere siempre el uso de bomba enteral (infusión continua), tiene mayor riesgo de desplazamiento y mayor dificultad para su reinstalación.

- Gastrostomía: acceso para una nutricíón entérica prolongada (mayor a 3 meses), la técnica de instalación (endoscópica, quirúrgica laparoscópica o abierta) dependerá del paciente, de sus condiciones concomitantes (solo en las últimas dos puede realizarse procedimiento antirreflujo) y de la experiencia del centro clínico. Se estima que en 5 a $10 \%$ de los pacientes con FQ se requiere realizar gastrostomía, situación que debe consensuarse precozmente con la familia, planteando que es una herramienta que puede ser transitoria o definitiva. $\mathrm{Su}$ realización tiene mortalidad de 1 a $2 \%$ y morbilidad de 3 a $12 \%$.

- Yeyunostomía (uso excepcional en niños).

\section{Procedimiento para iniciar la nutrición enteral (NE)}

1. Hospitalización, con los objetivos de verificar los aportes y respuesta clínica y tolerancia por parte del paciente, procurar educación para la familia y evaluar posible indicación de gastrostomía.

2. Progresión gradual de los aportes, con las fórmulas poliméricas, fortificadas con módulos si es necesario.

3. Alimentación enteral continua nocturna de preferencia (aportar $30-50 \%$ de los requerimientos diarios), dejando un sistema habitual de alimentación en el día.

4. Aporte de las enzimas pancreáticas:

- Por vía oral: $50 \%$ dosis al inicio de la NE y $50 \%$ dosis a la mitad de la infusión.

- Por sonda: cuando no sea posible la ingesta de enzimas por boca y la NE sea continua (mayor a $1 \mathrm{~h}$ ) se puede administrar la dosis proporcional de enzimas disueltas en $2 \mathrm{ml}$ de bicarbonato de sodio al 8,4\% (precaución con la dosis de bicarbonato), cada $4 \mathrm{~h}$.

- Se ha desarrollado recientemente un dispositivo que contiene enzimas, para ser conectado a continuación de la sonda de bajada, antes de la conexión a la ostomía. Requiere de un flujo enteral mínimo. Sin embargo, aún no está ampliamente disponible en el mercado.

- Monitorización de glicemia capilar durante la infusión: importante de considerar en estados previos a CFRD (Diabetes asociada a Fibrosis Quística) no en forma rutinaria.

Contraindicaciones para realizar una gastrostomía

- Absolutas: Que sea una medida terapéutica desproporcionada, que exista una alteración anatómica que imposibilite el paso del endoscopio hasta el estómago (en técnica endoscópica), infección activa de la pared anterior del abdomen,

- Hipertensión portal con várices gástricas que lo impidan, rechazo del paciente o del cuidador.

- Relativas: hepatomegalia, ascitis, hipertensión portal.

\subsection{Nutrición parenteral y otros $\mathbf{s}^{125}$}

La nutrición parenteral es un soporte nutricional eficaz para mejorar el estado nutricional, pero 
su uso es excepcional, y se limita a situaciones clínicas especificas en las cuales no pueda usarse la vía enteral o ésta sea insuficiente. En general se utiliza por plazos cortos o medianos: cirugías, trasplante de pulmón o hígado, síndrome de intestino corto.

\section{Otros}

- Estimulantes del apetito: Se ha demostrado ganancia de peso temporal con ciproheptadina. El nivel de evidencia es escaso.

- Anabólicos: el uso del acetato de megestrol no se recomienda de rutina, dado que tiene importantes efectos colaterales.

- Hormona de crecimiento: podría tener aplicación en un grupo seleccionado de niños de edades mayores.

\subsection{Manejo nutricional del paciente hospi- talizado}

La hospitalización de un paciente con $\mathrm{FQ}$ generalmente ocurre en el contexto de una exacerbación, por lo que es un período de riesgo nutricional que puede conducir a una malnutrición o agravarla, con deterioro de la función pulmonar y de la respuesta inmunológica, prolongando la estadía hospitalaria.

Una vez superada la etapa catabólica inicial y el paciente estabilizado, los objetivos nutricionales son:

1. Aprovechar la instancia para verificar indicaciones y ajustar aportes.

2. Evitar el deterioro y eventualmente tratar una deficiencia nutricional.

3. Pesquisar y tratar las complicaciones metabólicas.

\section{Evaluación en el hospital}

1. Antropometría y composición corporal:

- Tener referencia de los pesos y tallas de los controles ambulatorios previos.

- Vigilar y evitar la pérdida de peso.

Control perímetro braquial (masa magra) y pliegue tricipital (masa grasa). El perímetro braquial en lactantes y en desnutridos se modifica rápidamente, y es una estrategia clínica útil de seguimiento en desnutridos.

Metas: aporte calórico según recomendación y proteico con $\mathrm{P} \%$ de 15 a $20 \%$.

2. Control de Ingesta: Objetivar la ingesta real, monitorizar la adherencia a la indicación nutricional, modificar aportes y decidir la asistencia nutricional.
3. Exámenes de laboratorio:

- Estrés metabólico: Medir nitrógeno ureico urinario (NUU) y ajustar aporte proteico para lograr un balance nitrogenado neutro durante la hospitalización.

- Complicaciones metabólicas: Diabetes Mellitus asociada a FQ (CFRD). La glicemia de ayuno es insuficiente y hemoglobina glicosilada A1c puede estar falsamente baja. Se recomienda la realización de la prueba de tolerancia oral a la glucosa desde los 10 años (antes si existe alta sospecha).

\section{Intervención nutricional durante la hospitalización}

1. Considerar los factores que contribuyen a la malnutrición.

2. Objetivar el patrón de alimentación y la relación con el cuidador: administración de enzimas, limitar tiempo de alimentación, colaciones, orientación al cuidador.

3. Control de ingesta y medición de catabolismo proteico con NUU $24 \mathrm{~h}$.

4. Modificar y ajustar aportes: uso de fórmulas enterales altas en proteínas y energía. Evitar altos aportes de hidratos de carbono.

5. Asistencia nutricional oportuna: NE por sonda nasogástrica (períodos menores a tres meses) o plantear una gastrostomía, si requiere por mayor tiempo.

\subsection{Rol del equipo de nutrición}

Cada paciente debe tener un plan anticipatorio y un seguimiento individual, el equipo de nutrición se involucra en la evaluación completa del equipo multidisciplinario y colabora en la discusión y registro global.

\section{a. Médico nutriólogo}

- Realiza la evaluación integral del estado nutricional y crecimiento.

- Evalúa las comorbilidades asociadas.

- Solicita el estudio metabólico-nutricional complementario.

- Indica y ajusta la terapia enzimática.

- Prescribe las metas energéticas, de macro y micronutrientes de acuerdo a los requerimientos que calcula para el paciente en particular.

Cabe destacar que si en el lugar de control regular del paciente no tengan médico nutriólogo, se debe establecer una relación fluida con el hospital de referencia que cuente con dicho especialista. 


\section{b. Nutricionista}

$\mathrm{Su}$ labor es educativa en los principios nutricionales otorgados a los padres por el medico nutriólogo. La educación constituye el pilar fundamental para lograr un buen estado nutricional, especialmente en los niños con FQ que es la base para mantener un buen crecimiento y desarrollo general.

La consulta nutricional de la nutricionista involucra diversos aspectos:

- Realiza anamnesis nutricional: recolección de datos de alimentación aplicación de encuesta nutricional de frecuencia de consumo y de 24 $\mathrm{h}$, determinando así ingesta versus gasto calórico para la intervención nutricional individual.

- Lleva a cabo la evaluación antropométrica para establecer la calificación nutricional, utilizando todos los indicadores ya descritos (Tabla 15).

- Entrega una pauta de alimentación escrita, ajustada al paciente, según su ingesta, preferencias y entorno familiar, educando en hábitos alimentarios saludables. La familia de un paciente FQ debe estar involucrada en el tratamiento por lo que las indicaciones escritas son fundamentales.

- Apoya en la adecuada técnica de administración de enzimas y suplementos de indicados por el médico, así como indicaciones relacionadas a patologías asociadas.

- Registra la evolución nutricional del paciente y entrega un informe con la frecuencia que se necesite (mensual, trimestral o semestral) (Figura 3).

Mejorar la adherencia a las numerosas prescripciones nutricionales es un desafio clave por lo que la nutricionista especialista en $F Q$ proporciona un enfoque colaborativo aumentando la aceptación para los cambios y facilitando la discusión.

\section{Compromiso digestivo y hepatobiliar ${ }^{127,128}$}

Las anomalías gastrointestinales (GI) son parte integral de las manifestaciones clínicas de FQ,

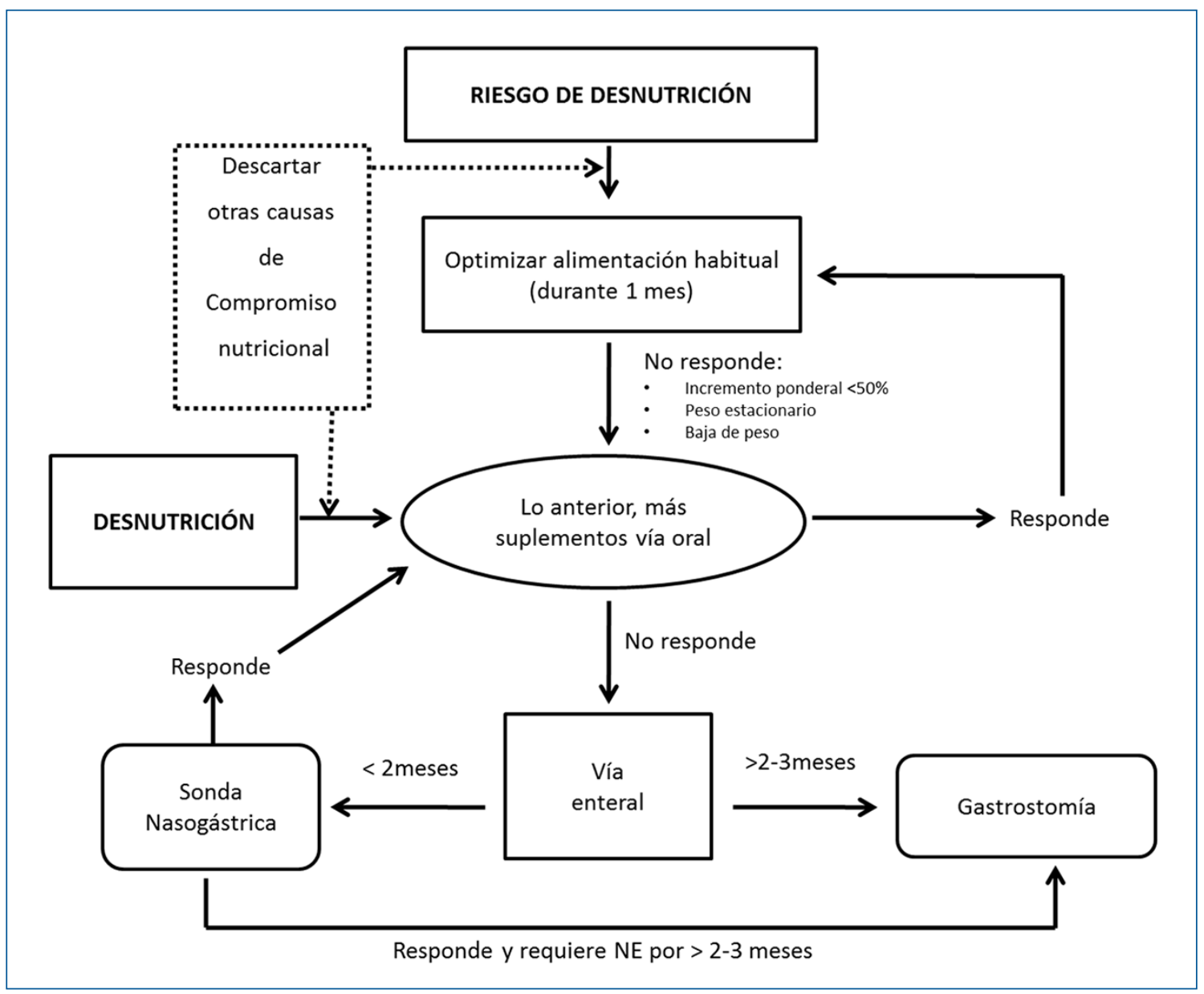

Figura 3. Flujograma sugerido para el manejo nutricional en niños con FQ (adaptado de Barja y Rebollo ${ }^{126}$ ). 
el espectro de presentación y la gravedad de la enfermedad es extremadamente amplio, incluso entre pacientes con el mismo perfil de variantes CFTR $^{127}$. La carga clínica de los trastornos gastrointestinales sigue siendo alta y afecta a pacientes de todas las edades. La atención continua y cuidadosa es esencial para disminuir la morbilidad y mejorar la calidad de vida de estos pacientes. Los exámenes que se indican para evaluar trastornos digestivos se especifican en la Tabla 21.

\section{Evaluación de síntomas digestivos ${ }^{128}$}

- Pirosis y epigastralgia.

- Vómitos secundarios a retraso del vaciamiento gástrico, a deglución de secreciones e hipersecreción ácida gástrica.

- Dolor periumbilical y distensión abdominal secundarios a malabsorción de grasas o por enteropatía secundaria a sobrepoblación bacteriana.

- Dolor hipogástrico: En pacientes de mayor edad, sospechar colonopatía fibrosante secundaria a dosis altas de enzimas (inflamación y estenosis del colon derecho). El síndrome de obstrucción intestinal distal puede simular una apendicitis aguda y/o producir obstrucción intestinal.

- Constipación: Es generalmente subclínica y se detecta a la palpación abdominal.

- Dolor en hipocondrio derecho: Investigar la posibilidad de litiasis biliar.

\section{Examen físico abdominal}

- Circulación venosa colateral en pared.

- Tamaño del bazo (hipertensión portal).

- Hígado: la primera manifestación de compromiso es la hepatomegalia y posteriormente el aumento de consistencia en presencia de cirrosis.
- Palpación de deposiciones duras: Es frecuente en niños mayores e indica impactación fecal, paso previo a la obstrucción intestinal funcional, con masa palpable y sensible en colon derecho.

\subsection{Páncreas ${ }^{129}$}

La insuficiencia pancreática ocurre en el 85 a $90 \%$ de los pacientes y clásicamente está asociada con fenotipos severos de la enfermedad, aunque cada vez es más frecuente detectarla en pacientes con manifestaciones leves y variantes atípicas.

La afectación del páncreas puede estar presente desde la vida intrauterina. En recién nacidos se puede observar conductos intralobulares llenos de moco y acinos con fibrosis, que progresará a la atrofia de la glándula y pérdida de capacidad para secretar enzimas. La función endocrina en general esta preservada durante años, pero con el tiempo los islotes de Langerhans son sustituidos por estoma fibro-adiposo.

La esteatorrea es la manifestación clínica más importante, consecuencia de la falta de enzimas en el lumen intestinal, con malabsorción de grasas y proteínas. Se manifiesta con dolor abdominal, meteorismo, mal incremento ponderal, pérdida de peso y síntomas inespecíficos como distensión abdominal, flatulencia y diarrea. El diagnóstico se realiza con medición de elastasa fecal.

El paciente con insuficiencia pancreática debe iniciar terapia de reemplazo enzimático, la dosis no debe sobrepasar las 10.000 unidades de lipasa por $\mathrm{kg} /$ día (Ver capítulo nutrición). El objetivo del tratamiento es aliviar los síntomas, mejorar la digestión y promover un adecuado crecimiento y desarrollo ${ }^{129}$.

Tabla 21. Indicación de exámenes digestivos de rutina

\begin{tabular}{|lll|}
\hline Examen & Objetivo & Frecuencia \\
$\begin{array}{l}\text { Ultrasonografía } \\
\text { abdominal }\end{array}$ & $\begin{array}{l}\text { Detección de hepatopatía crónica, hígado } \\
\text { graso y litiasis biliar }\end{array}$ & Anual \\
Eco-Doppler hepático & $\begin{array}{l}\text { Evaluar pacientes con compromiso hepático, } \\
\text { detectar hipertensión portal }\end{array}$ & Anual \\
Endoscopía digestiva & $\begin{array}{l}\text { Evaluar el reflujo gastroesofágico, epigastralgia } \\
\text { Detectar várices esofágicas }\end{array}$ & SOS \\
$\begin{array}{l}\text { Phmetría de 24 h } \\
\begin{array}{l}\text { Tomografía computada } \\
\text { de abdomen }\end{array}\end{array}$ & $\begin{array}{l}\text { Según hallazgos de ecografía, para precisar } \\
\text { diagnóstico }\end{array}$ & $\begin{array}{l}\text { SOS } \\
\text { Anual (si existe compromiso hepático) }\end{array}$ \\
\hline
\end{tabular}


La pancreatitis aguda se caracteriza por un dolor intenso epi o meso gástrico, a veces transfixiante e irradiado al dorso, asociado a vómitos, náuseas y compromiso del estado general con o sin alza febril. La confirmación diagnóstica se basa en la clínica, elevación de las enzimas pancreáticas en suero, estudio de imágenes con ecotomografía y Resonancia nuclear magnetica (RNM) El tratamiento de estos episodios es similar al efectuado en pacientes no portadores de FQ.

Diversos estudios han demostrado alteración de CFTR en pacientes que presentan pancreatitis recurrente idiopática y crónica, sin embargo, solo un $10 \%$ de ellos cumplen los criterios para díagnosticar FQ.

\subsection{Hígado}

La enfermedad hepática representa la tercera causa de muerte en FQ. El CFTR se expresa en la vía biliar intra y extrahepática, incluyendo la vesícula biliar, pero no en los hepatocitos. Entre 10 a $15 \%$ de los pacientes pediátricos presentan algún grado de compromiso hepático. La expresión fenotípica de la enfermedad es muy heterogénea, variando de elevación asintomática de enzimas hepáticas a cirrosis multilobular con hipertensión portal. Los estudios de casos de la literatura internacional describen frecuencia de presentación clínica muy variada (Tabla 22) ${ }^{130}$.

Los mecanismos fisiopatológicos propuestos del aumento de la viscosidad en la secreción biliar, por el defecto del CFTR, llevando a la retención de ácidos biliares, inflamación, fibrosis focal y finalmente cirrosis multilobular, no se han correlacionados con los hallazgos histológicos.
Se encuentran en investigación otros mecanismos: la teoría intestino - hígado (el microbioma de los pacientes con FQ es diferente a controles sanos) y la participación de las células estrelladas en la activación de miofibroblastos portales que llevarían a fibrosis. El CFTR también regula la respuesta inflamatoria mediada por los toll-like receptors 4 (TLR-4). Estos inhiben la actividad de un oncogen celular ( $\mathrm{Src})$. Las variantes en el CFTR perderían esta capacidad regulatoria, lo que llevaría a autoactivación del Src y un aumento de citoquinas inflamatorias y disrupción de la barrera epitelial, con producción de una translocación bacteriana a la circulación portal, pudiendo ocasionar inflamación hepática y fibrosis ${ }^{131}$.

El daño hepático asociado a FQ es severo cuando está presente cirrosis con hipertensión portal, lo cual ocurre en alrededor del 5\% de los pacientes. La mayoría de estos pacientes son portadores de las variantes I-III. El manejo clínico del daño hepático severo es difícil por la falta de marcadores que permitan predecir el desarrollo de esta condición.

\section{Laboratorio}

Solicitar ecotomografía abdominal, con estudio Doppler del sistema portal,

Es un hallazgo común la elevación de enzimas hepáticas con elevación de alanino aminotransferasas, aspartato aminotransferasa, gama glutamil transferasa, pero no son predictoras o indicadoras de daño hepático severo. Con valores de aminotransferasa en límites de hepatitis, se debe hacer diagnóstico diferencial con hepatitis infecciosa, hepatitis autoinmune, enfermedad de Wilson o incluso considerar daño hepático asociado medicamentos.

Tabla 22. Presentación clínica y frecuencia de compromiso hepático encontrada en la literatura ${ }^{133}$

\begin{tabular}{|ll|}
\hline Presentación clínica & Frecuencia estimada (\%) \\
\hline Elevación de enzimas hepáticas & $10-35$ \\
Esteatosis hepática & $20-60$ \\
Cirrosis biliar focal & $11-70$ \\
Cirrosis biliar multifocal & $5-15$ \\
Colestasia neonatal & Raro \\
Microvesícula & 30 \\
Colelitiasis- colecistitis & $1-10 \%$, aumentaría con la edad \\
Disquinesia biliar & Desconocida \\
Colangitis esclerosante & Desconocida \\
Hipertensión portal no asociada a cirrosis & Desconocida \\
\hline
\end{tabular}


La biopsia hepática constituye el Gold standard en el diagnóstico de daño hepático, sin embargo la falta de tratamientos que alteren el curso de la enfermedad sobrepasa el riesgo de eventuales complicaciones asociadas a la naturaleza invasiva de este procedimiento.

Una técnica ecográfica promisoria, no invasiva, pero aún con limitada evidencia es la elastografía hepática.

\section{Tratamiento}

Optimización de la nutrición y el crecimiento, aporte de vitaminas liposolubles en medio acuoso y suplemento de triglicéridos de cadena medía. La restricción de proteínas y sal es innecesaria en daño hepático compensado.

Evitar hepatotóxicos y asegurar vacunación contra virus de hepatitis A, B y varicela.

El uso de ácido ursodeoxicólico para el tratamiento y prevención del daño hepático severo es controvertido. Usar dosis que no sobrepasen 20 $\mathrm{mg}$ por $\mathrm{kg}$ de peso corporal.

La hipertensión portal es manejada con seguimiento endoscópico y eventual ligadura. El uso de beta-bloqueadores adrenérgicos tiene contraindicación relativa, dado el riesgo de broncoconstricción ${ }^{132}$.

Para la prevención de hemorragia por gastropatía hipertensiva y varices gastroesofágicas se debe evitar el uso de ácido acetilsalicílico y antiinflamatorios no esteroidales.

Evitar deportes de contacto especialmente en presencia de esplenomegalia.

El desarrollo de signos de insuficiencia hepática marca una etapa cercana a una fase terminal en el progreso de la enfermedad y se debe presentar al equipo de trasplante hepático. La sobrevida es similar a otros grupos de niños sin FQ que acceden a trasplante. El trasplante simultáneo hígado-páncreas está asociado con restauración de la función pancreática endocrina y exocrina.

Respecto al compromiso de la vesícula biliar, la mayoría de las complicaciones son asintomáticas y no requieren tratamiento. Puede haber presencia de barro biliar y cálculos, cuyo tratamiento es quirúrgico.

\subsection{Compromiso gastrointestinal}

\section{a. Ileo meconial}

Frente al antecedente de íleo meconial en RN siempre descartar FQ.

Es la manifestación más precoz con una prevalencia que varía entre $14 \%$ y $20 \%$. Se asocia a variantes severas de CFTR e insuficiencia pancreática ${ }^{134}$. La presentación clínica incluye distensión abdominal, vómitos biliosos, retraso en la expulsión de meconio y asa intestinal visible y / o palpable. Se clasifica en simple o complejo. El complejo se asocia a otras complicaciones intestinales como atresia, perforación, vólvulo, necrosis.

\section{Tratamiento}

Forma simple, uso de enemas hiperosmóticos por radiólogo. Después del enema se debe observar un rápido paso de trozos de meconio seguido de meconio semi líquido. De acuerdo a la respuesta repetir por 2 o 3 veces. Los posibles riesgos asociados a esta intervención incluyen perforación rectal o colónica, enterocolitis isquémica, hepatotoxicidad y shock hipovolémico (3\%). Esta opción de tratamiento tiene la ventaja que evita la intervención quirúrgica, y disminuye el tiempo de estadía intrahospitalaria. En caso de que no se logre la desimpactación o se trate de Íleo meconial complejo, la conducta es quirúrgica.

\section{b. Síndrome Obstrucción Intestinal Distal (DIOS)}

Se caracteriza clínicamente por masa palpable generalmente en cuadrante inferior derecho y se debe a la acumulación de material espesado en porciones distales del intestino delgado y en la unión íleo cecal. La completa obstrucción se expresa con vómitos biliosos, asas dilatadas, niveles hidroaéreos. Factores de riesgo son el antecedente de DIOS previo, genotipos severos de CFTR e insuficiencia pancreática ${ }^{135}$. La prevalencia aumenta en la adultez.

Prevención: Evitar la deshidratación, aumentar el aporte de líquidos en períodos calurosos (diagnóstico diferencial: apendicitis, invaginación intestinal).

El estudio radiológico y ecográfico es fundamental.

\section{Tratamiento ${ }^{136}$}

En caso de obstrucción intestinal parcial utilizar agentes osmóticos, lo que en general es suficiente. En la obstrucción completa, los esfuerzos van dirigidos a evitar la intervención quirúrgica mediante el uso de enema de contraste hidrosoluble.

Alternativas de tratamiento del DIOS incompleto

A.PEG (polietilenglicol) sin electrolitos $2 \mathrm{~g} / \mathrm{kg} /$ día máximo 80-100 g/día.

B. Solución iso-osmótica PEG lista para uso 20$40 \mathrm{ml} / \mathrm{kg} /$ hora máximo $1 \mathrm{~L} / \mathrm{h}$ en $8 \mathrm{~h}$.

C. Solución hiperosmótica en enema o vía nasogástrica. 


\section{Tratamiento del DIOS completo}

* Hidratación EV.

* Sonda nasogástrica con aspiración.

Enemas hiperosmóticos, (Gastrografin $\left.{ }^{\circledR}\right)(100 \mathrm{ml}$ diluido 4 veces con agua) administrado por radiólogo bajo visión directa con la intención de alcanzar íleon terminal.

Se debe estar atento a eventuales complicaciones como shock, perforación y enterocolitis necrosante.

Todo paciente que ha presentado DIOS, debe quedar con uso profiláctico de polietilenglicol por 6 a 12 meses.

\section{c. Invaginación intestinal}

Ocurre en 1 a $2 \%$ de los pacientes con FQ. La mayoría de las invaginaciones ocurren en la unión ileocólica y $25 \%$ de ellas están asociadas a masa palpable. El diagnóstico ecográfico es indispensable.

\section{d. Prolapso rectal}

Es la protrusión del recto por el ano. La incidencia exacta es desconocida, pero se presenta en alrededor del $23 \%$ en pacientes con FQ menores de 5 años En general es auto limitada y de tratamiento médico, excepcionalmente se hace necesario el tratamiento quirúrgico.

\section{e. Compromiso apendicular}

Por razones no aclaradas, la incidencia de apendicitis es menor en el grupo de pacientes con FQ. Sin embargo, aquellos que la desarrollan, tienen un riesgo aumentado de evolucionar a absceso apendicular por retraso en el diagnóstico, debido a las dificultades en el diagnóstico diferencial con DIOS.

Requiere cuidadosa evaluación clínica y por imágenes.

\section{f. Reflujo gastroesofágico ${ }^{137}$}

Es común en pacientes con FQ y existen factores predisponentes que lo favorecen como las exacerbaciones respiratorias, reducción en la función pulmonar, cambios inflamatorios y microbiológicos en la vía aérea, sin embargo, la relación causal no ha sido demostrada ${ }^{137}$. RGE sintomático se debe basar en guías estándar para la población general. Tratamiento es el omeprazol (dosis máxima $2 \mathrm{mg} / \mathrm{kg} /$ día). Como alternativa se puede utilizar la famotidina $(2 \mathrm{mg} / \mathrm{kg} /$ día fraccionado cada $12 \mathrm{~h}$ ).

\section{g. Cáncer de colon ${ }^{138}$}

Con el aumento de la sobrevida y el trasplante con terapia inmunosupresora se ha evidenciado la aparición precoz de cáncer de colon, sin embargo todo el tubo digestivo presenta riesgo de cáncer ${ }^{139}$. La edad promedio de inicio del cáncer colo-rectal en pacientes portadores de FQ es aproximadamente 40 años (alrededor de 20 a 30 años antes que la población no $\mathrm{FQ}^{140}$. En paciente FQ con trasplante pulmonar, el tamizaje de cáncer colorrectal debería realizarse precozmente después de la intervención y dentro de los dos años siguientes a menos que tengan una colonoscopía normal los cinco años previos ${ }^{138}$.

\section{Aspectos endocrinológicos}

\subsection{Diabetes mellitus}

La manifestación endocrinológica más importante es la diabetes mellitus asociada a FQ (CFRD)

\section{Generalidades e importancia de la pesquisa precoz}

La CFRD se presenta sólo en las formas graves de FQ (fenotipos I, II, III y VI), en pacientes con insuficiencia pancreática y está asociada al déficit de insulina. A nivel internacional se ha estimado una prevalencia en sujetos con $\mathrm{FQ}<5 \%$ en niños, $15-20 \%$ en adolescentes y $40-50 \%$ en adultos, sin diferencia por sexo. No hay datos de su frecuencia de presentación en Chile.

Las manifestaciones clínicas son similares a los síntomas clásicos de diabetes mellitus la mayoría de los pacientes con FQ no desarrollan síntomas, por lo que se debe sospechar en presencia de:

- Deterioro de la función pulmonar sin causa aparente.

- Alteración del estado nutricional a pesar de tratamiento nutricional adecuado.

- Falla de crecimiento y detención del desarrollo puberal.

- Puede presentarse inicialmente en situaciones asociadas a un aumento de la resistencia a la insulina: infecciones pulmonares agudas, corticoterapia, aumento de aporte de hidratos de carbono mediante alimentación enteral continua nocturna y en trasplante pulmonar.

Considerar que la CFRD representa un continuo de alteraciones en la tolerancia a la glucosa, inicialmente pude manifestarse con hiperglicemias postprandiales intermitentes, que sólo puede ser detectados mediante el uso de monitoreo continuo de glucosa o auto monitoreo con glicemias capilares. Esta etapa inicial es seguida por intolerancia a la glucosa detectada por la prueba 
de tolerancia a la glucosa (PTGO) y finalmente con diabetes ${ }^{141,142}$.

\section{Pesquisa}

Debido a que CFRD es clínicamente silente, el tamizaje es importante. El diagnóstico se efectúa con la prueba de tolerancia a la glucosa, que se debe realizar anualmente a partir de los 10 años. Independiente de la edad, se debe realizar en aquellos que iniciaron desarrollo puberal, presentan deterioro de la función pulmonar $\mathrm{y} / \mathrm{o}$ del estado nutricional, falla de crecimiento y detención de la pubertad.

La prueba de tolerancia oral a la glucosa no es sustituible por glicemia de ayuno ni por $\mathrm{Hb}$ glicosilada A1c, debido a que este examen no tiene suficiente sensibilidad para detectar el diagnóstico. El valor de la detección clínica de hiperglicemias leves detectadas por monitoreo continuo de glucosa no ha sido determinado, por lo cual esta herramienta no ha sido aún validada para el diagnóstico.

En los pacientes con glicemia de ayuno alterada, debe repetirse la PTGO cada 6 meses, aquellos con intolerancia a la glucosa y diabetes, deben ser referidos al especialista, endocrinólogo y/o díabetólogo, para su tratamiento.

\section{Criterios diagnósticos}

Son los utilizados en población general. Según los niveles de glicemia basal y PTGO se clasifican 4 categorías (Tabla 23).

El diagnóstico de CFRD es definido en el primer momento en que el paciente cumple los criterios diagnósticos, independiente si la hiperglicemia remite luego del término de una exacerbación o de alimentación enteral continua.

\section{Tratamiento de la diabetes asociada a $F Q^{142,143}$}

\section{a) Alimentación}

La indicación de alimentación está comandada por las necesidades nutricionales en pacientes con FQ y requiere la intervención de nutriólogo y nutricionista.

En pacientes con CFRD, a diferencia de otras formas de diabetes mellitus, no se indica restricción de hidratos de carbono, sal ni grasas y tampoco se restringe el horario de las comidas, pero debe considerarse el conteo de hidratos de carbono para el cálculo de dosis de insulina en aquellos que estén recibiendo esta terapia.

En términos generales:

Calorías: Al igual que en FQ sin CFRD, dieta hipercalórica que aporte entre 100 a $150 \%$ de las recomendaciones, adecuada al paciente en particular y que le permita mantener un peso normal (Índice P/T por NCHS (US National Center of Health and Statistics) en menores de 6 años y por IMC CDC en $>6$ años).

Hidratos de carbono: sin restricción en cantidad, de acuerdo a hábito del paciente. Generalmente 45 a $50 \%$ de calorías totales. Se recomienda el uso de carbohidratos complejos, que mejoran el índice glicémico de las comidas.

Edulcorantes: no son necesarios y si se utilizan debe sustituirse el valor calórico del azúcar con azucares complejos o lípidos.

Proteínas: recomendación habitual es de 10 a 15\% según RDA (Recommended Diateary Allowences). Grasas: 40\% de calorías totales.

Vitaminas y minerales: indicaciones habituales en pacientes con FQ (Vitaminas A D E K, B12, $\mathrm{Zn}, \mathrm{Cu}, \mathrm{Se}, \mathrm{Ca}, \mathrm{Fe})$.

\section{b) Hipoglicemiantes orales \\ No están recomendados actualmente para el manejo de CFRD.}

Los agentes insulinosensibilizadores (como la metformina) y secretagogos de insulina (sulfanilourea y glinidas) no han demostrado mejoría clínica en términos nutricionales ni metabólicos en pacientes con CFRD sin hiperglicemia de

Tabla 23. Niveles de glicemia y diagnóstico de diabetes mellitus*

\begin{tabular}{|ll|}
\hline Clasificación & Parámetros \\
I. Diabetes mellitus & $\begin{array}{l}\text { Síntomas clásicos }+ \text { glicemia }>200 \mathrm{mg} / \mathrm{dl} \text { (independiente del tiempo de ayuno) } \\
\text { 2 glicemias de ayuno }>126 \mathrm{mg} / \mathrm{dl}\end{array}$ \\
Glicemia $>200 \mathrm{mg} / \mathrm{dl}$ a los $120 \mathrm{~min}$ en PTGO \\
II. Intolerancia a la glucosa & $\begin{array}{l}\text { Glicemia de ayuno }<100 \mathrm{mg} / \mathrm{dl}+\text { glicemia a los } 120 \mathrm{~min} \text { en PTGO entre } 140 \mathrm{y} \\
199 \mathrm{mg} / \mathrm{dl}\end{array}$ \\
III. Glicemia de ayuno alterada & Glicemia de ayuno entre $100 \mathrm{y} 125 \mathrm{mg} / \mathrm{dl}$ \\
IV. Normal & $\begin{array}{l}\text { Glicemia de ayuno }<100 \mathrm{mg} / \mathrm{dl} \\
\text { Glicemia } 120 \mathrm{~min}<140 \mathrm{mg} / \mathrm{dl}\end{array}$ \\
\hline
\end{tabular}

*American Diabetes Association (ADA) 2017. 
ayuno. Por otro lado, hay que considerar que la insulinorresistencia no es el factor etiológico fundamental en esta patología y tienen efectos adversos asociados. No existe a la fecha literatura que respalde el uso de análogos de incretinas, tales como agonistas de GLP-1 (glucagon-like peptide-1) o inhibidores DPP-4 (dipeptidyl peptidase-4) en pacientes con CFRD.

\section{c) Insulinas}

Los efectos anabólicos de la insulina tienen un rol fundamental, considerando la relación establecida entre el estado nutricional y la sobrevida en pacientes con fibrosis quística. Se debe proveer una dosis de insulina tan alta como el paciente pueda tolerar de forma segura.

Los esquemas insulínicos a utilizar incluyen insulinas para cubrir los requerimientos basales (NPH regular, Glargina, Detemir, Degludec) y los bolos preprandiales (Cristalina, Lispro, Aspártica, Glulisina) para cubrir la ingesta (Tabla 24).

Debido que, en la etapa inicial del desarrollo de la CFRD, lo más frecuente son hiperglicemias postprandíales (intolerancia a glucosa), puede utilizarse bolos preprandíales de insulinas rápidas o ultrarrápidas; posteriormente cuando se presenta hiperglicemia de ayuno es necesario agregar insulinas basales, 1 a 3 dosis según requerimientos $\mathrm{y}$ tipo de insulina utilizada.

El manejo debe contemplar, además:

- Educación en diabetes.

- Conteo de hidratos de carbono para administración de bolos.

- Autocontrol con determinaciones de glicemias capilares ( 3 a 5 diarias).

- Exámenes de laboratorio periódicos.

- El tratamiento con insulina debe estar en manos de especialistas.

- El control metabólico se monitorea con determinaciones de Hemoglobina glicosilada A1c cada 3 meses.

\subsection{Otras complicaciones endocrinológicas}

\section{Talla baja y retraso puberal}

En promedio el peso de recién nacido con FQ está levemente disminuido. Si el apoyo nutricional es el adecuado no hay alteración del desarrollo pondoestatural.

En período adolescente puede haber compromiso de la estatura por el retraso puberal y la aparición de diabetes. Los niveles de hormona de crecimiento, gonadotrofinas y ACTH son normales pero la infección crónica, el uso de corticoides y la desnutrición pueden afectar los niveles hormonales.

El desarrollo testicular en los niños es normal, aunque hay azoospermia debido a la obstrucción de los vasos deferentes.

El retraso puberal afecta en forma significativa la esfera psicológica.

\section{Osteoporosis}

Está relacionada con la pobre nutrición y baja ingesta de vitaminas (K y D), balance de calcio negativo, hipogonadismo, pubertad retrasada, diabetes mellitus, tratamiento esteroidal, sedentarismo y alteración del CFTR que compromete las células del hueso ${ }^{144}$.

Densitometría ósea debe solicitarse a partir de los 10 años y antes en pacientes con riesgo (esteroides orales o inhalatorio a dosis alta, díabéticos, $\mathrm{VEF}_{1}<50 \%$ ). Si es normal repetir cada 3 años y cada 6-12 meses si esta alterado.

\section{Fertilidad}

E1 98\% de los pacientes masculinos presenta azoospermia. Esta condición debe ser informada al paciente y sus padres alrededor de los 10 - 12 años reforzando que no afecta la virilidad. Deben estudiarse con espermiograma (a partir de los 15

Tabla 24. Tipos de insulina y sus tiempos de acción

\begin{tabular}{|llccc|}
\hline Insulina & Tipo & Inicio de acción & Máxima acción & Duración de acción \\
NPH & Regular & $2 \mathrm{~h}$ & $6 \mathrm{~h}$ & $12 \mathrm{~h}$ \\
Glargina & Análogo de acción basal & $2 \mathrm{a} 4 \mathrm{~h}$ & Sin peak & $24 \mathrm{~h}$ \\
\hline Detemir & Análogo de acción basal & $15 \mathrm{a} 30 \mathrm{~min}$ & Sin peak & $12 \mathrm{~h}$ \\
Degludec & Análogo de acción basal & & Sin peak & $24-42 \mathrm{~h}$ \\
Cristalina & Rápida & $30 \mathrm{~min}$ & $3 \mathrm{~h}$ & $6 \mathrm{~h}$ \\
Lispro & Análogo de acción ultrarrápida & $<15 \mathrm{~min}$ & $30 \mathrm{a} 90 \mathrm{~min}$ & $4 \mathrm{~h}$ \\
Aspártica & Análogo de acción ultrarrápida & $<15 \mathrm{~min}$ & $30 \mathrm{a} 90 \mathrm{~min}$ & $4 \mathrm{~h}$ \\
Glulisina & Análogo de acción ultrarrápida & $10 \mathrm{a} 15 \mathrm{~min}$ & $30 \mathrm{a} 60 \mathrm{~min}$ & $4 \mathrm{~h}$ \\
\hline
\end{tabular}


años). Las mujeres tienen aparato genital normal, aunque hay una leve disminución de la fertilidad cuya causa no está clara y deben tener consejería genética.

\section{Compromiso otorrinlaringológico}

La fisiopatología de la FQ predispone a la inflamación crónica e infecciones recurrentes de la mucosa rinosinusal, causadas por acumulación de mucus y alteraciones anatómicas que disminuyen la ventilación de los senos y obstruyen sus ostium de drenaje.

\subsection{Sinusitis}

Frecuentemente los pacientes presentan compromiso sinusal pero un bajo porcentaje son sintomáticos $(10 \%)$. El compromiso rinosinusal puede causar exacerbaciones pulmonares al actuar como reservorio de patógenos Los signos clínicos frecuentes son cefalea, obstrucción nasal crónica, ronquido, anosmia, secreción purulenta, halitosis ${ }^{145}$

\section{Estudio por imágenes}

La radiografía de cavidades paranasales es de poco valor dado que la gran mayoría presenta ocupación sinusal, siendo la tomografía computarizada de cavidades paranasales ideal para la evaluación del compromiso sinusal. Se puede evidenciar la presencia de: mucoceles, esclerosis ósea, y alteraciones anatómicas como hipoplasia de cavidades perinasales o agenesia del seno frontal. Estos hallazgos en pacientes pediátricos deben hacer sospechar una FQ.

\section{Tratamiento}

Tratamiento médico: Lavados nasales de solución salina, descongestionantes nasales tópicos (uso máximo 7 días), orales y corticoides nasales. El tratamiento antibiótico es empírico con cobertura de, con una duración de 3 a 6 semanas, sólo en caso de tener síntomas. En seguimientos de 2 años el uso de tobramicina inhalada nasal ha demostrado reducir la recurrencia de sinusitis, la infección por $P$. Aeurginosa y la mejoría en calidad de vida. El uso de Alfa Dornasa intranasal durante 28 días con Pari Sinus ${ }^{\mathrm{R}}$ ha demostrado mejoría significativa de calidad de vida y de los síntomas.

Tratamiento quirúrgico: Infrecuente y está indicado en pacientes con fracaso a tratamiento médico, con buena adherencia, con persistencia de sus síntomas y mala calidad de vida, múltiples recurrencias con obstrucción del ostium radiológica y previo a trasplante pulmonar.

Evaluación debe ser por especialista en caso de recurrencia o mala evolución con tratamiento habitual.

\subsection{Poliposis nasal}

El diagnóstico es por observación directa de las fosas nasales. Frecuentemente asintomática, pero puede causar cefalea, obstrucción nasal crónica, ronquido, alteración del olfato $\mathrm{y}$ halitosis. Se considera un subgrupo de la rinosinusitis crónica y es de etiología incierta, sin embargo un factor de riesgo es la colonización por $P$. aeruginosa.

Se presenta en el 10\% de los niños mayores de 8 años y este porcentaje es mayor en los adultos El tratamiento médico es el uso de corticoides intranasales en pacientes sintomáticos, si no hay resultado debe derivarse al especialista. La intervención quirúrgica tiene alta recurrencia ${ }^{146}$.

\subsection{Ototoxicidad por aminoglucósidos ${ }^{147}$}

Incidencia varía entre 2 a $25 \%$. La amikacina, de amplio uso en la FQ, puede causar daño auditivo debido a la destrucción de células ciliadas externas por su lenta eliminación del órgano de Corti. La hipoacusia es generalmente bilateral simétrica y su momento de presentación es impredecible, desde la primera dosis hasta 6 meses después de la última dosis. Como factores de riesgo, son el uso prolongado, mayores dosis, mayores niveles séricos, edad avanzada, antecedente personal de hipoacusia, antecedente familiar de ototoxicidad, uso concomitante de diuréticos de asa $\mathrm{u}$ otros medicamentos ototóxicos o nefrotóxicos ${ }^{147}$. Se ha asociado más a una exposición prolongada que a niveles altos transitorios en suero. La administración de dosis diaria única del fármaco disminuye la ototoxicidad ${ }^{148}$.

En el estadio inicial, se afectan las frecuencias más altas y no se afecta la audición coloquial. El paciente puede referir tinitus y embotamiento auditivo, en general la hipoacusia pasa inadvertida. Si la toxicidad continúa, se afectan las frecuencias más bajas y la audición coloquial. La suspensión del tratamiento en forma precoz, puede determinar recuperación parcial de la audición, pero en general es irreversible.

Actualmente, el único tratamiento para el daño de la audición es el implante coclear, por lo que 
la prevención es clave. Ésta involucra monitorización de niveles séricos del fármaco, función renal, y evaluación auditiva antes, durante $\mathrm{y}$ después de la terapia. Los aminoglucósidos se mantienen en la cóclea por un largo tiempo luego del término del tratamiento, por lo que deben monitorizarse los efectos ototóxicos y evitar ambientes ruidosos por hasta 6 meses luego de terminada la terapia.

La N-acetilcisteína (NAC) tiene un efecto protector en un $80 \%$ de la sordera producida por aminoglucósidos en aquellos pacientes que reciben terapia prolongada (tratamiento para NTMB) o frecuente ${ }^{149}$.

Evaluación audiométrica se hará en pacientes que:

- Vayan a iniciar tratamiento prolongado EV para NTMB al ingreso y control anual.

- Que hayan recibido terapia con aminoglucósidos cada 3 meses.

- Pacientes que estando en tratamiento o que tienen el antecedente de haber tenido en la medición plasmática, niveles valle de aminoglucósidos altos.

\section{Otras manifestaciones en fibrosis quística}

\subsection{Artropatía}

Ocurre en el $10 \%$ de los pacientes entre los 13 y 20 años. Es una condición posiblemente mediada por complejos inmunes relacionada con la infección e inflamación crónica.

Clínicamente se presentan artritis de grandes articulaciones con fiebre baja, puede aparecer eritema nodoso, rash cutáneo o púrpura que responde bien a la terapia antiinflamatoria no esteroidal. La radiografía de articulaciones es normal.

Ocasionalmente (2 a 7\%) pueden presentar osteoartropatía hipertrófica en que además de la artritis hay compromiso periostal de huesos largos con traducción radiológica. En general se observa en pacientes con FQ severa ${ }^{150}$.

Hay que recordar que el ciprofloxacino puede causar tendinopatía tanto en niños como adultos con fibrosis quística.

\subsection{Compromiso renal ${ }^{151,152}$}

\section{Insuficiencia renal}

Los pacientes con fibrosis quística están en riesgo de presentar insuficiencia renal aguda y daño crónico ${ }^{151,153}$.

\section{Factores de riesgo}

- Exposición frecuente y a dosis altas de agentes nefrotóxicos como antibióticos (aminoglucósidos, ciprofloxacino, colistín, azitromicina, ceftazidima, sulfonamidas, rifampicina) inhibidores de la bomba de protones, diuréticos, antiinflamatorios no esteroidales y agentes inmunosupresores.

- La anormalidad en el trasporte de sal, colonización con $P$. eruginosa.

- Diabetes insulinodependiente relacionada a FQ.

Dado que los aminoglucósidos y la terapia inmunosupresora confieren mayor riesgo, la administración de aminoglucósidos en una dosis diaria reduce los niveles basales de la droga y la acumulación en el riñón permitiendo que los niveles peak altos alcanzados tengan efecto bactericida. La toxicidad está relacionada con el clearance o depuración renal y es dosis dependiente. Una estrategia para disminuir el riesgo es la administración vía nebulización.

Nota: La gentamicina es más nefrotóxica y por tanto no debe usarse.

En pacientes trasplantados, la disfunción renal aumenta con el tiempo, en aquellos de mayor edad y en las mujeres. El riesgo a 2 y 5 años post trasplante es de 35 y $58 \%$ respectivamente y $10 \%$ eventualmente requerirán diálisis. La diabetes mellitus asociada a FQ aumenta la posibilidad de daño renal lo que enfatiza la necesidad de un tratamiento precoz y agresivo.

\section{Nefrolitiasis y nefrocalcinosis ${ }^{152,153}$}

Los volúmenes bajos de orina asociados con pérdida de sal $(\mathrm{NaCl})$ y deshidratación, hiperoxaluria, hiperuricosuria y e hipercalciuria aumenta el riesgo. El uso de furosemida y prednisolona están asociados a hipercalciuria y la inmovilización con hipercalcemia e hipercalciuria.

El uso repetido de antibióticos lleva a la destrucción de bacterias intestinales que degradan oxalatos (Oxalobacter formignes), determinando la absorción intestinal mayor de oxalatos que cuando son re-excretados por la orina cristalizan y forman cálculos. La incidencia reportada de cálculos renales en FQ es del 6\% comparado con el $2 \%$ en población sana.

\section{Nefropatía por $\operatorname{Ig} A$}

Niveles elevados de IgA son hallazgos en FQ posiblemente secundarios a infecciones recurrentes e inflamación crónica. El depósito a nivel renal, sobre todo si se asocia a enfermedad he- 
pática que disminuye el clearance de complejos inmunes, puede ser causante de glomerulonefritis. La asociación de enfermedad autoinmune con FQ es de mal pronóstico.

\section{Medicina personalizada en fibrosis quística, o terapia moduladora del CFTR}

La nueva técnica del "Screening de Alto Rendimiento" para buscar moléculas que actúan al interior de la célula in vitro, generó la búsqueda acelerada de una terapia correctora de la falla molecular de la $\mathrm{FQ}^{154}$. En esta búsqueda de moduladores del CFTR, han aparecido varias sustancias y asociaciones de ellas, que corrigen (aumentan el tráfico intracelular del CFTR) y/o potencian (aumentan el tiempo de apertura del canal), permitiendo corregir el defecto básico de la enfermedad. Se abre así un horizonte de esperanza de encontrar un tratamiento definitivo de la FQ. Es el avance más importante del último tiempo en el manejo de esta enfermedad.

Los moduladores del CFTR que han sido aprobados para su uso en la actualidad se pueden dividir en:

\subsection{Correctores del CFTR}

Estas moléculas aumentan el tráfico de la proteína CFTR alterada, desde el núcleo celular hacia la membrana celular, a través del aparato de Golgi, impidiendo que las ubiquitinas la destruyan. Corresponden a este grupo: Lumacaftor, Tezacaftor, Elexacaftor, que actúan en las mutaciones de clase II, a la que pertenece F508del que es la más frecuente (Tabla 25).

\subsection{Potenciadores del CFTR}

Moléculas que inducen y mantienen la aper- tura del canal CFTR en la membrana celular. Ivacaftor es el primer y principal representante de los potenciadores, que actúan en la mayoría de mutaciones de tipo III y algunas de tipo IV. (Tabla 25).

La indicación y la eficacia de estas nuevas drogas depende de las mutaciones (variaciones genéticas) específicas de cada caso en particular, por lo que es condición previa para su indicación, contar con el registro de los 2 alelos en todos los pacientes y conocer así a qué clase específica de mutación pertenecen Para conocer la patogenicidad y frecuencia de las distintas mutaciones, se recomienda consultar la página web www.cftr2.org .

En Chile, donde aún no disponemos de estos medicamentos, se considerará para su uso los siguientes criterios:

1) Que hayan sido aprobadas por las agencias oficiales internacionales de medicamentos: Food and Drug Administration (FDA) y/o European Medicines Agency (EMA).

2) Que la evidencia demuestre diferencia suficiente en los parámetros de mejoría de función pulmonar, mejoría de los síntomas y reducción de las exacerbaciones pulmonares, por sobre lo obtenido con el tratamiento standard.

3) Que la evidencia demuestre seguridad y efectos secundarios mínimos y tolerables.

4) Que el paciente tenga adherencia al tratamiento estándar de la FQ, y sea confiable en el cumplimiento de las indicaciones.

5) Que el paciente tenga un daño pulmonar leve a moderado, con función pulmonar $\left(\mathrm{VEF}_{1}\right)$ $>40 \%$.

6) La indicación de terapia moduladora la deben realizar los equipos multidisciplinarios de los centros de FQ donde se controlan los pacientes. En el caso de los pacientes del sistema público de salud, la indicación deberá ser refrendada por la comisión técnica del Minsal.

En la Tabla 26 se muestran los moduladores disponibles actualmente y aprobados para su uso

Tabla 25. Clases de mutaciones del CFTR

\begin{tabular}{|c|c|c|c|c|c|c|c|}
\hline Clase & I & II & III & IV & $\mathbf{V}$ & VI & VII \\
\hline $\begin{array}{l}\text { Falla del } \\
\text { CFTR }\end{array}$ & $\begin{array}{l}\text { No se } \\
\text { produce } \\
\text { CFTR }\end{array}$ & $\begin{array}{c}\text { Falla de } \\
\text { tráfico en el } \\
\text { Golgi }\end{array}$ & $\begin{array}{c}\text { Falla de } \\
\text { apertura del } \\
\text { canal }\end{array}$ & $\begin{array}{c}\text { Disminución } \\
\text { de la } \\
\text { conductancia }\end{array}$ & $\begin{array}{c}\text { Escasa } \\
\text { proteína } \\
\text { CFTR }\end{array}$ & $\begin{array}{l}\text { Recambio } \\
\text { aumentado }\end{array}$ & $\begin{array}{c}\text { Ausencia } \\
\text { mRNA }\end{array}$ \\
\hline Ejemplos & $\begin{array}{c}\text { Gly542X } \\
\text { Trp1282X }\end{array}$ & $\begin{array}{l}\text { Phe508del } \\
\text { Asn1303Lys }\end{array}$ & $\begin{array}{l}\text { Gly551Asp } \\
\text { Ser549Arg }\end{array}$ & $\begin{array}{l}\text { Arg117His } \\
\text { Arg334Trp }\end{array}$ & $\begin{array}{c}\text { Ala455Glu } \\
3272-26 \\
\mathrm{~A} \rightarrow \mathrm{G}\end{array}$ & c. $120 \mathrm{del} 23$ & $\begin{array}{c}\text { Deleción } \\
\text { total o } \\
\text { parcial del } \\
\text { gen CFTR }\end{array}$ \\
\hline $\begin{array}{l}\text { Efecto } \\
\text { clínico }\end{array}$ & Severo & Severo & Severo & $\begin{array}{l}\text { Función } \\
\text { residual }\end{array}$ & $\begin{array}{l}\text { Función } \\
\text { residual }\end{array}$ & $\begin{array}{l}\text { Función } \\
\text { residual }\end{array}$ & Severo \\
\hline
\end{tabular}


Tabla 26. Moduladores aprobados por la FDA y sus indicaciones actuales (no disponibles en Chile)

\begin{tabular}{|c|c|c|c|c|c|c|}
\hline Genotipo & Grupo etario & $\begin{array}{l}\text { Elexacaftor } \\
\text { Tezacaftor } \\
\text { Ivacaftor } \\
\text { Trikafta }^{\circledR}\end{array}$ & $\begin{array}{l}\text { Tezacaftor } \\
\text { Ivacaftor } \\
\text { Symdeko }{ }^{\circledR}\end{array}$ & $\begin{array}{l}\text { Lumacaftor } \\
\text { Ivacaftor } \\
\text { Orkambi }{ }^{\circledR}\end{array}$ & $\begin{array}{l}\text { Ivacaftor } \\
\text { Kalideco }^{\circledR}\end{array}$ & $\begin{array}{l}\text { Sin terapia } \\
\text { moduladora } \\
\text { disponible }\end{array}$ \\
\hline \multirow[t]{3}{*}{ Homocigoto F508 } & 2 a 5 años & & & $\mathrm{X}$ & & \\
\hline & 6 a 12 años & $*$ & $\mathrm{X}$ & & & \\
\hline & $>12$ años & $\mathrm{X}$ & & & & \\
\hline \multirow{2}{*}{$\begin{array}{l}\text { Heterocigoto F508 sin } \\
\text { otra variante de apertura o } \\
\text { función residual }\end{array}$} & $<12$ años & & & & & $\mathrm{x}$ \\
\hline & $>12$ años & $X$ & & & & \\
\hline \multirow[t]{2}{*}{$\begin{array}{l}\text { Heterocigoto F508 CON } \\
\text { otra variante de apertura }\end{array}$} & $\begin{array}{l}6 \text { meses a } \\
11 \text { años }\end{array}$ & & & & X & \\
\hline & $>12$ años & $X$ & & & & \\
\hline \multirow{3}{*}{$\begin{array}{l}\text { Heterocigoto F508 CON } \\
\text { otra variante de función } \\
\text { residual }\end{array}$} & 6 meses a 5 años & & & & $\mathrm{X}$ & \\
\hline & 6 años a 12 años & & $\mathrm{X}$ & & & \\
\hline & $>12$ años & X & & & & \\
\hline $\begin{array}{l}\text { Variante de apertura sin } \\
\text { F508 }\end{array}$ & & & & & $\mathrm{X}$ & \\
\hline \multirow{2}{*}{$\begin{array}{l}\text { Variante de función residual } \\
\text { sin F508 }\end{array}$} & 6 meses a 5 años & & & & $\mathrm{X}$ & \\
\hline & $>6$ años & & $\mathrm{X}$ & & & \\
\hline
\end{tabular}

*En proceso de aprobación por la FDA al momento de esta publicación.

por la FDA hasta el momento. La indicación ha sido dinámica, a medida que se aprueban mejores moléculas y asociaciones. Es muy probable que, una vez que la triple asociación (Elexacaftor/ Tezacaftor/Ivacaftor) sea aprobada a edades menores, termine por reemplazar completamente a las de doble asociación (Tezacaftor o Lumacaftor más Ivacaftor), en pacientes con una o 2 mutaciones F508. La triple asociación ha demostrado una significativa mejor respuesta en todos los indicadores evaluados, tanto primarios como secundarios: mejoría en $\mathrm{VEF}_{1},(14 \%$ del predicho), reducción de las exacerbaciones, (caída de 63\%), mejoría en las encuestas de calidad de vida y en el índice de masa corporal. En este desarrollo dinámico, la asociación Tezacaftor/Ivacaftor ha reemplazado momentáneamente a Lumacaftor/ Ivacaftor por su mejor respuesta en homocigotos y heterocigotos F508del, pero la triple asociación los supera en todos los índices para ese grupo de pacientes. Ninguno de estos medicamentos está disponible aún en Chile.

\section{Indicaciones actuales de moduladores del CFTR}

Ivacaftor (Kalydeco $)^{155,156}$

Indicado en mutaciones "de apertura", que son aquellas que producen una proteína CFTR instalada en la membrana celular, pero que falla en abrirse y/o en mantenerse abierta para el paso del ion cloruro, originando formas severas de la enfermedad. Corresponden a la mayoría de las mutaciones de clase III y algunas de clase IV, y son específicamente: G551D, G551S, G1244E, G1349D, G178R, R117H, S1251N, S1255P, S549N, S549R, G1069R, R1070Q ${ }^{155-157}$.

\section{Dosificación}

Niños de 6 meses a 5 años: 5 a $7 \mathrm{~kg}$ de peso: sachet de $25 \mathrm{mg}$ oral cada $12 \mathrm{~h}$.

7 a $14 \mathrm{~kg}$ de peso: sachet de $50 \mathrm{mg}$ oral cada $12 \mathrm{~h}$.

Niños > 6 años: tabletas de $150 \mathrm{mg}$ cada $12 \mathrm{~h}$.

\section{Elexacaftor/Tezacaftor/Ivacaftor (Trikafta $\left.{ }^{R}\right)^{158}$}

Indicado en homocigotos y heterocigotos F508del, (mayores de 12 años al momento de esta revisión) ${ }^{158-160}$.

Dosificación en mayores de 12 años: 2 tabletas combinadas de Elexacaftor $100 \mathrm{mg} /$ Tezacaftor 50 $\mathrm{mg} /$ Ivacaftor $75 \mathrm{mg}$ en la mañana, 1 tableta de Ivacaftor $150 \mathrm{mg}$ en la noche.

Tezacaftor/Ivacaftor $\left(\text { Symdeko }{ }^{R}\right)^{159,161,162}$

Indicado en mutaciones de "función residual" 
$\sin$ F508del. Son aquellas mutaciones en las cuales la falla del CFTR permite cierto grado de función del canal, por lo que el fenotipo resultante es de menor severidad, manifestándose frecuentemente como formas de FQ con suficiencia pancreática, habitualmente de diagnóstico más tardío, menos sintomáticas y con menos frecuencia de infecciones por $P$. aeruginosa $a^{162}$. Corresponden a mutaciones de clase IV, V y VI (Tabla 25).

Dosificación: Niños 6 a 11 años o $<$ de $30 \mathrm{~kg}$ de peso: 1 tableta combinada Tezacaftor $50 \mathrm{mg} /$ Ivacaftor $75 \mathrm{mg}$ en la mañana, 1 tableta Ivacaftor $75 \mathrm{mg}$ en la noche.

Niños $>12$ años, o $>30 \mathrm{~kg}$ de peso: 1 tableta combinada Tezacaftor $100 \mathrm{mg} /$ Ivacaftor $150 \mathrm{mg}$ en la mañana, 1 tableta Ivacaftor $150 \mathrm{mg}$ en la noche.

\section{Transición a centro de adultos}

El diagnóstico precoz y los avances en el tratamiento de la FQ han determinado un aumento en las expectativas de vida en estos pacientes, cada vez más complejos. La transición es un camino hacia la maduración, independencia y responsabilidad que ocurre a partir de la infancia. El cambio de un modelo pediátrico de atención a uno adulto debe ser un proceso planificado para evitar que se pierda el seguimiento, la adherencia al tratamiento y permitir que se generen lazos con el nuevo equipo ${ }^{163}$. Esta etapa requiere que sea un proceso coordinado, planificado, flexible y gradual que involucre a los integrantes de ambos equipos de salud, al paciente y su familia. La transición involucra cambios: nuevas expectativas, nuevas responsabilidades, implica dejar atrás años de dependencia de un equipo de salud pediátrico.

El cuidado de la transición es un componente clave de la calidad de atención. Los adolescentes y sus padres necesitan tiempo para prepararse e información sobre cómo y cuándo será el proceso, quien los atenderá y dónde.

\section{Planificación de la transición}

La transición no corresponde a un día específico, sino a un período de traspaso, que requiere de preparación de todos quienes se involucran en el cuidado, incluso del paciente.

El período de traspaso se recomienda que ocurra durante la adolescencia, comenzando el proceso de preparación desde los 14 años, aunque la información a los padres y al paciente se debe iniciar alrededor de los 10 años. Esto permite que los padres tengan una visión más esperanzadora sobre la sobrevida del niño.

Se recomienda que el cuidado pediátrico sea hasta los 18 años, con un proceso de transición entre los 14 y 18 años, con programas individuales y adaptados a las necesidades identificadas en cada paciente y su familia.

\section{Formación de los equipos}

Un programa de transición debe comprender trabajo en equipo multidisciplinario.

Equipo de salud pediátrico: procurará desde el diagnóstico un conjunto de prácticas que permitan entregar al paciente y su familia conocimientos sobre su enfermedad, manejo de su tratamiento y la importancia del autocuidado.

A partir de los 14-15 años el paciente debe iniciar entrevistas sin sus padres. El pedíatra debe presentar el nuevo equipo de salud al paciente y su familia.

Equipo de salud adultos: Debe estar preparado para atender a jóvenes con distintas experiencias de atención, con un largo recorrido en establecimientos de salud, con la vivencia de hospitalizaciones frecuentes y con familiares altamente conocedores de la patología.

El médico de adultos debe informar al paciente los planes de tratamiento, reforzar la adherencia adaptándose a las capacidades del paciente.

Ambos equipos deben trabajar en conjunto $\mathrm{y}$ en red, de manera de obtener una transición planificada, transfiriendo los cuidados en forma ordenada, informada y gradual.

\section{Traspaso de la información}

La responsabilidad del equipo pediátrico es llevar una ficha médica actualizada con información demográfica, nutricional, función pulmonar, bacteriología y tratamiento actualizado; además de los aspectos psicológicos relevantes del paciente y su familia. Esta ficha se recomienda que sea parte de un sistema de informático.

\section{Requerimientos para una transición exitosa ${ }^{163-164}$}

El paciente debe:

- Estar en conocimiento completo de su enfermedad y sus complicaciones.

- Participar activamente en desarrollar su plan de atención médica con el equipo de FQ.

- Asistir a su control médico.

- Ser capaz de verbalizar la lista de medicamentos, terapias y de informar falta de ellos.

- Solicitar hora para su control médico y exámenes.

- Reconocer signos de exacerbación o compli- 
caciones y saber contactarse con el equipo de salud para informar el problema.

- Identificar las situaciones que requieren un contacto inmedíato con servicio de urgencia más cercano a domicilio y que se encuentre en conocimiento que es un paciente FQ.

\section{Traslado definitivo a hospital de adultos ${ }^{163}$}

Pacientes mayores de 18 años atendidos en hospitales pediátricos serán trasladados en forma definitiva a un hospital de adultos una vez cumplido el proceso de transición. Las excepciones deben ser calificadas por el equipo de adulto para su eventual aceptación (enfermedad terminal).

La petición de traslado quedará a cargo del equipo médico y enfermera GES de hospital de origen cuando sean derivados a otros establecimientos, conforme a flujos establecidos por hospital de adultos.

Evaluación de pacientes con $F Q$ en fase avanzada al Instituto Nacional del Tórax (INT)

Se considera pacientes con enfermedad pulmonar en fase avanzada:

- $\mathrm{VEF}_{1}<40 \%$ de predicho en fase estable de enfermedad.

- Que cumpla una o más de las siguientes características:

1. Admisión a unidad de cuidados intensivos por falla respiratoria.

2. Hipercapnia con $\mathrm{PaCO}_{2}>50 \mathrm{mmHg}$.

3. Insuficiencia respiratoria oxigeno dependiente.

4. Hipertensión pulmonar (presión sistólica de arteria pulmonar en ecocardiograma $>50 \mathrm{mmHg}$ ).

5. Falla respiratoria que requiera ventilación mecánica no invasiva (VMNI).

6. Severa alteración funcional por enfermedad respiratoria con capacidad funcional IV.

7. Distancia recorida en test de caminata de 6 min: $<400$ metros.

Tabla 27. Marcadores pronósticos en fibrosis quística

$<400 \mathrm{~m}$ en test de marcha $6 \mathrm{~min}$

Hipoxemia $\left(\mathrm{SpO}_{2}<88 \%\right.$ o $\left.\mathrm{PaO}_{2}<55 \mathrm{mmHg}\right)$ en reposo o con ejercicio

Hipercapnia $\left(\mathrm{PaCO}_{2}>50 \mathrm{mmHg}\right.$ confirmada en gasometría arterial)

Hipertensión pulmonar (PsAP $>50 \mathrm{mmHg}$ en ecocardiograma)

Índice de masa corporal $<18 \mathrm{~kg} / \mathrm{m}^{2}$
Los pacientes en fase avanzada (Tabla 27) serán evaluados en el INT por médico encargado de $\mathrm{FQ}$, quien determinará la pertinencia del control transitorio o traslado definitivo. Previamente se cursará una interconsulta e informe vía correo electrónico a la enfermera encargada del programa FQ y a la enfermera GES (garantías explicitas en salud).

Según criterio clínico y los antecedentes del paciente existen tres alternativas:

1. Ingresar formalmente a control regular (población) y tratamiento en INT.

2. Ser derivado al programa de trasplante pulmonar del INT con comunicación estrecha con el hospital de origen, donde se realizará el estudio pre-trasplante.

3. Seguir controles en el hospital de origen con seguimiento ocasional en el INT.

\section{Trasplante pulmonar}

La enfermedad pulmonar avanzada permanece como la principal causa de morbimortalidad en pacientes con FQ

Los objetivos del trasplante pulmonar (TP) son prolongar la supervivencia y mejorar la calidad de vida del paciente ${ }^{164}$. Es esencial entender que el trasplante es un proceso que requiere el compromiso del médico, del hospital que deriva al paciente, del equipo multidisciplinario del centro de trasplante y del propio paciente. Es necesario tener soporte social y familiar pre y post trasplante. La evaluación adecuada del paciente permitirá decidir de mejor manera el momento óptimo de inclusión a lista para trasplante. El objetivo no es trasplantar al paciente ni muy precoz dentro de la evolución de su enfermedad, ni muy tardíamente donde el paciente se encuentre con riesgo operatorio muy alto o posibilidades de supervivencia a corto y mediano plazo mínimas ${ }^{165}$.

La derivación oportuna permite al paciente y familia conocer los riesgos y beneficios, otorga el tiempo necesario para un completo estudio del potencial candidato, identificar contraindicaciones y condiciones clínicas susceptibles de modificar y corregir (estado nutricional y diabetes mal controlada) pre trasplante. La derivación tardía puede asociarse a mayor riesgo de mortalidad en lista de espera o mayor riesgo de morbimortalidad en el post operatorio inmediato.

En el año 2019 la Fundación de Fibrosis Quística Americana (CFF) da recomendaciones en relación a trasplante pulmonar ${ }^{164}$ :

1- En pacientes con $\mathrm{VEF}_{1}<50 \%$ del predicho, discutir sobre TP como una potencial opción tera- 
péutica (discusión precoz).

2- Barreras para el trasplante deberían ser identificadas precozmente en los centros de FQ y tratar de optimizarlas: adherencia, factores psicológicos, estado nutricional, inactividad física, soporte social, distancia geográfica.

\subsection{Criterios de referencia en pacientes con FQ}

\section{Mayores de 18 años}

$\mathrm{VEF}_{1}<50 \%$ del predicho y con rápido deterioro (declinación $>20 \%$ del $\mathrm{VEF}_{1}$ en los últimos 12 meses).

$\mathrm{VEF}_{1}<40 \%$ del predicho con marcadores de menor supervivencia (Tabla 28). $\mathrm{VEF}_{1}<30 \%$.

\section{Menores de 18 años}

1. $\mathrm{VEF}_{1}<50 \%$ del predicho y rápido deterioro (declinación $>20 \%$ del $\mathrm{VEF}_{1}$ en los últimos 12 meses).

2. $\mathrm{VEF}_{1}<50 \%$ del predicho con marcadores de menor supervivencia (Tabla 1).

3. $\mathrm{VEF}_{1}<40 \%$.

Los niños con FQ tienden a tener menor sobrevida comparados con adultos con igual $\mathrm{VEF}_{1}$ del predicho por lo que se recomienda referirlos más precozmente.

\section{Otros criterios de referencia ${ }^{164}$}

1 . $\mathrm{VEF}_{1}<40 \%$ del predicho y $>2$ exacerbaciones por año que requieran antibióticos endovenosos o 1 exacerbación severa que requiera ventilación mecánica invasiva o no invasiva.

2. Pacientes con $\mathrm{VEF}_{1}<40 \%$ del predicho y hemoptisis masiva que requiera admisión en unidad de intensivo o embolización de arterias bronquiales.

3. Pacientes adultos con índice de masa corporal $<18$ y $\mathrm{VEF}_{1}<40 \%$.

4. Neumotórax refractario o recurrente.

El neumólogo debe conocer no sólo cuando referir al paciente, sino también estar familiarizado con los requisitos y contraindicaciones generales para enviar a un paciente a un centro de trasplante ${ }^{165}$.

\subsection{Contraindicaciones para trasplante}

\section{Contraindicaciones absolutas}

1. Historia de cáncer en los últimos 5 años, con excepción de tumores de piel basocelular o escamoso en donde se acepta período libre de enfermedad de 2 años.

2. Disfunción avanzada e intratable de otro órgano (corazón, riñón, cerebro, etc).

3. Infección crónica por gérmenes resistentes no posibles de ser controlados pretrasplante o cuadro infeccioso agudo no controlado por antibióticos.

4. Tuberculosis activa.

5. Deformidad espinal o de pared torácica significativa.

6. Historia de no adherencia o incapacidad de seguir tratamiento o controles.

7. Ausencia de soporte social y/o familiar adecuado y confinable.

8. Condición psiquiátrica intratable con falta de cooperación que aumente el riesgo de no adherencia post trasplante.

9. Adicción activa a sustancias como el alcohol, tabaco y drogas en los últimos 6 meses.

10. Severa limitación funcional que impida proceso de rehabilitación pre trasplante.

\section{Contraindicaciones relativas}

1. Edad $>65$ años.

2. Desnutrición severa o progresiva a pesar de una intervención óptima.

3. Osteoporosis severa sintomática (fractura ósea).

4. Cirugía torácica previa con resección pulmonar.

5. Ventilación mecánica invasiva (VMI) y/o ECMO (Oxigenación por membrana extracorpórea). Los pacientes en lista de espera pueden presentar agravamiento de su enfermedad y requerir ingreso a unidad de cuidados intensivos con posibilidad de necesitar VMI o ECMO. Este último soporte debe considerarse como algo excepcional y debería realizarse en centros con experiencia en manejo de este tipo de técnica.

6. Pacientes con infección por virus hepatitis $\mathrm{C}$, virus hepatitis $\mathrm{B}, \mathrm{VIH}$.

7. Infección con bacterias, hongos y/o ciertas cepas de micobacterias no TBC multiresistentes o altamente virulentas.

8. Infección por Burkholderia cenocepacia, Burkholderia gladioli y Micobacterias abscessus (gran parte de los programas lo considera una contraindicación absoluta).

9. Condiciones médicas mal controladas: diabetes mellitus, reflujo gastroesofágico, enfermedad hepática avanzada.

Si bien, estos puntos son considerados contraindicaciones relativas por la Sociedad Internacional de Trasplante de Corazón y Pulmón, la decisión final de ingreso a lista será del equipo 
multidisciplinario del centro de referencia para trasplante pulmonar.

Después de un estudio acucioso del candidato, la decisión de enlistar a un paciente con FQ es compleja y debería considerar la tasa de declinación de la función pulmonar, la frecuencia de exacerbaciones y el desarrollo de insuficiencia respiratoria e hipertensión pulmonar.

\subsection{Criterios de inclusión para colocar en lista de trasplante pulmonar ${ }^{166}$}

1. Insuficiencia respiratoria crónica:

- Con $\mathrm{PaO}_{2}<60 \mathrm{mmHg}$

- Con $\mathrm{PaCO}_{2}>50 \mathrm{mmHg}$

2. Usuario crónico de ventilación mecánica no invasiva.

3. Pacientes con hipertensión pulmonar.

4. $\mathrm{VEF}_{1}<30 \%$ del predicho o rápido deterioro de la función pulmonar.

5. Exacerbación reciente que requirió ventilación mecánica.

6. Neumotórax refractario o recurrente.

7. Hemoptisis recurrente a pesar de embolización.

8. Exacerbaciones frecuentes con pérdida acelerada de función pulmonar y alteración de calidad de vida, con pobre recuperación entre exacerbaciones.

La mediana sobrevida post trasplante en FQ es de 9,5 años, mejor que cualquier otra patología candidata a trasplante. Las principales causas de muerte dentro del primer año son la infección y falla primaria del injerto. Después del primer año las causas de muerte son principalmente por disfunción crónica del injerto pulmonar y las infecciones.

En resumen, el TP es una opción de tratamiento en pacientes con FQ y enfermedad pulmonar avanzada. La derivación a un centro de trasplante debe ser precoz en el curso de la enfermedad y una estrecha colaboración es necesaria entre el hospital que deriva y el centro de referencia para trasplante.

\section{Mail contacto:}

joelmelot@hotmail.com

edonoso@torax.cl

\section{Cuidados paliativos en fibrosis quística}

La OMS ha definido el cuidado paliativo (CP) como una especialidad médica interdisciplinaria cuyo objetivo es prevenir y aliviar el sufrimiento, mejorando la calidad de vida en pacientes con enfermedades terminales ${ }^{167}$.

Este cuidado debe ser aplicado a pacientes y familiares en todos los estados de la enfermedad y no limitado a la condición terminal; de hecho en el CP pediátrico de enfermedades crónicas y potencialmente progresivas como la $\mathrm{FQ}$, la paliación debería iniciarse al momento del diagnóstico.

El principal objetivo del cuidado paliativo (CP) es el manejo y alivio sintomático; implementando planes de cuidados relacionados con los valores y preferencias del paciente. El CP está centrado en el paciente y su familia, debe optimizar la calidad de vida, prevenir y tratar el sufrimiento.

El término familia se usa en forma independiente de la edad y filiación.

El CP debe ser un continuo durante la enfermedad considerando aspectos terapéuticos, psicosociales, emocionales y espirituales ${ }^{168}$, facilitando la autonomía del enfermo crónico, acceso a la información y preferencias.

\section{Equipo de cuidado paliativo}

Médico: El equipo tratante de FQ debe establecer vínculo de con médico de familia o médico de la Atención Primaria en Salud (APS) que puede capacitarse con los equipos de paliativo no-oncológico ${ }^{169}$, para ofrecer el soporte básico en alivio de la disnea, dolor, fatiga, tos y secreciones.

Psiquiatra y psicoterapeuta: Los pacientes tienen una alta carga de síntomas y tratamientos que ocupan buena parte de su día. Esta condición deteriora su calidad de vida y adherencia a tratamiento, provoca síntomas de ansiedad, insomnio y depresión ${ }^{170}$ que requieren del manejo de un equipo de salud mental entrenado en este tipo de enfermos.

Kinesiólogo(a): ver kinesioterapia.

Enfermera: Capacitada en paliativo no-oncológico que pueda hacer la visita domiciliaria al paciente y sus familiares idealmente 2 veces por semana en la etapa final de la enfermedad.

Terapeuta ocupacional: Encargado de programar actividades de interés y distracción.

Trabajador(a) social: Evalúa e informa los aspectos sociales del paciente, familia y entorno.

La paliación debe cursar en paralelo con las terapias propias de la enfermedad.

Los equipos de FQ deben comprender las 
posibilidades y limitaciones de sus tratamientos, deben trabajar en conjunto con pacientes y familiares en un plan al final de la vida, proveyendo alivio y no limitando el uso de analgesia y sedación.

La falla respiratoria es la causa de muerte más común en paciente $\mathrm{FQ}$ y muchos pacientes fallecen ventilados en UCI en espera de trasplante sin haber planificado sus tratamientos al final de la vida ${ }^{171}$. Menos del $25 \%$ de los pacientes han expresado hasta cuando mantener las terapias. Los pacientes candidatos a trasplante no deben excluirse del CP.

El CP pediátrico es una actividad de cuidado del cuerpo, mente y espíritu del niño e involucra darle soporte a la familia. Esta intervención tiene que estar relacionada con el nivel de habilidades cognitivas y madurez emocional del niño o adolescente.

\section{Intervenciones de manejo no farmacológicas}

- Terapias de relajación, masajes, acupuntura, yoga.

- Actividades diarias con técnicas de manejo de la fatiga y ansiedad. Proponer objetivos realizables de la vida diaria que mejoren su ánimo (lavado de pelo en las adolescentes).

- Aire fresco (con ventanas abiertas o ventiladores y abanicos).

- Actividades de índole religioso o espiritual de acuerdo con la creencia del paciente y familiares.

- Desarrollo de aplicaciones vía Smartphone $e^{172}$ que contribuyan a aliviar la depresión y aislamiento social en pacientes jóvenes con enfermedad avanzada.

\section{Intervenciones farmacológicas}

La disnea es el síntoma cardinal, presente en el 90\% de los casos de la enfermedad avanzada. Los opiáceos ${ }^{173}$ son significativamente mejores que el oxígeno para el manejo de la disnea refractaria, tanto en pacientes hipoxémicos como no-hipoxémicos.

\section{Morfina}

Dosis en niños: $0,1 \mathrm{mg} / \mathrm{kg}$ cada 4 a $6 \mathrm{~h}$ oral titulando la dosis.

Dosis en adolescentes y adultos: 2,5 a $5 \mathrm{mg}$ oral cada 4 a $6 \mathrm{~h}$ oral titulando la dosis.

En los equipos de CP disponemos de Oramo$\mathrm{ph}^{\circledR}$ (morfina sulfato solución oral) $20 \mathrm{mg} / \mathrm{ml} \mathrm{y}$ Samor ${ }^{\circledR}$ (solución de morfina clorhidrato) $10 \mathrm{mg} /$ $\mathrm{ml} \mathrm{y} 20 \mathrm{mg} / \mathrm{ml}$.

En la condición terminal se indica morfina en infusión continua con 30 a $50 \%$ de la dosis total que se administra por vía oral.

Manejo de la ansiedad e insomnio: Pueden asociarse a la morfina, benzodíacepinas como lorazepam, midazolam. No hay acuerdo en la literatura respecto a la mejor vía de administración.

\section{Oxígeno paliativo}

La necesidad del aporte de oxígeno no se correlaciona con la severidad de la disnea en el paciente con disnea refractaria. La oxigenoterapia es un elemento más en el $\mathrm{CP}$ de estos pacientes y su indicación forma parte de las buenas prácticas $^{172}$

\section{Salud mental}

De mucha importancia es que los centros que controlan pacientes con FQ cuenten con psicólogo clínico que aborde distintos aspectos que tienen repercusión psicológica y que formen equipo con psiquiatras que deben manejar patología más severa. Variados estudios han demostrado que los pacientes y familias con enfermedades crónicas, tienen riesgo elevado de depresión y ansiedad. La FQ es una de las patologías crónicas más difíciles de manejar con pronóstico reservado y tratamiento que consume muchas horas diarias.

La prevalencia de depresión fluctúa entre $8 \%$ al $28 \%$ en niños y adolescentes y alrededor del $33 \%$ en adultos. Los cuidadores también presentan cifras elevadas del 20 al 35\%. El riesgo de suicidio, componente central de la depresión, corresponde a un 1,6\% de las muertes por FQ (Cystic Fibrosis Foundation (CFF) Registry data $)^{174}$.

Es importante destacar que los síntomas psicológicos se han asociado con compromiso de la calidad de vida, disminución de la función pulmonar, compromiso nutricional, mala adherencia al tratamiento, hospitalizaciones más frecuentes por exacerbaciones respiratorias y aumento de costos en salud.

Dado que la sobrevida ha aumentado, esta intervención debe ser planificada, continua y de largo plazo $^{175}$.

\section{Objetivos}

- Aceptación del diagnóstico reciente.

- Ayudar al paciente y la familia a entender la enfermedad y a cooperar con el tratamiento.

- Ayudar al paciente y a la familia a adaptarse emocionalmente.

- Mejorar la adherencia al tratamiento, especialmente en adolescentes y adultos.

- Enfrentar las fobias y temores (punciones, 
intervenciones invasivas).

- Intervenir en las alteraciones de la alimentación.

- Considerar la posibilidad de trasplante.

- Enfrentar la muerte.

La evaluación sistemática de los síntomas con intervención apropiada, ofrece la oportunidad estar alerta para un tratamiento adecuado cuando la sintomatología es de riesgo.

\section{Enfermería en la atención de pacientes con fibrosis quística}

El objetivo general de la atención de enfermería en el programa de $\mathrm{FQ}$ es entregar una atención integral y personalizada al paciente y a su familia, desde un enfoque biopsicosocial ${ }^{107,176}$.

La labor del profesional de enfermería resulta imprescindible para la gestión de los cuidados y la articulación con la red asistencial.

Las principales actividades que debe realizar la enfermera/o son:

1. Coordinación y gestión administrativa.

2. Supervisión del cumplimiento de las medidas de aislamiento en paciente ambulatorio.

3. Control clínico.

4. Educación.

5. Procedimientos.

6. Manejo de equipos e insumos.

\subsection{Coordinación y gestión administrativa}

El profesional de enfermería en FQ cumple el rol de coordinador del equipo de salud, gestiona la atención oportuna con los profesionales de distintas especialidades, es intermedíario entre paciente y familia y el resto del equipo de FQ y es facilitador del acceso del paciente a las distintas prestaciones contenidas en la canasta de FQ.

En la gestión administrativa el profesional de enfermería deberá:

- Recibir y orientar en el flujo de atención a los pacientes que ingresan al programa.

- Coordinar horas de control que permitan asegurar la atención oportuna con los diferentes integrantes del equipo de salud.

- Ser nexo entre la familia y equipo tratante, a través de una comunicación presencial o contacto telefónico.

- Coordinar en todos los niveles de la red asistencial la atención que el paciente de FQ requiera.

- Gestionar hospitalizaciones en unidad de aislamiento.
- Asegurar continuidad de la atención en pacientes hospitalizados, medíante la entrega de antecedentes clínicos relevantes.

- Hacer seguimiento del calendario de vacunación del Programa Nacional y especiales y coordinar la administración con vacunatorio si corresponde.

- Gestionar solicitud de insumos específicos de FQ y control de stock.

- Coordinar con farmacia entrega de medicamentos mensuales y de fármacos de entrega excepcional.

- Generar canales de comunicación intersectorial (colegios, jardín, universidad, trabajo) para dar continuidad de los cuidados.

- Coordinar el proceso de transición y traslado de paciente al Centro de Adulto.

16.2 Supervisión del cumplimiento de las medidas de aislamiento en paciente ambulatorio $^{177}$

Es función de enfermería proporcionar los insumos necesarios y velar por el cumplimiento de las medidas de prevención y control de infecciones asociadas a la atención en salud, es responsabilidad de cada miembro del equipo aplicarlas. Estas son:

- Lavado de manos, en los 5 momentos definidos para realizarlo. Uso de pechera y guantes de procedimiento.

- Uso de mascarilla quirúrgica por el paciente con FQ para circulación en establecimientos de salud. Uso de mascarilla N95 en pacientes con sospecha de TBC.

- Separación por al menos 2 metros de distancia entre pacientes, independiente de su microbiología.

- El paciente debe mantenerse en un box y el equipo tratante rotara para las atenciones.

- Realizar aseo del box entre la atención de cada paciente.

- Asegurar disponibilidad de recursos para realizar atención de pacientes utilizando las medidas de aislamiento correspondientes.

- Realizar evaluación mensual de cumplimiento de medidas de aislamiento por parte del equipo de salud de cabecera.

- Notificar a unidad de IAAS (Infecciones asociadas a la atención en salud) cuando se detecte a algún paciente cursando infección por microorganismo resistente.

\subsection{Control clínico}

Se realiza valoración del estado de salud del 
paciente y planificación de los cuidados. Es muy útil la aplicación del cuestionario de salud que posteriormente es revisado por el médico y comentado con el paciente y su familia (Anexo 1).

El control de enfermería debe contemplar diversas actividades de acuerdo a la condición del paciente:

- Asegurar uso de box exclusivo por paciente, supervisar aseo de superficies entre cada atención (según recomendación sobre aseo y desinfección de superficies ambientales).

- La atención directa al paciente se debe efectuar utilizando pechera manga larga y guantes de procedimientos.

- Realizar entrevista inicial, control de signos vitales y seguimiento de condición clínica con un registro de resultado de la función pulmonar, estado nutricional, microbiología y adherencia al tratamiento.

- Pesquisar en control, complicaciones propias de la enfermedad o patologías concomitantes, e informar al médico tratante.

- Responder consultas del paciente y familia que surjan en cada visita, ya sea del ciclo vital o de enfermedad, asegurando confidencialidad y empatía.

- Identificar factores de riesgo de la esfera psicosocial que afectan la adherencia al tratamiento y planificar intervención o derivación si corresponde.

- Verificar estado y vigencia de equipos y coordinar o realizar cambios según necesidad o según lo definido en canasta GES de FQ.

\subsection{Educación ${ }^{107}$}

La educación constituye un pilar fundamental del tratamiento. Es un proceso multidiciplinario liderado por le enfermera quien deberá velar por el cumplimiento de los objetivos.

"La tarea del educador no es imponer lo que debe hacer la persona, sino facilitar el proceso de aprendizaje y el cumplimiento de los objetivos, logrando que las personas desarrollen las capacidades necesarias para tomar decisiones conscientes y autónomas sobre su propia salud"

Enfermería debe contar con programas educativos para el personal y otros profesionales implicados en la atención de pacientes con este diagnóstico.

Este es un proceso continuo, secuencial y planificado (Figura 4) en el cual el paciente y su familia participan activamente en el control y toma de decisiones de su salud.

Al momento de planificar la educación es importante considerar las diferentes etapas del ciclo vital y evolución de la enfermedad.

\section{Educación en la etapa del diagnóstico}

En esta etapa se genera angustia, incertidumbre y dudas siendo fundamental favorecer un ambiente acogedor que permita al paciente y cuidador ser capaces de recibir y comprender la información proporcionada, muchas veces desconocida para ellos.

Los objetivos son educar para:

- Comprender los conceptos básicos de la enfermedad.

- Internalizar la importancia de la nutrición, kinesioterapia y adherencia al tratamiento. Identificar los medicamentos de uso crónico.

- Enseñar cómo administrar correctamente sus medicamentos y en los horarios establecidos.

\section{Educación en la niñez, hasta los 12 años}

Es importante considerar que en la primera etapa la educación será básicamente para los padres y tutores, una vez que el niño tiene la ma-

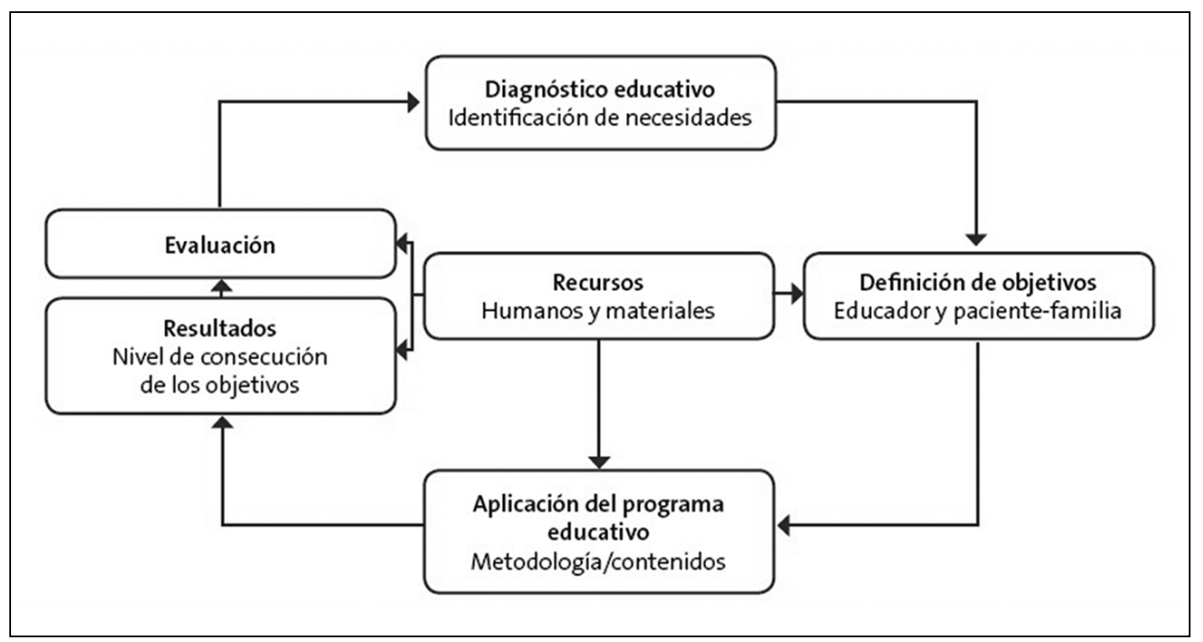

Figura 4. Secuencia educativa realizada por enfermería. 
durez suficiente se debe incorporar al aprendizaje. Los objetivos son:

- Conocer con mayor profundad la patología y su manejo.

- Conocer los medicamentos indicados.

- Reconocer signos y síntomas de descompensación.

- Lograr equilibrio entre tratamiento y rutina familiar/ escolar.

- Lograr adherencia al tratamiento y controles.

- Establecer compromisos y responsabilidades compartidas.

- Comprender la importancia de la actividad física e incorporarla a su rutina.

Se deberá informar al establecimiento educacional sobre el cuidado del paciente.

\section{Educación en la adolescencia}

En esta etapa, la educación es enfrentar desafíos que van más allá de transmitir información y compartir conocimientos específicos; sino más bien generar cambios de actitud y comportamiento que permita una buena adherencia y un proceso de toma de decisiones que permita un buen autocuidado y preparación para la edad adulta.

Los objetivos son:

- Desarrollar progresivamente autonomía en el manejo de su tratamiento.

- Reconocer signos y síntomas de descompensación y dar aviso oportuno.

- Comprender la importancia de la actividad física e incorporarla a su rutina.

- Manejar conceptos básicos en relación a sexualidad y reproducción en FQ.

- Establecer proyección a futuro.

\section{Educación en la adultez.}

La educación en la edad adulta debe considerar las necesidades, intereses y expectativas de los pacientes.

Los objetivos son:

- Lograr completa autonomía en el manejo de su patología.

- Integrar el tratamiento a la rutina.

- Mantener actividad física según condición clínica.

- Lograr independencia en la toma de decisiones con respecto a su futuro, que favorezca un equilibro entre el cuidado de su salud y las metas que desea alcanzar.

\subsection{Procedimientos:}

Algunos pacientes con FQ son usuarios de dispositivos de alimentación enteral (gastrostomías, sondas naso enterales) y de catéter venoso central.

\section{Gastrostomía $^{178}$}

En pacientes con diagnóstico de FQ con indicación de nutrición enteral, la pauta alimentaria será entregada por especialista en nutrición y reforzada por el profesional de enfermería. La administración de la alimentación puede ser intrahospitalaria o domiciliaria, en ambos casos se debe considerar:

- Revisión de la indicación médica, recordar que el paciente debe recibir enzimas pancreáticas.

- Lavarse las manos antes y después de la manipulación.

- Conectar la sonda de alimentación a una jeringa grande (50 a $60 \mathrm{ml}$ ) la leche debe bajar a caída libre por acción de la aceleración de gravedad, no empujar el émbolo para evitar distensión abdominal brusca.

- Llenar el balón con cantidad de agua bidestilada según indica proveedor del dispositivo.

- Identificar lumen del cuff.

- Previo a comenzar la alimentación de debe aspirar sonda de gastrostomía; si existe presencia de contenido alimentario más del $10 \%$ se debe esperar una hora para administrar alimentación que corresponda y aspirar nuevamente para asegurar que el contenido gástrico es menor al 10\%.

- Elevar la cabecera a $30-45^{\circ}$, posición semi fowler durante la alimentación y dejarla hasta una hora después de alimentarse.

- Si el paciente se encuentra imposibilitado de recibir suplementación enzimática por vía oral, se puede administrar las enzimas pancreáticas en bolo activándolas previamente con bicarbonato de sodio al 8\% (la cantidad de bicarbonato va a depender de la dosis de enzimas, generalmente se usa entre 2 y $10 \mathrm{ml}$ ), dejándolas reposar durante 15 a 20 min. Considerar en este caso alimentación inmedíata.

- En caso de alimentación enteral continua programar administración de enzimas pancreáticas $50 \%$ al inicio y el resto a la mitad del tiempo programado.

- Administrar agua hervida tibia posterior a la alimentación: niños pequeños 10 a $20 \mathrm{ml}$ y niños mayores: $20-50 \mathrm{ml}$.

- No mezclar alimentación con medicamentos.

- Evaluar si los fármacos indicados pueden ser triturados para su administración enteral.

- En sonda de gastrostomía (GTT) mantener el tope fijo a la pared del abdomen, con distancia mínima que permita su rotación diaria, al igual que botón de GTT para prevenir lesiones por presión. 
Uso de tela hipo alergénica (Micropore) para inmovilización de sonda por sobre el tope. Evitar el uso de gasas alrededor de la sonda que favorezcan humedad.

- Limpiar la piel alrededor de la sonda de GTT 1 a 3 veces al día con jabón de $\mathrm{pH}$ neutro y agua. Secar en forma suave para evitar la maceración e infección.

- Girar el botón de GTT una vez al día en el sentido de las agujas del reloj.

- Se debe verificar mensualmente que el cuff tenga la cantidad de agua destilada colocada en la instalación.

- Evaluar en el sitio de inserción:

- Observar presencia de secreciones, inflamación, mal olor, enrojecimiento alrededor del dispositivo.

- Alteraciones en la indemnidad de la piel.

- Estomago distendido, dilatado o sensible a la palpación.

Algunos pacientes con gastrostomía pueden tener una imagen distorsionada de su aspecto físico, en cuyo caso debe ser derivado a salud mental.

\section{Catéter venoso central (CVC) ${ }^{179,180}$}

Pacientes FQ con hospitalizaciones recurrentes con uso de antibióticos por tiempo prolongado y malos accesos vasculares periféricos son candidatos a instalación de catéter venoso central.

Se debe tener presente en el cuidado del CVC con reservorio:

- Manipulación exclusiva por profesional de enfermería.

- Uso de técnica aséptica durante todo el procedimiento utilizando elementos de protección (mascarilla, pechera manda larga, guantes estériles).

- Lavar sitio de inserción con agua y jabón utilizando apósito y secar.

- Desinfectar zona de punción con solución de clorhexidina $2 \%$ y dejar actuar 5 min.

- Puncionar con aguja gripper de tamaño adecuado al reservorio, edad y contextura del paciente.

- Después de cada administración de medicamentos se debe irrigar con pulsos de solución salina al 0,9\% 10-20 ml generando turbulencia en el interior del catéter y sellar a presión positiva.

- La permeabilización de catéter en forma ambulatoria debe realizarse según normativa IAAS de cada centro hospitalario. Se recomienda al menos cada 3 meses si el funcionamiento de catéter es adecuado.
- Evaluación del funcionamiento del catéter: Si el catéter no refluye sangre, lo más probable es que la punta este adosada a un borde del vaso sanguíneo, realizar maniobras de Valsalva (indicar que paciente tosa, respiración profunda, modificar posición de cuerpo y/o brazo). Si el catéter esta permeable, se puede infundir el tratamiento.

- El proceso de heparinización del CVC será según protocolo de cada centro.

\subsection{Equipos e insumos}

Se debe mantener registro actualizado del stock de insumos y de lo requerido por los pacientes FQ según edad, para gestionar la adquisición a tiempo por el hospital con el proveedor.

Asegurar bodega para almacenamiento en lugar limpio y seco, considerar repisas que cumplan normativa IAAS.

La supervisión del correcto uso se deberá programar en los controles de seguimiento, considerar la entrega de material educativo que describa: limpieza, desinfección y esterilización de equipos en conjunto con el kinesiólogo.

\section{Anexos}

Ver Anexos:

Anexo 1. Cuestionario de salud para aplicar en cada visita al paciente o su madre.

Anexo 2. Antibióticos orales-ev.

Anexo 3. Antibióticos nebulizados.

Anexo 4. Dosis de antibióticos en tratamiento de micobacteria no tuberculosas.

Anexo 5. Efectos adversos del tratamiento de micobacterias no tuberculosas.

Anexo 6. Escala de Borg.

Anexo 7. Valores de distancia caminada en niños sanos de Chile según edad y sexo.

Anexo 8. Valores de Presión inspiratoria. máxima(PImax) y de Presión espiratoria máxima (PEmax) según edad y sexo.

\section{Agradecimientos}

A Dra. Marcela Linares, editora Revista de Neumología Pediátrica, por su generosa asesoría y colaboración en la edición del manuscrito.

A Dr. Héctor Gutiérrez, Director del Centro de Fibrosis Quística, Universidad de Alabama, USA (UAB) por la revisión y opinión experta del documento. 


\section{Anexo 1. Cuestionario de salud para aplicar en cada visita al paciente o su madre}

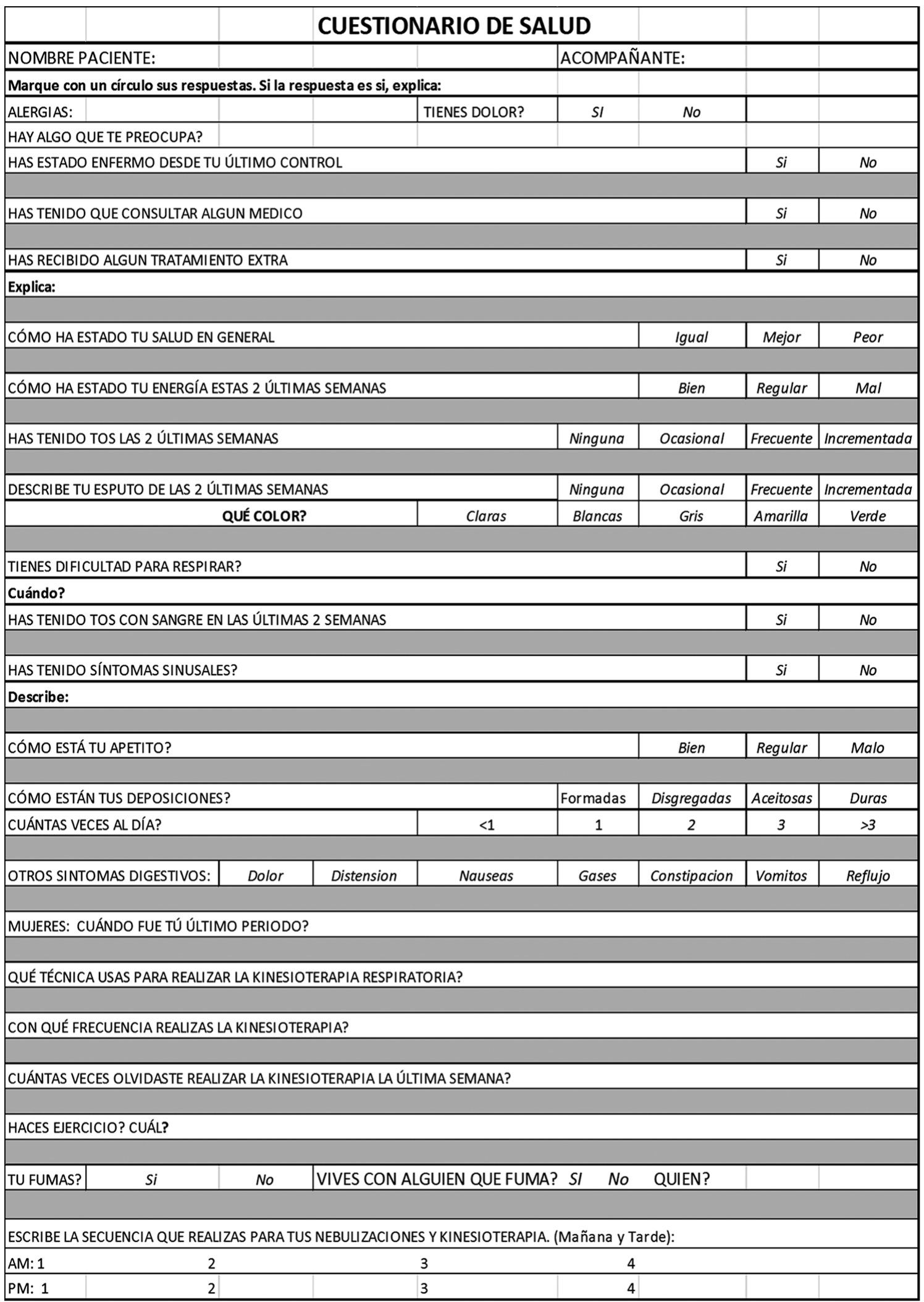

*Autorizado y adaptado de “Patient History Form”, UAB/COA Cystic Fibrosis Center. Birmingham, AL. USA. 2019. 
Anexo 2. Antibióticos orales y endovenosos en FQ. Recordar que los pacientes con FQ requieren dosis mayores a las habituales

\begin{tabular}{|c|c|c|}
\hline Antibióticos & Niños & Adultos \\
\hline Amoxicilina-Acido Clavulánico & $80-90 \mathrm{mg} / \mathrm{kg} /$ día $\mathrm{c} / 12 \mathrm{~h}$ oral & $875 / 125 \mathrm{c} / 12-8 \mathrm{~h}$ oral \\
\hline Amikacina & $\begin{array}{l}30 \mathrm{mg} / \mathrm{kg} / \text { día ev cada } 24 \text { h máx } \\
1.500 \mathrm{mg}\end{array}$ & $30 \mathrm{mg} / \mathrm{kg} /$ día ev cada $24 \mathrm{~h}$ \\
\hline Azitromicina & $10 \mathrm{mg} / \mathrm{kg} /$ día oral c/24 h & $500 \mathrm{mg}$ oral $\mathrm{c} / 24 \mathrm{~h}$ \\
\hline Aztreonam & $300 \mathrm{mg} / \mathrm{kg} /$ día ev c/6 h ev & $2 \mathrm{~g} \mathrm{c} / 8 \mathrm{~h} \mathrm{ev}$ \\
\hline Ceftazidima & $200 \mathrm{mg} / \mathrm{kg} /$ día ev c/8 h & $2 \mathrm{~g} \mathrm{ev} \mathrm{c} / 8 \mathrm{~h}$ \\
\hline Ciprofloxacino & $30 \mathrm{mg} / \mathrm{kg} /$ día c/ $8 \mathrm{~h} \mathrm{ev}$ & $400 \mathrm{mg} \mathrm{c} / 8 \mathrm{~h} \mathrm{o} 750 \mathrm{mg}$ oral c/12 h \\
\hline Colistín & $8 \mathrm{mg}(240 \mathrm{mil} \mathrm{UI}) / \mathrm{kg} /$ día ev c/8 h & $\begin{array}{l}3 \text { MUI c/8 h } \\
\text { Considerar dosis de carga de 9MUI }\end{array}$ \\
\hline Clindamicina & $40 \mathrm{mg} / \mathrm{kg}$ /día c/ 6 h oral - ev & $\begin{array}{l}450 \mathrm{mg} \mathrm{c} / 6 \mathrm{~h} \text { oral } \\
600 \mathrm{mg} \mathrm{c} / 8 \mathrm{~h} \mathrm{ev}\end{array}$ \\
\hline Cloxacilina & $200 \mathrm{mg} / \mathrm{kg} /$ día c/6 h ev- oral & $2 \mathrm{~g} \mathrm{c} / 6 \mathrm{~h}$ \\
\hline Doxiciclina & $4 \mathrm{mg} / \mathrm{kg} /$ día oral c/12 h & $100 \mathrm{mg}$ oral $\mathrm{c} / 12 \mathrm{~h}$ \\
\hline Flucloxacilina & $100 \mathrm{mg} / \mathrm{kg} /$ día c/8 h oral & $1 \mathrm{~g}$ oral $\mathrm{c} / 8 \mathrm{~h}$ \\
\hline Imipenem (para Achromobacter) & $100 \mathrm{mg} / \mathrm{kg} /$ día c/ $6 \mathrm{~h} \mathrm{ev}$ & $1 \mathrm{~g} \mathrm{ev} \mathrm{c} / 6 \mathrm{~h}$ \\
\hline Linezolid & $\begin{array}{l}<11 \text { años } 30 \mathrm{mg} / \mathrm{kg} / \text { día ev- oral c/8 h } \\
\text { Mayor de } 11 \text { años } 600 \mathrm{mg} \mathrm{c} / 12 \mathrm{~h}\end{array}$ & $600 \mathrm{mg} \mathrm{ev}-$ oral c/12 h \\
\hline Levofloxacino & $\begin{array}{l}<5 \text { años } 20 \mathrm{mg} / \mathrm{kg} / \text { día ev - oral c/12 h } \\
>5 \text { años } 10 \mathrm{mg} / \mathrm{kg} / \text { día ev - oral } 1 \text { vez } \\
\text { x día }\end{array}$ & 750 mg ev - oral 1 vez x día \\
\hline Meropenem & $120 \mathrm{mg} / \mathrm{kg} /$ día ev c/8 h & $2 \mathrm{~g} \mathrm{ev} \mathrm{c} / 8 \mathrm{~h}$ \\
\hline Minociclina & $\begin{array}{l}>12 \text { años } 4 \mathrm{mg} / \mathrm{k} / \text { día } \mathrm{c} / 12 \mathrm{~h} \text { oral (no } \\
\text { aprobado en }<\text { de } 12 \text { años) }\end{array}$ & $\begin{array}{l}200 \mathrm{mg} \text { por } 1 \mathrm{vez} \text { y luego } 100 \mathrm{mg} \\
\mathrm{c} / 12 \mathrm{~h}\end{array}$ \\
\hline Tobramicina & $7-10 \mathrm{mg} / \mathrm{kg} /$ día ev c/24 h & 7-10 mg/kg día ev c/24 h \\
\hline Trimetroprin /Sulfametoxazol & $\begin{array}{l}20 \mathrm{mg} / \mathrm{kg} / \text { día c/ } 8-6 \mathrm{~h} \text { (Achromobacter } \\
\text { o Stenotrofomona) } \\
10 \mathrm{mg} / \mathrm{kg} / \text { día c/ } 12 \mathrm{~h} \text { (Staphylococcus } \\
\text { aureus) }\end{array}$ & $\begin{array}{l}20 \mathrm{mg} / \mathrm{kg} / \text { día (Achromobacter o } \\
\text { Stenotrofomona) c/8-6 h }\end{array}$ \\
\hline Tigeciclina & $2,5 \mathrm{mg} / \mathrm{kg} /$ día ev c $/ 12 \mathrm{~h}$ & $\begin{array}{l}100 \mathrm{mg} \text { de carga y luego } 50 \mathrm{mg} \text { ev } \\
\mathrm{c} / 12 \mathrm{~h}\end{array}$ \\
\hline Vancomicina & $\begin{array}{l}60 \mathrm{mg} / \mathrm{kg} / \text { día ev c/6 h } \\
\text { Guiar con niveles plasmáticos }\end{array}$ & 4 gr ev día fraccionado $\mathrm{c} / 6 \mathrm{~h}$ \\
\hline
\end{tabular}

Anexo 3. Antibióticos nebulizados en FQ. Usar nebulizador Pari $^{\circledR}$ o e-flow ${ }^{\circledR}$

\begin{tabular}{|l|l|}
\hline Tobramicina nebulizada & $300 \mathrm{mg} \mathrm{c} / 12 \mathrm{~h}$ \\
\hline Tobramicina polvo (Podhaler) & Cápsulas de $28 \mathrm{mg}: 4$ cápsulas c/12 h (112 mg) \\
\hline Aztreonam & $75 \mathrm{mg} \mathrm{c} / 8 \mathrm{~h}$ \\
\hline Colistín* & $1-3 \mathrm{millones} \mathrm{UI} \mathrm{c/} 12 \mathrm{~h}(1 \mathrm{millón} \mathrm{UI} \mathrm{=} 80 \mathrm{mg})$ \\
\hline Colistín Metato Sódico Polvo (Colobreathe) & $125 \mathrm{mg}(1 \mathrm{cápsula} \mathrm{c/} 12 \mathrm{~h})$ \\
\hline Meropenem** (uso ev) & $\begin{array}{l}<12 \text { Años: } 125 \mathrm{mg} \mathrm{c} / 12 \mathrm{~h} \\
>12 \text { Años: } 250 \mathrm{mg} \mathrm{c} / 12 \mathrm{~h}\end{array}$ \\
\hline Amikacina (uso ev) & $<12$ Años: $250 \mathrm{mg} \mathrm{c} / 12 \mathrm{~h}$ \\
& $>12$ Años: $500 \mathrm{mg} \mathrm{c} / 12 \mathrm{~h}$ \\
\hline Ceftazidima (uso ev) & $500-1000 \mathrm{mg} \mathrm{c} / 12 \mathrm{~h}$ \\
\hline Vancomicina (uso ev) & $250-500 \mathrm{mg} \mathrm{c} / 12 \mathrm{~h}$ \\
\hline
\end{tabular}

*Colistín: Diluir con $4 \mathrm{ml}$ de $\mathrm{NaCl}$ 0,9\% por ampolla. **Reconstituir $500 \mathrm{mg}$ con $10 \mathrm{ml} \mathrm{de} \mathrm{NaCl} 0,9 \%$ (refrigerar el sobrante); ev: endovenoso. 


\section{Anexo 4. Dosis de antibióticos en tratamiento de micobacteria no tuberculosis}

\begin{tabular}{|c|c|}
\hline Amikacina & $\begin{array}{l}\text { Dosis e.v. } 30 \mathrm{mg} \mathrm{kg} / \text { dosis una vez al día } \\
\text { Dosis máxima } 1.500 \mathrm{mg} / \text { día } \\
\text { Dosis nebulizada } 250-500 \mathrm{mg} \text { una o dos veces al día (según tolerancia) }\end{array}$ \\
\hline Azitromicina & Dosis oral 10-12 mg/kg/día (dosis máxima 500 mg) \\
\hline $\begin{array}{l}\text { Cefoxitina } \\
\text { (No disponible Chile) }\end{array}$ & $\begin{array}{l}\text { Dosis EV infantil: } 50 \mathrm{mg} / \mathrm{kg} / \text { dosis por tres veces al día (dosis máxima } 12 \mathrm{~g} / \text { día) } \\
\text { Dosis EV adultos: } 200 \mathrm{mg} / \mathrm{kg} / \text { día dividido en } 3 \text { dosis ( dosis máxima } 12 \mathrm{~g} / \text { día) }\end{array}$ \\
\hline Claritromicina & Dosis oral: $7,5 \mathrm{mg} / \mathrm{kg} /$ dosis (dosis máxima $500 \mathrm{mg} 2$ v/día) \\
\hline Clofazimina & $\begin{array}{l}\text { Dosis oral: } 1-2 \mathrm{mg} / \mathrm{kg} / \mathrm{dosis} \text { una vez al día } \\
\text { Dosis adulto } 50-100 \mathrm{mg} 1 \mathrm{vez} \text { al día (según tolerancia) }\end{array}$ \\
\hline Etambutol & Dosis oral: 15 mg/kg/dosis una vez al día, (dosis máxima 1200 mg/día) \\
\hline Imipenem & Dosis EV: $15-20 \mathrm{mg} / \mathrm{kg} /$ dosis 2 v/día (dosis máxima $1.000 \mathrm{mg} 2$ v/día) \\
\hline Linezolid & $\begin{array}{l}\text { Dosis EV: Dosis infantil: } \\
<12 \text { años } 10 \mathrm{mg} / \mathrm{kg} / \text { dosis } 3 \mathrm{v} / \text { día } \\
>12 \text { años } 10 \mathrm{mg} / \mathrm{kg} / \text { dosis } 2 \mathrm{v} / \text { día (dosis máxima infantil } 600 \mathrm{mg}) \\
\text { Dosis adultos } 600 \mathrm{mg} 1 \text { o } 2 \text { veces/día }\end{array}$ \\
\hline Moxifloxacino & Dosis oral: 7,5-10 mg/kg/día (dosis máxima $400 \mathrm{mg} 1$ vez al día) \\
\hline Minociclina & Dosis oral: 2 mg/kg/dosis una vez al día (dosis máxima 200 mg/día) \\
\hline Rifampicina & $\begin{array}{l}\text { Dosis oral : } 10 \mathrm{mg} / \mathrm{kg} / \mathrm{dosis} \text { una vez al día } \\
\text { Dosis máxima } 450 \mathrm{mg} \text { una vez al día en }<50 \mathrm{~kg} \text { de peso corporal } \\
600 \mathrm{mg} \text { una vez al día en }>50 \mathrm{~kg} \text { de peso corporal }\end{array}$ \\
\hline Rifabutina & Dosis oral: $5-10 \mathrm{mg} / \mathrm{kg} /$ dosis una vez al día (dosis máxima: $300 \mathrm{mg}$ ) \\
\hline Estreptomicina & $\begin{array}{l}\text { Dosis intramuscular-endovenoso, diario dosis máxima } 1.000 \mathrm{mg} \\
\text { Niños } 20-40 \mathrm{mg} / \mathrm{kg} / \text { dosis } \\
\text { Adultos } 15 \mathrm{mg} / \mathrm{kg} / \text { dosis }\end{array}$ \\
\hline
\end{tabular}

Anexo 5. Efectos adversos del tratamiento de micobacterias no tuberculosas

\begin{tabular}{|l|l|}
\hline Amikacina & Alteración vestibular/auditiva, nefrotoxicidad \\
\hline Azitromicina & Alteración de pruebas hepáticas, vómitos, diarrea, aumento del riesgo de arritmias \\
\hline Cefoxitina & Anemia, leucopenia, eosinofilia \\
\hline Claritromicina & Alteración de pruebas hepáticas \\
\hline Clofazimina & Ictiosis, coloración negro-parduzca de piel, escleras y retina \\
\hline Etambutol & Neuritis óptica \\
\hline Imipenem & Alteración de pruebas hepáticas, trombocitopenia, anemia, leucopenia \\
\hline Linezolid & Neuropatía periférica, anemia, trombocitopenia \\
\hline Moxifloxacino & Vómitos, diarrea, tendinitis \\
\hline Minociclina & Vértigo, fotosensibilidad \\
\hline Rifampicina & Alteración pruebas hepáticas, trombocitopenia \\
\hline Rifabutina & Alteración pruebas hepáticas, leucopenia, uveítis \\
\hline Estreptomicina & Alteración vestibular/auditiva, nefrotoxicidad \\
\hline Tigeciclina & Vómitos, diarrea, fotosensibilidad, pancreatitis \\
\hline
\end{tabular}


Anexo 6. Escala de Borg ${ }^{181}$

\begin{tabular}{|c|l|}
\hline Valor & Apreciación \\
\hline 0 & Nada \\
\hline 0,5 & Muy leve (apenas apreciable) \\
\hline 1 & Muy leve \\
\hline 2 & Leve \\
\hline 3 & Moderada \\
\hline 4 & Algo fuerte \\
\hline 5 & Fuerte o intensa \\
\hline 6 & Fuerte o intensa \\
\hline 7 & Muy fuerte \\
\hline 8 & Muy fuerte \\
\hline 9 & Muy fuerte \\
\hline 10 & Muy fuerte (submáxima) \\
\hline
\end{tabular}

Anexo 7. Valores de distancia caminada en niños sanos de Chile según edad y sexo ${ }^{121}$

\begin{tabular}{|l|c|c|c|c|c|c|c|c|c|}
\hline & $\mathbf{6}$ años & $\mathbf{7}$ años & $\mathbf{8}$ años & $\mathbf{9}$ años & $\mathbf{1 0}$ años & $\mathbf{1 1}$ años & $\mathbf{1 2}$ años & $\mathbf{1 3}$ años & $\mathbf{1 4}$ años \\
\hline Mujeres & $\begin{array}{c}562,5 \pm \\
39,1\end{array}$ & $\begin{array}{c}568,2 \pm \\
31,6\end{array}$ & $\begin{array}{c}556,5 \pm \\
48,9 * * *\end{array}$ & $\begin{array}{c}575,7 \pm \\
53,2\end{array}$ & $\begin{array}{c}585,7 \pm \\
28,7\end{array}$ & $\begin{array}{c}606,7 \pm \\
60,3\end{array}$ & $\begin{array}{c}629,4 \pm \\
20,3\end{array}$ & $\begin{array}{c}631,4 \pm \\
50,2 * * *\end{array}$ & $\begin{array}{c}638,5 \pm \\
20,9\end{array}$ \\
\hline \multirow{2}{*}{ Hombres } & $\begin{array}{c}562 \pm \\
43,1\end{array}$ & $\begin{array}{c}597,11 \pm \\
33,6\end{array}$ & $\begin{array}{c}605,8 \pm \\
62,2 * * *\end{array}$ & $\begin{array}{c}611,4 \pm \\
47\end{array}$ & $\begin{array}{c}618,7 \pm \\
67,5\end{array}$ & $\begin{array}{c}608,7 \pm \\
35,9\end{array}$ & $\begin{array}{c}636,1 \pm \\
47,3\end{array}$ & $\begin{array}{c}673,9 \pm \\
45 * * *\end{array}$ & $\begin{array}{c}674,3 \pm \\
54,2\end{array}$ \\
\hline \multirow{2}{*}{ Total } & $\begin{array}{c}562,3 \pm \\
39,8\end{array}$ & $\begin{array}{c}580,9 \pm \\
34,7\end{array}$ & $\begin{array}{c}580,1 \pm \\
59,9\end{array}$ & $\begin{array}{c}587,6 \pm \\
52,8\end{array}$ & $\begin{array}{c}603,7 \pm \\
55\end{array}$ & $\begin{array}{c}607,8 \pm \\
47,3\end{array}$ & $\begin{array}{c}633 \pm \\
36,8\end{array}$ & $\begin{array}{c}650,3 \pm \\
51,8\end{array}$ & $\begin{array}{c}657,2 \pm \\
44,7\end{array}$ \\
\hline
\end{tabular}

$* * * \mathrm{p}<0,05$

Anexo 8. Valores de Presión inspiratoria máxima (PImax) y de Presión espiratoria máxima (PEmax) según edad y sexo ${ }^{120}$

\begin{tabular}{|c|c|c|c|c|}
\hline Edad (años) & PImax & \multicolumn{3}{|c|}{ PEmax } \\
\hline & Masculino & Femenino & Masculino & Femenino \\
\hline 8 & $77 \pm 27$ & $71 \pm 29$ & $99 \pm 23$ & $74 \pm 25$ \\
\hline 10 & $105 \pm 24$ & $71 \pm 29$ & $123 \pm 17$ & $126 \pm 32$ \\
\hline $11-13$ & $114 \pm 27$ & $108 \pm 29$ & $161 \pm 37$ & $135 \pm 29$ \\
\hline
\end{tabular}




\section{Glosario}

ABPA : Aspergilosis broncopulmonar alérgica.

ACTB : Active cicle breathing technique (Técnica de ciclo activo de la respiración).

AG : Acidos grasos.

ATS : American Thoraxic Society.

BCC : (Burkholderia cepacea complex) Complejo Burkholderia cepacea.

BIPAP : Bilevel positive airway pressure. Sistema de presión positiva en dos niveles.

CDC : Center for Disease Control and Prevention.

CFRD : Díabetes Mellitus asociada a FQ.

CFTR : (Cystic fibrosis transmembrane conductance regulator) Proteína reguladora de conductancia de transmembrana de fibrosis quística.

CHO : Carbono, hidrogeno y oxigeno: Hidratos de carbono.

CIM : Concentración inhibitoria mínima.

CP : Cuidados paliativos.

CVF : Capacidad vital forzada.

DA : Drenaje autógeno.

DHA : Ácido docosahexaenoico.

DIOS : Distal intestinal obstructive syndrome (Síndrome obstrucción intestinal distal).

DNA : Acido desoxirribonucleico.

DNasa : Desoxirribonucleasa.

DP : Drenaje Postural.

EV : Endovenoso.

ECMO : (extracorporeal membrane oxygenation). Oxigenación por membrana extracorpórea.

EFSA : European Food Safety Authority.

EII : Enfermedad inflamatoria intestinal.

ELPr : Espiración Lenta Prolongada.

ELTGOL: Espiración lenta total con glotis abierta en lateral.

EMI : Entrenamiento muscular inspiratorio.

FCMax : Frecuencia cardíaca máxima.

FEF : Flujo espiratorio forzado.

FENA : Fracción excretada de sodio.

FQ : Fibrosis quística.

GES : Garantías explicitas en salud.

GI : Gastrointestinal.

HBA1c : Hemoglobina glicosilada A1c.

HDA : Hemorragia digestiva alta.

ICM : (Intestinal current Measurement). Medición de corriente intestinal.

IDSA : Infectious Disease Society of America.

IgA : Inmunoglobulina A.

IgE : Inmunoglobulina E.

IgG : Inmunoglobulina G.

IL-8 : Interleuquina 8.

IMC : Índice masa corporal.

LBA : Lavado broncoalveolar.

LM : Lactancia materna.
MAC : (Mycobacterium Avis Complex). Complejo Mycobacterium avium.

MCT : (Medium Chain Triglycerides). Triglicérido de cadena medíana.

NCHS : National Center Health Statistics.

NE : Nutrición enteral.

NPH : protamina neutra de Hagedorn.

NPS : (Nasal potential difference) Diferencia de potencial nasal.

NTMB : (Non Tuberculous Mycobacteria). Micobacteria no tuberculosa.

NUU : Nitrógeno ureico urinario.

PCR : Proteína C Reactiva.

PEP : Dispositivos de presión positiva espiratoria.

PEmax : Presión espiratoria máxima.

PImax : Presión inspiratoria máxima.

PA : Pseudomonas Aeruginosa.

PTGO : Prueba de tolerancia a la glucosa oral.

RDI : Recomendaciones internacionales.

RGE : Reflujo gastroesofágico.

RN : Recién nacido.

SHO : Soluciones de hidratación oral.

TEF : Técnica de espiración forzada.

TM6 : Test de marcha de 6 min.

TTGO : Test tolerancia a la glucosa.

$\mathbf{V E F}_{1}$ : Volumen espiratorio forzado en el $1^{\text {er }}$ segundo.

VHB : Virus hepatitis B.

VHC : Virus hepatitis C.

VIH : Virus inmunodeficiencia humana.

VMNI : Ventilación mecánica no invasiva.

\section{Bibliografía}

1.- ROWE SM, MILlER S, SORSCHER EJ. Cystic fibrosis. N Engl J Med 2005; 352 (19): 1992-2001.

2.- RATJEN F, DÖRING G. Cystic fibrosis. Lancet 2003; 361 (9358): 681-9.

3.- PARANJAPE SM, MOGAYZEL PJ. Cystic fibrosis. Pediatr Rev 2014; 35 (5): 194-205.

4.- BOZA L, LOBO G, HENRÍQUEZ M, VALDEBENITO S, ESPINOZA X, NAVARRO S, et al. Resultado programa piloto. Pesquisa neonatal de fibrosis quistica en la Región Metropolitana y V Región. Período 2015-2017. Neumol Pediátrica 2017; 12: 195.

5.- LAY-SON G, PUGA A, ASTUDILLO P, REPETTO GM. Cystic fibrosis in Chilean patients: Analysis of 36 common CFTR gene mutations. J Cyst Fibros 2011; 10 (1): 66-70.

6.- CERDA LJ, VALDIVIA CG, GUIRALDES CE, SÁNCHEZ DI. Mortalidad por fibrosis quística en Chile (1997-2003). Rev Med Chile 2008; 136 (2): $157-62$.

7.- CASTELLANI C, DUFF AJA, BELL SC, HEIJER- 
MAN HGM, MUNCK A, RATJEN F, et al. ECFS best practice guidelines: the 2018 revision. J Cyst Fibros 2018; 17 (2): 153-78.

8.- FARRELL PM, WHITE TB, REN CL, HEMPSTEAD SE, ACCURSO F, DERICHS N, et al. Diagnosis of Cystic Fibrosis: Consensus Guidelines from the Cystic Fibrosis Foundation. J Pediatr 2017; 181: S4-S15.e1.

9.- SOSNAY PR, WHITE TB, FARRELL PM, REN CL, DERICHS N, HOWENSTINE MS, et al. Diagnosis of Cystic Fibrosis in Nonscreened Populations. J Pediatr 2017; 181: S52-S57.e2.

10.- ENG W, LEGRYS VA, SCHECHTER MS, LAUGHON MM, BARKER PM. Sweat-testing in preterm and full-term infants less than 6 weeks of age. Pediatr Pulmonol 2005; 40 (1): 64-7.

11.- LEGRYS VA, BRISCOE D, MCCOLLEY SA. Sweat Testing: Specimen collection and quantitative chloride analysis. 4th ed. Wayne PC and LSI, editor. Vol. 39. 2019.

12.- SMYTH AR, BELL SC, BOJCIN S, BRYON M, DUFF A, FLUME P, et al. European cystic fibrosis society standards of care: Best practice guidelines. J Cyst Fibros 2014; 13 (S1).

13.- FIELBAUM OD. Test del sudor, técnica y errores. Neumol Pediatr 2016; 11 (1): 19-22.

14.- ROSENSTEIN BJ, CUTTING GR. The diagnosis of cystic fibrosis: A consensus statement. J Pediatr 1998; 132 (4): 589-95.

15.- BARBEN J, RUEEGG CS, JURCA M, SPALINGER J, KUEHNI CE, BARAZZONE C, et al. Measurement of fecal elastase improves performance of newborn screening for cystic fibrosis. J Cyst Fibros 2016; 15 (3): 313-7.

16.- VANGA RR, TANSEL A, SIDIQ S, EL-SERAG HB, OTHMAN MO. Diagnostic performance of measurement of fecal elastase- 1 in detection of exocrine pancreatic insufficiency: Systematic review and meta-analysis. Clin Gastroenterol Hepatol 2018; 16 (8): 1220-8.e4.

17.- DAFTARY A, ACTON J, HEUBI J, AMIN R. Fecal elastase-1: Utility in pancreatic function in cystic fibrosis. J Cyst Fibros 2006; 5 (2): 71-6.

18.- OFFEY MJ, WHITAKER V, GENTIN N, JUNEK R, SHALHOUB C, NIGHTINGALE S, et al. Differences in Outcomes between Early and Late Diagnosis of Cystic Fibrosis in the Newborn Screening Era. J Pediatr 2017; 181: 137-45.e1.

19.- BOZA ML. Fibrosis quistica y tamizage neonatal. Neumol Pediatr 2016; 11 (1): 10-4.

20.- SARLES J, GIORGI R, BERTHÉZÈNE P, MUNCK A, CHEILLAN D, DAGORN JC, et al. Neonatal screening for cystic fibrosis: Comparing the performances of IRT/DNA and IRT/PAP. J Cyst Fibros 2014; 13 (4): 384-90.

21.- SERMET-GAUDELUS I, MAYELL SJ,
SOUTHERN KW. Guidelines on the early management of infants diagnosed with cystic fibrosis following newborn screening. J Cyst Fibros 2010; 9 (5): 323-9.

22.- CASTELLANI C, SOUTHERN KW, BROWNLEE $\mathrm{K}$, DANKERT ROELSE J, DUFF A, FARRELL $\mathrm{M}$, et al. European best practice guidelines for cystic fibrosis neonatal screening. J Cyst Fibros 2009; 8 (3): 153-73.

23.- SLY PD, BRENNAN S, GANGELL C, DE KLERK $\mathrm{N}$, MURRAY C, MOTT L, et al. Lung disease at diagnosis in infants with cystic fibrosis detected by newborn screening. Am J Respir Crit Care Med 2009; 180 (2): 146-52.

24.- FARRELL PM, ROSENSTEIN BJ, WHITE TB, ACCURSO FJ, CASTELLANI C, CUTTING GR, et al. Guidelines for Diagnosis of Cystic Fibrosis in Newborns through Older Adults: Cystic Fibrosis Foundation Consensus Report. J Pediatr 2008; 153 (2).

25.- PharmGKB [Internet]. [citado 28 de agosto de 2020]. Disponible en: https://www.pharmgkb.org/

26.- Welcome to CFTR2 | CFTR2 [Internet]. [citado 28 de agosto de 2020]. Disponible en: https://cftr2.org/

27.- DEN DUNNEN JT, DALGLEISH R, MAGLOTT DR, HART RK, GREENBLATT MS, MCGOWANJORDAN J, et al. HGVS Recommendations for the Description of Sequence Variants: 2016 Update. Hum Mutat 2016; 37 (6): 564-9.

28.- RICHARDS S, AZIZ N, BALE S, BICK D, DAS S, GASTIER-FOSTER J, et al. Standards and guidelines for the interpretation of sequence variants: A joint consensus recommendation of the American College of Medical Genetics and Genomics and the Association for Molecular Pathology. Genet Med 2015; 17 (5): 405-24.

29.- REN CL, BOROWITZ DS, GONSKA T, HOWENSTINE MS, LEVY $H$, MASSIE $J$, et al. Cystic Fibrosis Transmembrane Conductance Regulator-Related Metabolic Syndrome and Cystic Fibrosis Screen Positive, Inconclusive Diagnosis. J Pediatr 2017; 181: S45-S51.e1.

30.- MUNCK A, MAYELL SJ, WINTERS V, SHAWCROSS A, DERICHS N, PARAD R, et al. Cystic Fibrosis Screen Positive, Inconclusive Diagnosis (CFSPID): A new designation and management recommendations for infants with an inconclusive diagnosis following newborn screening. J Cyst Fibros 2015; 14 (6): 706-13.

31.- SOUTHERN KW, BARBEN J, GARTNER S, MUNCK A, CASTELLANI C, MAYELL SJ, et al. Inconclusive diagnosis after a positive newborn bloodspot screening result for cystic fibrosis; clarification of the harmonised international definition. J Cyst Fibros 2019; 18 (6): 778-80.

32.- Clinical guidelines: Care of children with cystic fibro- 
sis, 2020 | Royal Brompton \& Harefield NHS Foundation Trust [Internet]. [citado 4 de septiembre de 2020]. Disponible en: https://www.rbht.nhs.uk/childrencf

33.- BILTON D, CANNY G, CONWAY S, DUMCIUS S, HJELTE L, PROESMANS M, et al. Pulmonary exacerbation: Towards a definition for use in clinical trials. Report from the EuroCareCF Working Group on outcome parameters in clinical trials. J Cyst Fibros 2011; 10 (SUPPL. 2).

34.- SMYTH A, ELBORN JS. Exacerbations in cystic fibrosis: 3 - Management. Thorax 2008; 63 (2): 180-4.

35.- SANDERS DB, BITTNER RCL, ROSENFELD M, HOFFMAN LR, REDDING GJ, GOSS CH. Failure to recover to baseline pulmonary function after cystic fibrosis pulmonary exacerbation. Am J Respir Crit Care Med 2010; 182 (5): 627-32.

36.- FUCHS HJ, CHRISTIANSEN DH, BOROWITZ DS, NASH ML, RAMSEY BW, SMITH AL, et al. Effect of aerosolized recombinant human dnase on exacerbations of respiratory symptoms and on pulmonary function in patients with cystic fibrosis. $\mathrm{N}$ Engl J Med 1994; 331 (10): 637-42.

37.- GOSS CH, BURNS JL. Exacerbations in cystic fibrosis 1 : Epidemiology and pathogenesis. Thorax 2007; 62 (4): 360-7.

38.- RATJEN F, BELL SC, ROWE SM, GOSS CH, QUITTNER AL, BUSH A. Cystic fibrosis. Nat Rev Dis Prim 2015; 1 (1): 15010.

39.- AURORA P, GUSTAFSSON P, BUSH A, LINDBLAD A, OLIVER C, WALLIS CE, et al. Multiple breath inert gas washout as a measure of ventilation distribution in children with cystic fibrosis. Thorax 2004; 59 (12): 1068-73.

40.- VERMEULEN F, PROESMANS M, BOON M, HAVERMANS T, DE BOECK K. Lung clearance index predicts pulmonary exacerbations in young patients with cystic fibrosis. Thorax 2014; 69 (1): 39-45.

41.- BURNS JL, ROLAIN JM. Culture-based diagnostic microbiology in cystic fibrosis: Can we simplify the complexity? J Cyst Fibros 2014; 13 (1): 1-9.

42.- JORGENSEN J, CARROLL K, FUNKE G, PFALLER M, LANDRY M, SS et al R. Manual of Clinical Microbiology. Washington, DC, USA: ASM Press; 2015.

43.- Respiratory Tract Cultures, In: Leber AL (Ed). Clinical Microbiology Procedures Handbook, 4th Edition. ASM Press, Washington, DC. c2016. (cited october 2020. doi: 10.1128/9781683670438.CMPH.ch3.11.

44.- TACCETTI G, DENTON M, HAYES K, BILTON D, CAMPANA S, DOLCE D, et al. A critical review of definitions used to describe Pseudomonas aeruginosa microbiological status in patients with cystic fibrosis for application in clinical trials. J Cyst Fibros 2020; 19 (1): 52-67.

45.- RATJEN F, MUNCK A, KHO P, ANGYALOSI G. Treatment of early Pseudomonas aeruginosa infection in patients with cystic fibrosis: The ELITE trial.
Thorax 2010; 65 (4): 286-91.

46.- GILLIGAN PH, DOWNEY DG, STUART ELBORN J, FLUME PA, FUNK S, GILPIN D, et al. "Pathogen eradication" and "emerging pathogens": Difficult definitions in cystic fibrosis. J Clin Microbiol 2018; 56 (9).

47.- LEE TWR, BROWNLEE KG, CONWAY SP, DENTON M, LITTLEWOOD JM. Evaluation of a new definition for chronic Pseudomonas aeruginosa infection in cystic fibrosis patients. J Cyst Fibros 2003; 2 (1): 29-34.

48.- CHMIEL JF, AKSAMIT TR, CHOTIRMALL SH, DASENBROOK EC, ELBORN JS, LIPUMA JJ, et al. Antibiotic management of lung infections in cystic fibrosis: I. The microbiome, methicillin-resistant Staphylococcus aureus, gram-negative bacteria, and multiple infections. Ann Am Thorac Soc 2014; 11 (7): 1120-9.

49.- DOLCE D, NERI S, GRISOTTO L, CAMPANA S, RAVENNI N, MISELLI F, et al. Methicillin-resistant Staphylococcus aureus eradication in cystic fibrosis patients: A randomized multicenter study. PLoS One 2019; 14 (3).

50.- MUHLEBACH MS, BECKETT V, POPOWITCH E, MILLER MB, BAINES A, MAYER-HAMBLETT N, et al. Microbiological efficacy of early MRSA treatment in cystic fibrosis in a randomised controlled trial. Thorax 2017; 72 (4): 318-26.

51.- VESTERGAARD M, FREES D, INGMER H. Antibiotic Resistance and the MRSA Problem. Microbiol Spectr 2019; 7 (2).

52.- Cystic Fibrosis Foundation Patient Registry 2018 Annual Data Report. Bethesda, Maryland, (C2019 Cystic Fibrosis Foundation;

53.- SOUTHERN KW, BARKER PM, SOLIS-MOYA A, PATEL L. Macrolide antibiotics for cystic fibrosis. Cochrane Database Syst Rev 2012; 11 (11).

54.- BROOKE JS. Stenotrophomonas maltophilia: An emerging global opportunistic pathogen. Clin Microbiol Rev 2012; 25 (1): 2-41.

55.- AMIN R, JAHNKE N, WATERS V. Antibiotic treatment for Stenotrophomonas maltophilia in people with cystic fibrosis. Cochrane Database Syst Rev 2020; 3 (3): CD009249.

56.- GONG J, SU D, SHANG J, YU H, DU G, LIN Y, et al. Efficacy and safety of high-dose tigecycline for the treatment of infectious diseases: A meta-analysis. Med (United States) 2019; 98 (38): e17091.

57.- ABBOTT IJ, PELEG AY. Stenotrophomonas, achromobacter, and nonmelioid burkholderia species: Antimicrobial resistance and therapeutic strategies. Semin Respir Crit Care Med 2015; 36 (1): 99-110.

58.- EDWARDS BD, GREYSSON-WONG J, SOMAYAJI R, WADDELL B, WHELAN FJ, STOREY DG, et al. Prevalence and outcomes of achromobacter species infections in adults with cystic fibrosis: A 
North American cohort study. J Clin Microbiol 2017; 55 (7): 2074-85.

59.- $\quad$ SWENSON CE, SADIKOT RT. Achromobacter respiratory infections. Ann Am Thorac Soc 2015; 12 (2): 252-8.

60.- WANG M, RIDDERBERG W, HANSEN CR, HØIBY N, JENSEN-FANGEL S, OLESEN HV, et al. Early treatment with inhaled antibiotics postpones next occurrence of Achromobacter in cystic fibrosis. J Cyst Fibros 2013; 12 (6): 638-43.

61.- GARCÍA BA, CARDEN JL, GOODWIN DL, SMITH TA, GAGGAR A, LEON K, et al. Implementation of a successful eradication protocol for Burkholderia Cepacia complex in cystic fibrosis patients. BMC Pulm Med 2018; 18 (1).

62.- MARTINIANO SL, DAVIDSON RM, NICK JA. Nontuberculous mycobacteria in cystic fibrosis: Updates and the path forward. Pediatr Pulmonol 2017; 52 (S48): S29-36.

63.- FLOTO RA, OLIVIER KN, SAIMAN L, DALEY CL, HERRMANN JL, NICK JA, et al. US Cystic Fibrosis Foundation and European Cystic Fibrosis Society consensus recommendations for the management of non-tuberculous mycobacteria in individuals with cystic fibrosis. Thorax 2016; 71 (Suppl 1): i1-22.

64.- HAWORTH CS, BANKS J, CAPSTICK T, FISHER AJ, GORSUCH T, LAURENSON IF, et al. British Thoracic Society guidelines for the management of non-tuberculous mycobacterial pulmonary disease (NTM-PD). Thorax 2017; 72 (Suppl 2): ii1-64.

65.- WATERS V, RATJEN F. Antibiotic treatment for nontuberculous mycobacteria lung infection in people with cystic fibrosis. Cochrane Database Syst Rev 2016; 2016 (12).

66.- $\quad$ BRANDT C, ROEHMEL J, RICKERTS V, MELICHAR V, NIEMANN N, SCHWARZ C. Aspergillus Bronchitis in Patients with Cystic Fibrosis. Mycopathologia 2018; 183 (1): 61-9.

67.- IZUMIKAWA K, YAMAMOTO Y, MIHARA T, TAKAZONO T, MORINAGA Y, KURIHARA S, et al. Bronchoalveolar lavage galactomannan for the diagnosis of chronic pulmonary aspergillosis. Med Mycol 2012; 87 (8): 811-7.

68.- TRACY MC, OKORIE CUA, FOLEY EA, MOSS RB. Allergic bronchopulmonary aspergillosis. J Fungi 2016; 2 (2).

69.- KING J, BRUNEL SF, WARRIS A. Aspergillus infections in cystic fibrosis. J Infect 2016; 72: S50-5.

70.- BAXTER CG, DUNN G, JONES AM, WEBB K, GORE R, RICHARDSON MD, et al. Novel immunologic classification of aspergillosis in adult cystic fibrosis. J Allergy Clin Immunol 2013; 132 (3).

71.- BURGEL PR, PAUGAM A, HUBERT D, MARTIN C. Aspergillus fumigatus in the cystic fibrosis lung: Pros and cons of azole therapy. Infect Drug Resist 2016; 9: 229-38.
72.- STEVENS DA, MOSS RB, KURUP VP, KNUTSEN AP, GREENBERGER P, JUDSON MA, et al. Allergic Bronchopulmonary Aspergillosis in Cystic Fibrosis - State of the Art: Cystic Fibrosis Foundation Consensus Conference. Clin Infect Dis 2003; 37 (Suppl. 3).

73.- PATEL AR, PATEL AR, SINGH S, SINGH S, KHAWAJA I. Diagnosing Allergic Bronchopulmonary Aspergillosis: A Review. Cureus 2019; 11 (4).

74.- GHDIFAN S, COUDERC L, MICHELET I, LEGUILLON C, MASSELINE B, MARGUET C. Bolus methylprednisolone efficacy for uncontrolled exacerbation of cystic fibrosis in children. Pediatrics 2010; 125 (5).

75.- COHEN-CYMBERKNOH M, BLAU H, SHOSEYOV D, MEI-ZAHAV M, EFRATI O, ARMONI S, et al. Intravenous monthly pulse methylprednisolone treatment for ABPA in patients with cystic fibrosis. J Cyst Fibros 2009; 8 (4): 253-7.

76.- ELPHICK HE, SOUTHERN KW. Antifungal therapies for allergic bronchopulmonary aspergillosis in people with cystic fibrosis. Cochrane Database Syst Rev 2016; 2016 (11).

77.- CHEN J, CHAN C, COLANTONIO D, SETO W. Therapeutic drug monitoring of voriconazole in children. Ther Drug Monit 2012; 34 (1): 77-84.

78.- GODET C, GOUDET V, LAURENT F, MOAL G LE, GOUNANT V, FRAT JP, et al. Nebulised liposomal amphotericin B for Aspergillus lung diseases: Case series and literature review. Mycoses 2015; 58 (3): 173-80.

79.- PARISI GF, PORTALE A, PAPALE M, TARDINO L, ROTOLO N, LICARI A, et al. Successful treatment with omalizumab of allergic bronchopulmonary aspergillosis in patients with cystic fibrosis: Case reports and literature review. J Allergy Clin Immunol Pract 2019; 7 (5): 1636-8.

80.- DESCHAMP AR, HATCH JE, SLAVEN JE, GEBREGZIABHER N, STORCH G, HALL GL, et al. Early respiratory viral infections in infants with cystic fibrosis. J Cyst Fibros 2019; 18 (6): 844-50.

81.- WATERS V, RATJEN F. Pulmonary exacerbations in children with cystic fibrosis. Ann Am Thorac Soc 2015; 12: S200-6.

82.- WARK P, MCDONALD VM. Nebulised hypertonic saline for cystic fibrosis. Cochrane Database Syst Rev 2018; 2018 (9).

83.- TARRAN R, DONALDSON S, BOUCHER RC. Rationale for hypertonic saline therapy for cystic fibrosis lung disease. Semin Respir Crit Care Med 2007; 28 (3): 295-302.

84.- LAHIRI T, HEMPSTEAD SE, BRADY C, CANNON CL, CLARK K, CONDREN ME, et al. Clinical practice guidelines from the cystic fibrosis foundation for preschoolers with cystic fibrosis. Pediatrics 2016; 137 (4). 
85.- DELLON EP, DONALDSON SH, JOHNSON R, DAVIS SD. Safety and tolerability of inhaled hypertonic saline in young children with cystic fibrosis. Pediatr Pulmonol 2008; 43 (11): 1100-6.

86.- ROSENFELD M, DAVIS S, BRUMBACK L, DANIEL S, ROWBOTHAM R, JOHNSON R, et al. Inhaled hypertonic saline in infants and toddlers with cystic fibrosis: Short-term tolerability, adherence, and safety. Pediatr Pulmonol 2011; 46 (7): 666-71.

87.- YANG C, MONTGOMERY M. Dornase alfa for cystic fibrosis. Cochrane Database Syst Rev 2018; 2018 (9).

88.- KONSTAN MW, WAGENER JS, PASTA DJ, MILLAR SJ, JACOBS JR, YEGIN A, et al. Clinical use of dornase alfa is associated with a slower rate of FEV 1 decline in cystic fibrosis. Pediatr Pulmonol 2011; 46 (6): 545-53.

89.- DENTICE R, ELKINS M. Timing of dornase alfa inhalation for cystic fibrosis. Cochrane Database Syst Rev 2016; 2016 (7).

90.- CHENG K, ASHBY D, SMYTH RL. Oral steroids for long-term use in cystic fibrosis. Cochrane Database Syst Rev 2015; 2015 (12).

91.- BALFOUR-LYNN IM, WELCH K. Inhaled corticosteroids for cystic fibrosis. Cochrane Database Syst Rev 2016; (8).

92.- PRINCIPI N, BLASI F, ESPOSITO S. Azithromycin use in patients with cystic fibrosis. Eur J Clin Microbiol Infect Dis 2015; 34 (6): 1071-9.

93.- WILMS EB, TOUW DJ, HEIJERMAN HGM, VAN DER ENT CK. Azithromycin maintenance therapy in patients with cystic fibrosis: A dose advice based on a review of pharmacokinetics, efficacy, and side effects. Pediatr Pulmonol 2012; 47 (7): 658-65.

94.- LANDS LC, STANOJEVIC S. Oral non-steroidal anti-inflammatory drug therapy for lung disease in cystic fibrosis. Cochrane Database Syst Rev 2019; 2019 (9)

95.- LAUBE BL, JANSSENS HM, DE JONGH FHC, DEVADASON SG, DHAND R, DIOT P, et al. What the pulmonary specialist should know about the new inhalation therapies. Eur Respir J 2011; 37 (6): 130831.

96.- SAIMAN L, SIEGEL J. Infection Control in Cystic Fibrosis. Vol. 17, Clinical Microbiology Reviews. American Society for Microbiology (ASM); 2004. p. 57-71.

97.- SAIMAN L, SIEGEL JD, LIPUMA JJ, BROWN RF, BRYSON EA, CHAMBERS MJ, et al. Infection Prevention and Control Guideline for Cystic Fibrosis: 2013 Update. Infect Control Hosp Epidemiol 2014; 35 (S1): s1-67.

98.- KING CS, BROWN AW, ARYAL S, AHMAD K, DONALDSON S. Critical Care of the Adult Patient With Cystic Fibrosis. Chest 2019; 155 (1): 202-14.

99.- KIOUMIS I, ZAROGOULIDIS K, HUANG H, LI
Q, DRYLLIS G, PITSIOU G, et al. Pneumothorax in cystic fibrosis. J Thorac Dis 2014; 6 (Suppl 4).

100.- LORD RW, JONES AM, WEBB AK, BARRY PJ. Pneumothorax in cystic fibrosis: beyond the guidelines. Paediatr Respir Rev 2016; 20: 30-3.

101.- FLUME PA, MOGAYZEL PJ, ROBINSON KA, ROSENBLATT RL, QUITTELL L, MARSHALL BC, Et al. Cystic fibrosis pulmonary guidelines: Pulmonary complications: Hemoptysis and pneumothorax. Am J Respir Crit Care Med 2010; 182 (3): 298-306.

102.- DE VRIES JJV, CHANG AB, MARCHANT JM. Comparison of bronchoscopy and bronchoalveolar lavage findings in three types of suppurative lung disease. Pediatr Pulmonol 2018; 53 (4): 467-74.

103.- PAUL L. Is bronchoscopy an obsolete tool in cystic fibrosis? The role of bronchoscopy in cystic fibrosis and its clinical use. J Thorac Dis 2017; 9 (Suppl 10): S1139-45.

104.- JAIN K, WAINWRIGHT C, SMYTH AR. Bronchoscopy-guided antimicrobial therapy for cystic fibrosis. Cochrane Database Syst Rev 2018; 2018 (9).

105.- FAYON M, KENT L, BUI S, DUPONT L, SERMET I. Clinimetric properties of bronchoalveolar lavage inflammatory markers in cystic fibrosis. Eur Respir J 2014; 43 (2): 610-26.

106.- NEWTON TJ. Respiratory care of the hospitalized patient with cystic fibrosis. Respir Care 2009; 54 (6): 769-75.

107.- CONWAY S, BALFOUR-LYNN IM, DE RIJCKE K, DREVINEK P, FOWERAKER J, HAVERMANS T, et al. European cystic fibrosis society standards of care: Framework for the cystic fibrosis centre. J Cyst Fibros 2014; 13 (S1).

108.- CÁCERES GUIDO P, PÉREZ M, HALAC A, FERRARI M, IBARRA M, LICCIARDONE N, et al. Population pharmacokinetics of amikacin in patients with pediatric cystic fibrosis. Pediatr Pulmonol 2019; 54 (11): 1801-10.

109.- PETTIT RS, PETERS SJ, MCDADE EJ, KREILEIN K, PATEL R, EPPS K, et al. Vancomycin dosing and monitoring in the treatment of cystic fibrosis: Results of a national practice survey. J Pediatr Pharmacol Ther 2017; 22 (6): 406-11.

110.- ROGERS D, DOULL IJM. Physiological principles of airway clearance techniques used in the physiotherapy management of cystic fibrosis. Curr Paediatr 2005; 15 (3): 233-8.

111.- BUTTON BM, WILSON C, DENTICE R, COX NS, MIDDLETON A, TANNENBAUM E, et al. Physiotherapy for cystic fibrosis in Australia and New Zealand: A clinical practice guideline. Respirology 2016; 21 (4): 656-67.

112.- NICOLAIS CJ, BERNSTEIN R, SAEZ-FLORES E, MCLEAN KA, RIEKERT KA, QUITTNER AL. Identifying Factors that Facilitate Treatment 
Adherence in Cystic Fibrosis: Qualitative Analyses of Interviews with Parents and Adolescents. J Clin Psychol Med Settings 2019; 26 (4): 530-40.

113.- SCHNEIDERMAN JE, WILKES DL, ATENAFU EG, NGUYEN T, WELLS GD, ALARIE N, et al. Longitudinal relationship between physical activity and lung health in patients with cystic fibrosis. Eur Respir J 2014; 43 (3): 817-23.

114.- WILSON LM, MORRISON L, ROBINSON KA. Airway clearance techniques for cystic fibrosis: An overview of Cochrane systematic reviews. Cochrane Database Syst Rev 2019; 1 (1): CD011231.

115.- VAN DER SCHANS CP. Conventional chest physical therapy for obstructive lung disease. Respir Care 2007; 52 (9): 1198-206.

116.- PUPPO H, HIDALGO G. Chest Physiotherapy. En: Bertrand P, Sánchez I, editores. Pediatric Respiratory Diseases: A Comprehensive Textbook. Santiago, Chile: Springer Nature Switzerland AG 2020; 2020.

117.- MUÑOZ G, DE GRACIA J, BUXÓ M, ALVAREZ A, VENDRELL M. Long-term benefits of airway clearance in bronchiectasis: A randomised placebocontrolled trial. Eur Respir J 2018; 51 (1).

118.- WARD N, STILLER K, HOLLAND AE. Exercise as a therapeutic intervention for people with cystic fibrosis. Expert Rev Respir Med 2019; 13 (5): 449-58.

119.- (No Title) [Internet]. [citado 19 de noviembre de 2020]. Disponible en: https://www.neumologiapediatrica.cl/wp-content/uploads/2017/07/guiasrehabilitacion.pdf

120.- SZEINBERG A, MARCOTTE JE, ROIZIN H, MINDORFF C, ENGLAND S, TABACHNIK E, et al. Normal values of maximal inspiratory and expiratory pressures with a portable apparatus in children, adolescents, and young adults. Pediatr Pulmonol 1987; 3 (4): 255-8.

121.- GATICA D, PUPPO H, VILLARROEL G, MARTÍN IS, LAGOS R, MONTECINO JJ, et al. Valores de referencia del test de marcha de seis minutos en niños sanos. Rev Med Chile 2012; 140 (8): 1014-21.

122.- TURCK D, BRAEGGER CP, COLOMBO C, DECLERCQ D, MORTON A, PANCHEVA R, et al. ESPEN-ESPGHAN-ECFS guidelines on nutrition care for infants, children, and adults with cystic fibrosis. Clin Nutr 2016; 35 (3): 557-77.

123.- SOMARAJU URR, SOLIS-MOYA A. Pancreatic enzyme replacement therapy for people with cystic fibrosis. Cochrane Database Syst Rev 2020; 2020 (8).

124.- STALLINGS VA, STARK LJ, ROBINSON KA, FERANCHAK AP, QUINTON H. Evidence-Based Practice Recommendations for Nutrition-Related Management of Children and Adults with Cystic Fibrosis and Pancreatic Insufficiency: Results of a Systematic Review. J Am Diet Assoc 2008; 108 (5): 832-9.

125.- SCHWARZENBERG SJ, HEMPSTEAD SE, MC-
DONALD CM, POWERS SW, WOOLDRIDGE J, BLAIR S, et al. Enteral tube feeding for individuals with cystic fibrosis: Cystic Fibrosis Foundation evidence-informed guidelines. J Cyst Fibros 2016; 15 (6): 724-35.

126.- BARJA YS, REBOLLO G. MJ. Manejo nutricional en niños y adolescentes con fibrosis quística. Rev Chil Pediatr 2009; 80 (3): 274-84.

127.- TABORI H, ARNOLD C, JAUDSZUS A, MENTZEL HJ, RENZ DM, REINSCH S, et al. Abdominal symptoms in cystic fibrosis and their relation to genotype, history, clinical and laboratory findings. PLoS One 2017; 12 (5).

128.- ASSIS DN, FREEDMAN SD. Gastrointestinal Disorders in Cystic Fibrosis. Clin Chest Med 2016; 37 (1): 109-18.

129.- SANKARARAMAN S, SCHINDLER T, SFERRA TJ. Management of Exocrine Pancreatic Insufficiency in Children. Nutr Clin Pract 2019; 34 (S1): S27-42.

130.- SAKIANI S, KLEINER DE, HELLER T, KOH C. Hepatic Manifestations of Cystic Fibrosis. Clin Liver Dis 2019; 23 (2): 263-77.

131.- DEBRAY D, NARKEWICZ MR, BODEWES FAJA, COLOMBO C, HOUSSET C, DE JONGE HR, et al. Cystic Fibrosis-related Liver Disease: Research Challenges and Future Perspectives. J Pediatr Gastroenterol Nutr 2017; 65 (4): 443-8.

132.- DEBRAY D, KELLY D, HOUWEN R, STRANDVIK B, COLOMBO C. Best practice guidance for the diagnosis and management of cystic fibrosis-associated liver disease. J Cyst Fibros 2011; 10 (Suppl. 2).

133.- KOBELSKA-DUBIEL N, KLINCEWICZ B, CICHY W. Liver disease in cystic fibrosis. Prz Gastroenterol 2014; 9 (3): 136-41.

134.- CARLYLE BE, BOROWITZ DS, GLICK PL. A review of pathophysiology and management of fetuses and neonates with meconium ileus for the pediatric surgeon. J Pediatr Surg 2012; 47 (4): 772-81.

135.- HOUWEN RH, VAN DER DOEF HP, SERMET I, MUNCK A, HAUSER B, WALKOWIAK J, et al. Defining DIOS and Constipation in Cystic Fibrosis With a Multicentre Study on the Incidence, Characteristics, and Treatment of DIOS. J Pediatr Gastroenterol Nutr 2010; 50 (1): 38-42.

136.- COLOMBO C, ELLEMUNTER H, HOUWEN R, MUNCK A, TAYLOR C, WILSCHANSKI M. Guidelines for the diagnosis and management of distal intestinal obstruction syndrome in cystic fibrosis patients. J Cyst Fibros 2011; 10 (Suppl. 2).

137.- ROBINSON NB, DIMANGO E. Prevalence of gastroesophageal reflux in cystic fibrosis and implications for lung disease. Ann Am Thorac Soc 2014; 11 (6): 964-8.

138.- MAISONNEUVE P, FITZSIMMONS SC, NEGLIA JP, CAMPBELL PW, LOWENFELS AB. Cancer risk in nontransplanted and transplanted cystic fibrosis 
patients: A 10-year study. J Natl Cancer Ins 2003; 95 (5): 381-7.

139.- MAISONNEUVE P, MARSHALL BC, KNAPP EA, LOWENFELS AB. Cancer risk in cystic fibrosis: A 20-year nationwide study from the United States. J Natl Cancer Inst 2013; 105 (2): 122-9.

140.- HADJILIADIS D, KHORUTS A, ZAUBER AG, HEMPSTEAD SE, MAISONNEUVE P, LOWENFELS AB, et al. Cystic Fibrosis Colorectal Cancer Screening Consensus Recommendations. Gastroenterology 2018; 154 (3): 736-45.e14.

141.- CODNER E, ACERINI CL, CRAIG ME, HOFER SE, MAAHS DM. ISPAD Clinical Practice Consensus Guidelines 2018: What is new in diabetes care? Pediatr Diabetes 2018; 19: 5-6.

142.- MORAN A, PILLAY K, BECKER D, GRANADOS A, HAMEED S, ACERINI CL. ISPAD Clinical Practice Consensus Guidelines 2018: Management of cystic fibrosis-related diabetes in children and adolescents. Pediatr Diabetes 2018; 19: 64-74.

143.- Assocsiation AD. Standards of Medical Care in Diabetes-2017: Summary of Revisions. Diabetes Care 2017; 40.

144.- SERMET-GAUDELUS I, BIANCHI ML, GARABÉDIAN M, ARIS RM, MORTON A, HARDIN $\mathrm{DS}$, et al. European cystic fibrosis bone mineralisation guidelines. J Cyst Fibros 2011; 10 (Suppl. 2).

145.- FUNDAKOWSKI C, OJO R, YOUNIS R. Rhinosinusitis in the pediatric patient with cystic fibrosis. En: Pediatric and Adult SinoNasal Disorders. Nova Science Publishers, Inc.; 2015. p. (pp. 171-179).

146.- MAINZ JG, KOITSCHEV A. Pathogenesis and management of nasal polyposis in cystic fibrosis. Curr Allergy Asthma Rep 2012; 12 (2): 163-74.

147.- SELIMOGLU E. Aminoglycoside-Induced Ototoxicity. Curr Pharm Des 2006; 13 (1): 119-26.

148.- SMYTH AR, BHATT J, NEVITT SJ. Once-daily versus multiple-daily dosing with intravenous aminoglycosides for cystic fibrosis. Cochrane Database Syst Rev 2017; 3 (3): CD002009.

149.- KRANZER K, ELAMIN WF, COX H, SEDDON JA, FORD N, DROBNIEWSKI F. A systematic review and meta-analysis of the efficacy and safety of $\mathrm{N}$-acetylcysteine in preventing aminoglycosideinduced ototoxicity: Implications for the treatment of multidrug-resistant TB. Thorax 2015; 70 (11): 1070-7.

150.- CLARKE EA, WATSON P, FREESTON JE, PECKHAM DG, JONES AM, HORSLEY A. Assessing arthritis in the context of cystic fibrosis. Pediatr Pulmonol 2019; 54 (6): 770-7.

151.- NAZARETH D, WALSHAW M. A review of renal disease in cystic fibrosis. J Cyst Fibros 2013; 12 (4): 309-17.

152.- GIBNEY EM, GOLDFARB DS. The association of nephrolithiasis with cystic fibrosis. Am J Kidney Dis 2003; 42 (1 Suppl. 2): 1-11.
153.- LAI S, MAZZAFERRO S, MITTERHOFER AP, BONCI E, MAROTTA PG, PELLIGRA F, et al. Renal involvement and metabolic alterations in adults patients affected by cystic fibrosis. J Transl Med 2019; 17 (1).

154.- FOX S, FARR-JONES S, SOPCHAK L, BOGGS A, NICELY HW, KHOURY R, et al. High-throughput screening: Update on practices and success. J Biomol Screen 2006; 11 (7): 864-9.

155.- MOSS RB, FLUME PA, ELBORN JS, COOKE J, ROWE SM, MCCOLLEY SA, et al. Efficacy and safety of ivacaftor in patients with cystic fibrosis who have an Arg117His-CFTR mutation: A double-blind, randomised controlled trial. Lancet Respir Med 2015; 3 (7): 524-33.

156.- ROSENFELD M, WAINWRIGHT CE, HIGGINS M, WANG LT, MCKEE C, CAMPBELL D, et al. Ivacaftor treatment of cystic fibrosis in children aged 12 to $<24$ months and with a CFTR gating mutation (ARRIVAL): a phase 3 single-arm study. Lancet Respir Med 2018; 6 (7): 545-53.

157.- RAMSEY BW, DAVIES J, MCELVANEY NG, TULLIS E, BELL SC, DŘEVÍNEK $\mathrm{P}$, et al. A CFTR potentiator in patients with cystic fibrosis and the G551D mutation. N Engl J Med 2011; 365 (18): 1663-72.

158.- MIDDLETON PG, MALL MA, DŘEVÍNEK P, LANDS LC, MCKONE EF, POLINENI D, et al. Elexacaftor-tezacaftor-ivacaftor for cystic fibrosis with a single Phe508del allele. N Engl J Med 2019; 381 (19): 1809-19.

159.- KEATING D, MARIGOWDA G, BURR L, DAINES C, MALL MA, MCKONE EF, et al. VX445-tezacaftor-ivacaftor in patients with cystic fibrosis and one or two Phe508del alleles. N Engl J Med 2018; 379 (17): 1612-20.

160.- HEIJERMAN HGM, MCKONE EF, DOWNEY DG, VAN BRAECKEL E, ROWE SM, TULLIS E, et al. Efficacy and safety of the elexacaftor plus tezacaftor plus ivacaftor combination regimen in people with cystic fibrosis homozygous for the F508del mutation: a double-blind, randomised, phase 3 trial. Lancet 2019; 394 (10212): 1940-8.

161.- TAYLOR-COUSAR JL, MUNCK A, MCKONE EF, VAN DER ENT CK, MOELLER A, SIMARD $\mathrm{C}$, et al. Tezacaftor-ivacaftor in patients with cystic fibrosis homozygous for Phe508del. N Engl J Med 2017; 377 (21): 2013-23.

162.- ROWE SM, DAINES C, RINGSHAUSEN FC, KEREM E, WILSON J, TULLIS E, et al. Tezacaftor-ivacaftor in residual-function heterozygotes with cystic fibrosis. N Engl J Med 2017; 377 (21): 2024-35.

163.- LIZAMA CM, ÁVALOS AME, VARGAS CNA, VARELA GMA, NAVARRETE SCL, GALANTI $\mathrm{DM}$, et al. Transition for young adults with special health care needs: Recommendations of the committee 
on NANEAS of pediatric Chilean society. Rev Chil Pediatr 2011; 82 (3): 238-44.

164.- RAMOS KJ, SMITH PJ, MCKONE EF, PILEWSKI JM, LUCY A, HEMPSTEAD SE, et al. Lung transplant referral for individuals with cystic fibrosis: Cystic Fibrosis Foundation consensus guidelines. J Cyst Fibros 2019; 18 (3): 321-33.

165.- MELO J, BARVO C, MONFORTE V, ROMÁN A. Consideraciones en la derivación y selección de candidatos a trasplante pulmonar. Rev Chil Enferm Respir 2017; 33 (1): 37-46.

166.- MORRELL MR, KIEL SC, PILEWSKI JM. Organ Transplantation for Cystic Fibrosis. Semin Respir Crit Care Med 2019; 40 (6): 842-56.

167.- WHO. WHO definition of palliative care. [Internet]. WHO Definition of Palliative Care. 2020 [citado 18 de septiembre de 2020]. p. 1-2. Disponible en: https:// www.who.int/cancer/palliative/definition/en/

168.- RICHARDSON P. Spirituality, religion and palliative care. Ann Palliat Med 2014; 3 (3): 150-9.

169.- DELLON EP, GOGGIN J, CHEN E, SABADOSA K, HEMPSTEAD SE, FARO A, et al. Defining palliative care in cystic fibrosis: A Delphi study. J Cyst Fibros 2018; 17 (3): 416-21.

170.- HIGGINSON IJ, BAUSEWEIN C, REILLY CC, GAO W, GYSELS M, DZINGINA M, et al. An integrated palliative and respiratory care service for patients with advanced disease and refractory breathlessness: A randomised controlled trial. Lancet Respir Med 2014; 2 (12): 979-87.

171.- DHINGRA L, WALKER P, BERDELLA M, PLACHTA A, CHEN J, FRESENIUS A, et al. Addressing the burden of illness in adults with cystic fibrosis with screening and triage: An early intervention model of palliative care. J Cyst Fibros 2020; 19 (2): 262-70.

172.- FRANCIS J, CROSS D, SCHULTZ A, ARMSTRONG D, NGUYEN R, BRANCH-SMITH C. Developing a smartphone application to support social connectedness and wellbeing in young people with cystic fibrosis. J Cyst Fibros 2020; 19 (2): 277-83.

173.- JANSEN K, HAUGEN DF, PONT L, RUTHS S.
Safety and Effectiveness of Palliative Drug Treatment in the Last Days of Life-A Systematic Literature Review. J Pain Symptom Manage 2018; 55 (2): 508-21. e3.

174.- QUITTNER AL, ABBOTT J, GEORGIOPOULOS AM, GOLDBECK L, SMITH B, HEMPSTEAD $\mathrm{SE}$, et al. International Committee on Mental Health in Cystic Fibrosis: Cystic Fibrosis Foundation and European Cystic Fibrosis Society consensus statements for screening and treating depression and anxiety. Thorax 2016; 71 (1): 26-34.

175.- NOBILI RM, DUFF AJA, ULLRICH G, SMREKAR U, HAVERMANS T, BRYON M, et al. Guiding principles on how to manage relevant psychological aspects within a CF team: Interdisciplinary approaches. J Cyst Fibros 2011; 10 (Supp. 2).

176.- KEREM E, CONWAY S, ELBORN S, HEIJERMAN H, BARRETO C, BILTON D, et al. Standards of care for patients with cystic fibrosis: A European consensus. J Cyst Fibros 2005; 4 (1): 7-26.

177.- SCHAFFER K. Epidemiology of infection and current guidelines for infection prevention in cystic fibrosis patients. J Hosp Infect 2015; 89 (4): 309-13.

178.- FRIGINAL-RUIZ A, GONZÁLEZ-CASTILLO S, LUCENDO A. Gastrostomía endoscópica percutánea: una actualización sobre indicaciones, técnica y cuidados de enfermería. Enfermería Clínica 2011; 21 (3): 173-8.

179.- Registred Nurses' Association of Ontario. Guía de buenas prácticas en enfermería. Cuidados y mantenimiento de los accesos vasculares para reducir las complicaciones. Investen 2008; 1-102.

180.- Guidelines TRMNF-P care. Guidelines for Care of a Peripherally Inserted Central Catheter ( PICC ) by Community Staff / Practice Nurses [Internet]. 2016. Disponible en: https://www.nice.org.uk/guidance/ mtg34/resources/guidelines-for-care-of-a-piccs-bycommunity-staffpractice-nurses-royal-marsden-nhsft-pdf-4481503168

181.- BORG GA. Psychophysical bases of perceived exertion. Med Sci Sports Exerc 1982; 14 (5): 377-81.

Correspondencia a:

Dra. María Lina Boza C.

Departamento Procesos Clínicos Integrados, DIGERA,

Ministerio de Salud. Chile.

Hospital Clínico San Borja-Arriarán y

Facultad de Medicina, Universidad de Chile.

Email: bozaml@gmail.com 